\author{
UNIVERSIDADE DE SÃO PAULO \\ FACULDADE DE ECONOMIA, ADMINISTRAÇÃO E CONTABILIDADE \\ DEPARTAMENTO DE ECONOMIA \\ PROGRAMA DE PÓS-GRADUAÇÃO EM ECONOMIA
}

MODELO DE EQUILÍBRIO GERAL ESTOCÁSTICO E O MERCADO DE TRABALHO BRASILEIRO

Marcos da Costa Fantinatti

Orientador: Prof. Dr. Fabio Kanczuk

SÃO PAULO 
Prof. Dr. Marco Antonio Zago

Reitor da Universidade de São Paulo

Prof. Dr. Adalberto Américo Fischmann

Diretor da Faculdade de Economia, Administração e Contabilidade

Prof. Dr. Hélio Nogueira da Cruz

Chefe do Departamento de Economia

Prof. Dr. Márcio Issao Nakane

Coordenador do Programa de Pós-Graduação em Economia 


\section{MODELO DE EQUILÍBRIO GERAL ESTOCÁSTICO E O MERCADO DE TRABALHO BRASILEIRO}

Tese apresentada ao Departamento de Economia da Faculdade de Economia, Administração e Contabilidade da Universidade de São Paulo, como requisito para a obtenção do título de Doutor em Ciências.

Área de Concentração: Teoria Econômica

Orientador: Prof. Dr. Fabio Kanczuk

Versão Original

\section{SÃO PAULO}


FICHA CATALOGRÁFICA

Elaborada pela Seção de Processamento Técnico do SBD/FEA/USP

\section{Fantinatti, Marcos da Costa}

Modelo de equilíbrio geral estocástico e o mercado de trabalho brasileiro / Marcos da Costa Fantinatti. -- São Paulo, 2015.

$138 \mathrm{p}$.

Tese (Doutorado) - Universidade de São Paulo, 2015.

Orientador: Fábio Kanczuk.

1. Macroeconomia 2. Mercado de trabalho 3. Econometria bayesiana I. Universidade de São Paulo. Faculdade de Economia, Administração e Contabilidade. II. Título. 
À minha família. 


\section{AGRADECIMENTOS}

À Universidade de São Paulo pela excelente base que me proporcionou tanto no curso de doutorado quanto no de graduação em Economia.

Ao meu orientador, Professor Dr. Fabio Kanczuk, pela excelente orientação, além da atenção e da dedicação dispensada a mim desde o início do trabalho.

Aos demais professores do departamento pelas aulas ministradas ao longo do doutorado.

Aos funcionários do departamento pelo apoio dado aos alunos.

Aos colegas da universidade que sempre estiveram aptos a ajudar e propiciaram um excelente ambiente de convivência.

À Pontifícia Universidade Católica do Rio de Janeiro e seus professores pelo excelente curso de mestrado.

Aos meus irmãos, Marcelo, Neto e Mariângela que me deram força necessária para superar mais este obstáculo e sempre estiveram prontos para me ajudar.

Aos meus pais, Licinio e Maria Isabel, pela formação exemplar que propiciaram a seus filhos e pelo amoroso suporte dado em todos os momentos. Vocês foram fundamentais na minha formação como pessoa e economista.

À minha esposa Amanda gostaria de fazer um agradecimento especial. Ela teve participação fundamental ao longo do doutorado. Foi um período muito duro, mas ela soube administrar com maestria e me apoiou e incentivou em todos os momentos. Sem ela, dificilmente teria conseguido chegar até aqui.

Finalmente, agradeço aos meus avôs e avós pelo exemplo de vida e superação. 


\section{RESUMO}

Os três artigos desta tese focam no mercado de trabalho. O primeiro artigo calculou a probabilidade com que um trabalhador deixa o emprego e a probabilidade com que um desempregado encontra trabalho no Brasil. A metodologia utilizada foi a desenvolvida por Shimer (2012). O objetivo foi determinar qual destes dois fatores é o mais importante para explicar as flutuações da taxa de desemprego no Brasil. Os resultados mostraram que é a dinâmica da probabilidade com que um desempregado encontra emprego que explica o comportamento da taxa de desemprego. Este resultado é distinto daquele encontrado normalmente na literatura.

No segundo artigo, log-linearizamos e estimados o modelo de Christiano, Eichenbaum e Trabandt (2013) para o Brasil. Este modelo difere dos modelos novos keynesianos tradicionais ao colocar uma estrutura de searching (busca) para o mercado de trabalho. A ideia foi comparar este modelo com o modelo de rigidez de preços e salários tradicional e analisar se esta estrutura para o mercado de trabalho é capaz de fazer o papel das rigidezes tradicionais, no que se refere à propagação dos choques na economia. As funções impulso resposta a um choque contracionista de política monetária mostraram que o modelo explicou o comportamento esperado para variáveis como PIB, inflação e taxa de desemprego. Ainda, a estimação do modelo mostrou, no geral, que os preços no Brasil são reajustados com uma frequência menor do que a frequência indicada pelos modelos novos keynesianos com rigidez de preços e salários. Por sua vez, ao desligar a rigidez da utilização do capital e a do working capital channel, este modelo mais completo, maior e mais detalhado para mercado de trabalho pareceu não ser capaz de dar conta do movimento inercial e persistente observado para as variáveis macroeconômicas como PIB e inflação.

Por fim, no terceiro artigo, estimamos novamente o modelo de Christiano, Eichenbaum e Trabandt (2013), mas agora para os Estados Unidos. Entretanto, adotamos uma estratégia de estimação diferente: optamos por primeiro log-linearizar o modelo para depois fazer a estimação, para dois períodos: até 2008, assim como no artigo original, e até 2014 . O objetivo principal foi comparar os resultados da nossa estimativa com os resultados de Christiano, Eichenbaum e Trabandt (2013). Para o conjunto de dados até 2008 , os resultados indicam que os valores estimados estão em linha com os encontrados na literatura e, no geral, não estão muito distantes das estimações do artigo original. Mas, os parâmetros estimados apontaram para um modelo com um pouco mais de rigidez de preços, uma maior persistência de consumo e com uma regra de política monetária um pouco menos inercial em relação à do artigo original. Entretanto, esta regra mostrou uma reação muito maior à inflação do que ao produto, assim como em Christiano, Eichenbaum e Trabandt (2013). Considerando a amostra toda, isto é, até o final de 2014, observamos que o modelo estimado continuou a ter uma maior rigidez de preço em relação ao modelo original e uma regra de política monetária menos inercial. Além disso, os dados mais recentes afetaram de modo mais expressivo os valores estimados para variáveis do mercado de trabalho. Por sua vez, as funções impulso resposta refletiram esta menor inércia da política monetária e, no geral, apresentaram as trajetórias esperadas.

Palavras-chave: Macroeconomia, Mercado de trabalho e Econometria bayesiana. 


\begin{abstract}
The three articles of this thesis focus on the labor market. The first article calculated the probability of a worker leaving his job and the probability of an unemployed person finding a job in Brazil, using the methodology developed by Shimer (2012). The aim was to determine which of these factors was the most important to explain the unemployment rate fluctuations. The results showed that the probability of an unemployed worker finding a job is more important to explain the dynamic of the unemployment rate. Commonly, the literature has found an opposite result in Brazil. In the second article, we log linearized and estimated the model built by Christiano, Eichenbaum and Trabandt (2013) for Brazil. This model is different from the traditional New Keynesian models because it has a structure of searching in the labor market. The idea was to compare this model with the traditional one with sticky wage and sticky prices. Moreover, the idea was to analyze if this model with searching structure in the labor market was able to substitute some traditional rigidity when the concern is the propagation of shocks. The impulse response functions to a contractionary monetary policy shock showed that this model explains the dynamic that is normally found in GDP, inflation and unemployment rate. Furthermore, the estimation showed that, in general, the prices are readjusted less frequently than the frequency estimated by New Keynesian models with sticky wage and sticky prices. Besides, when the rigidities (capital utilization and working capital channel) are eliminated, this model did not properly explain the inertial and persistence dynamic of the macroeconomics variables, such as GDP and inflation.

Finally, in the last article, we estimated the Christiano, Eichenbaum and Trabandt (2013) model for the United States, but we adopted a different estimation strategy. We log linearized the model and estimated it with Bayesian methods. Moreover, we estimated for two different periods. The aim was to compare our results with the original model. When the model was estimated with data up to 2008, the results showed that the estimations were in line with the values found in the literature and, in general, they were not too far from the values estimated in the original article. However, the parameters estimated showed a model in which the prices are more rigid, the consumption habit is higher and the monetary rule is less inertial than observed in the original model. However, the monetary authority reacted much more to inflation than GDP, as it happened in the original article. When we considered the data until 2014, we observed that the estimated model remained with more sticky prices and a more inertial monetary rule. Moreover, we noted that this more recent data affected more expressively the estimated values of the labor market. The analysis of impulse response function showed this less inertial dynamic of the monetary rule and, overall, they followed the expected dynamics.
\end{abstract}

Keywords: Macroeconomics, Labor market, Bayesian Econometrics. 


\section{SUMÁRIO}

LISTA DE ILUSTRAÇÕES ..........................................................................15

1 ANÁLISE DOS FATORES QUE AFETAM O COMPORTAMENTO CÍCLICO

DA TAXA DE DESEMPREGO NO BRASIL ..............................................17

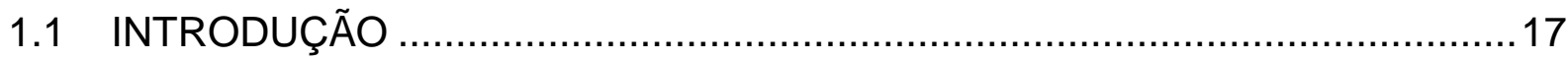

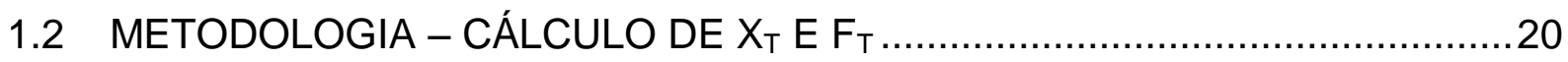

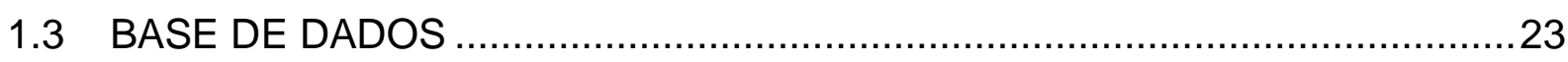

1.4 METODOLOGIA DE CÁCULO DAS CONTRIBUIÇÕES DE X E F PARA

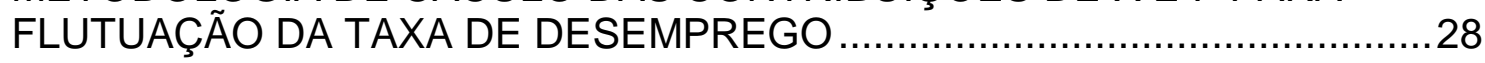

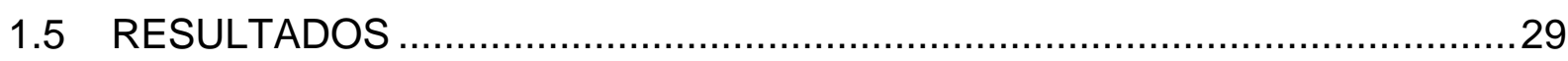

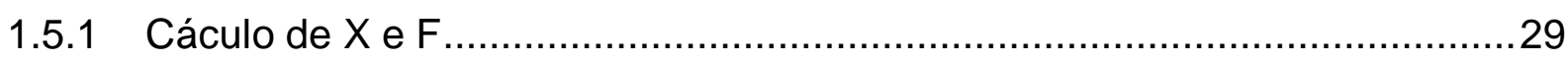

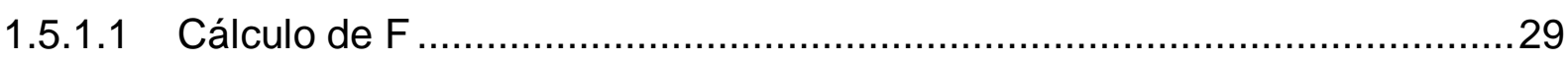

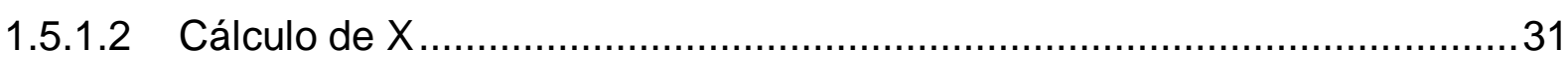

1.5.2 Cálculo das Contribuições da Probabilidade de Encontrar Emprego e de Deixar o Emprego para Flutuação da Taxa de Desemprego .........................33

1.6 IMPORTÂNCIA CÍCLICA DA PROBABILIDADE DE ENCONTRAR

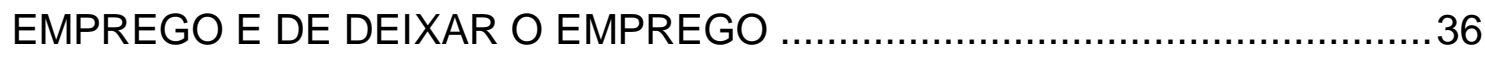

1.7 CÁLCULO DE F E X POR GRAU DE ESCOLARIDADE ...............................39

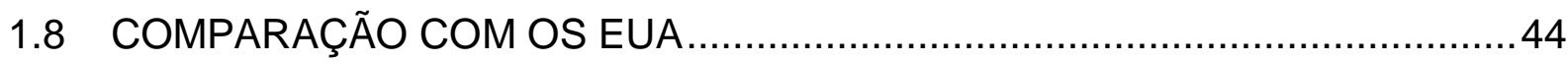

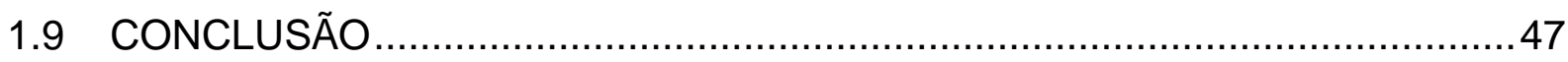

2 MODELO DE EQUILÍBRIO GERAL CONSIDERANDO SEARCHING NO MERCADO DE TRABALHO PARA O BRASIL..............................................49

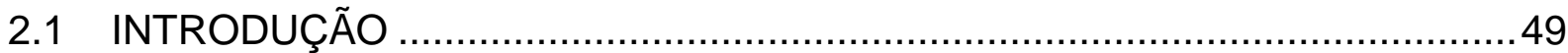

2.2 MODELO DSGE DE MÉDIO PORTE COM ESTRUTURA DE SEARCHING

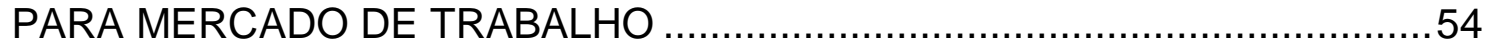

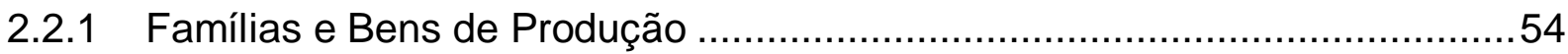

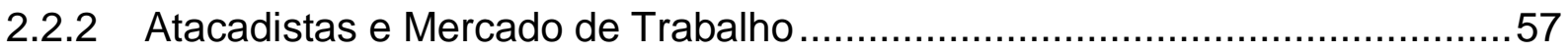

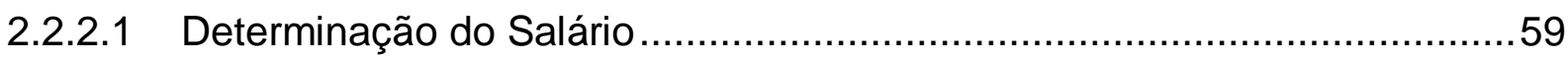

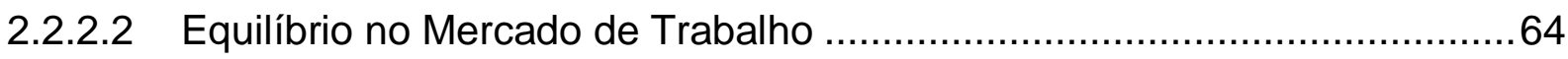

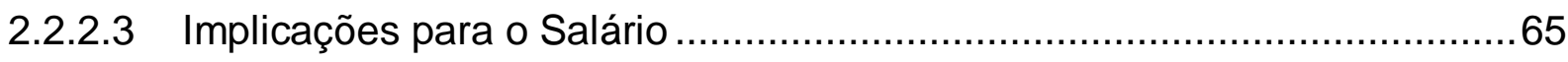

2.2.3 Market Clearing, Política Monetária e Formas Funcionais. ............................65

2.3 ALTERAÇÕES DO MODELO ORIGINAL, CONJUNTO DE EQUAÇÕES

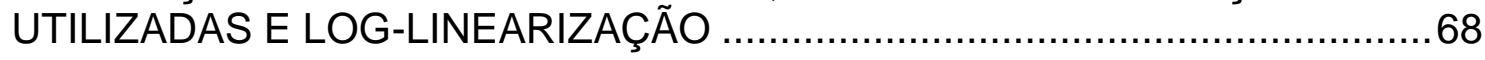

2.3.1 Conjunto de Equações do Modelo e o Resultado da Log-linearização. .........69

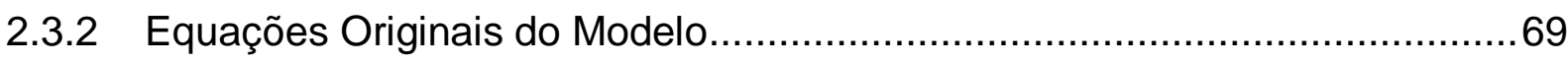




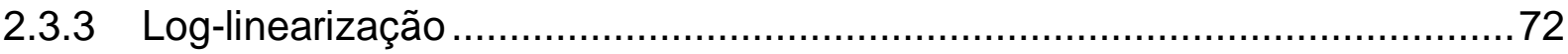

2.4 MODELO DE MÉDIO PORTE COM RIGIDEZ DE PREÇOS E SALÁRIOS .....75

2.5 METODOLOGIA, DADOS E PARÂMETROS............................................... 77

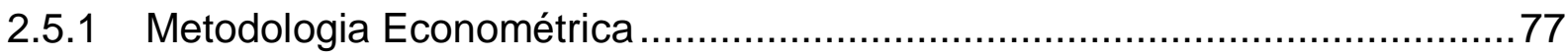

2.5.2 Dados, parâmetros e distribuições a priori utilizadas .................................77

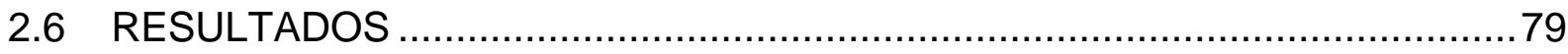

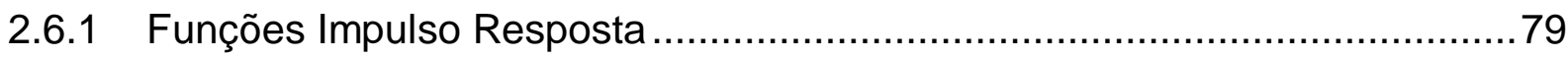

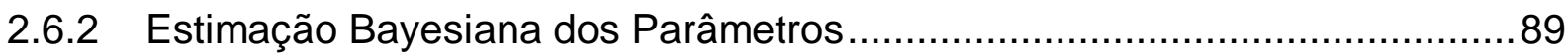

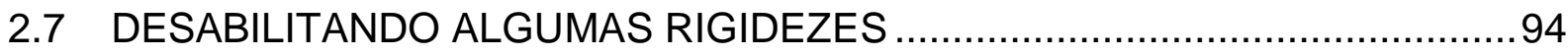

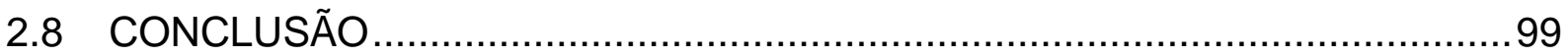

3 ESTIMATIVA ALTERNATIVA DO MODELO DE CHRISTIANO, EICHENBAUME

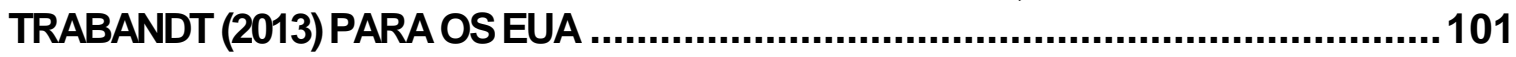

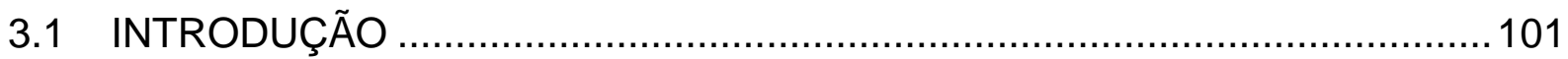

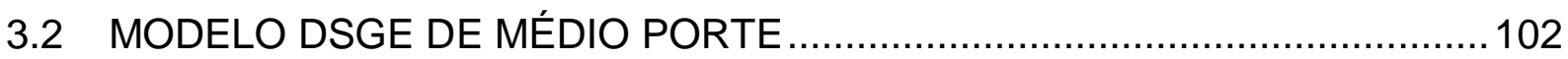

3.2.1 Famílias e Bens de Produção ………………....................................102

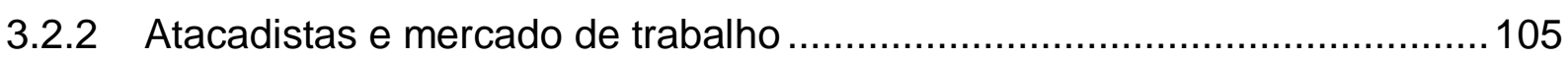

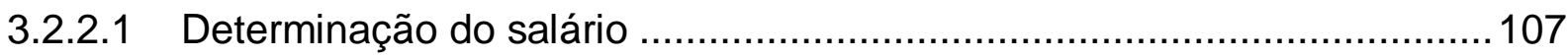

3.2.2.2 Equilíbrio no Mercado de Trabalho .................................................112

3.2.2.3 Implicações para o Salário ............................................................113

3.2.3 Market Clearing, Política Monetária e Formas Funcionais..........................113

3.3 ALTERAÇÕES DO MODELO ORIGINAL E LOG-LINEARIZAÇÃO ...............116

3.3.1 Conjunto de Equações do Modelo e o Resultado da Log-linearização ........117

3.3.2 Equações Originais do Modelo..........................................................117

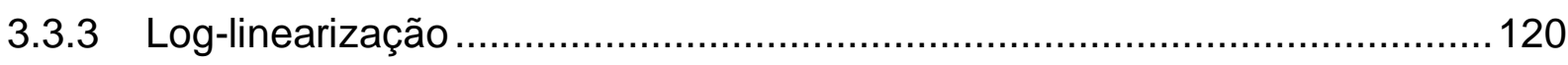

3.4 METODOLOGIA, DADOS E PARÂMETROS .......................................... 123

3.4.1 Metodologia Econométrica ................................................................ 123

3.4.2 Dados, parâmetros e distribuições a priori utilizadas ................................. 124

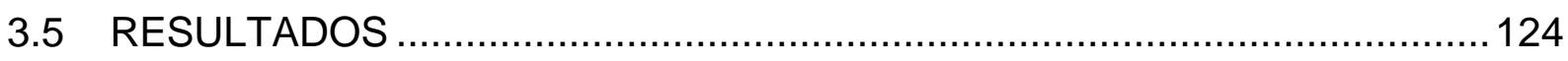

3.5.1 Estimação Bayesiana dos Parâmetros até 2008 ......................................124

3.5.2 Estimação Bayesiana dos parâmetros até 2014 ........................................127

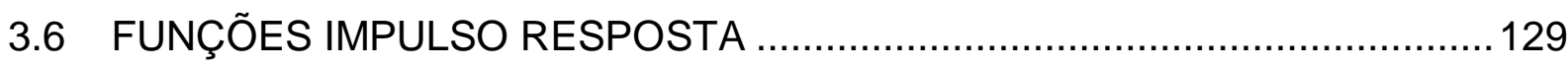

3.7 CONCLUSÃO

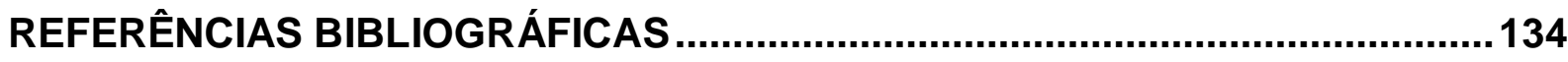




\section{LISTA DE ILUSTRAÇÕES}

TABELA 1 - DIFERENÇAS ENTRE CAGED E PME 24

FIGURA 1 - VARIAÇÃO INTERANUAL DA POPULAÇÃO OCUPADA 26

FIGURA 2 - CRESCIMENTO INTERANUAL DA RENDA DOS

TRABALHADORES

FIGURA 3 - CÁLCULO DA PROBABILIDADE DE ENCONTRAR EMPREGO -

$F$.

FIGURA 4 - CÁLCULO DA PROBABILIDADE DE DEIXAR O EMPREGO - X...32

FIGURA 5 - CONTRIBUIÇÕES PARA A TAXA DE DESEMPREGO - PIA ........34

FIGURA 6 - CONTRIBUIÇÕES PARA A TAXA DE DESEMPREGO -

CAGED_PME.

FIGURA 7 - CONTRIBUIÇÕES PARA A TAXA DE DESEMPREGO - CP

(APENAS PME)

TABELA 2 - RESULTADO DA REGRESSÃO SIMPLES DAS VARIÁVEIS Z

EM U/L .36

TABELA 3 - ESTATÍSTICAS DESCRITIVAS E CORRELAÇÃO DOS HIATOS

DE F COM HIATO DO PIB E DA TAXA DE DESEMPREGO - FILTRO HP........37

TABELA 4 - ESTATÍSTICAS DESCRITIVAS E CORRELAÇÃO DOS HIATOS

DE X COM HIATO DO PIB E DA TAXA DE DESEMPREGO - FILTRO HP........38

FIGURA 8 - PROBABILIDADE DE ENCONTRAR TRABALHO (F), POR

GRAU DE ESCOLARIDADE

FIGURA 9 - PROBABILIDADE DE ENCONTRAR TRABALHO (X), POR

GRAU DE ESCOLARIDADE

FIGURA 10 - CONTRIBUIÇÃO PARA A TAXA DE DESEMPREGO PARA OS

MAIS QUALIFICADOS (HIGH).

FIGURA 11 - CONTRIBUIÇÃO PARA A TAXA DE DESEMPREGO PARA OS

MENOS QUALIFICADOS (LOW) .

TABELA 5 - RESULTADO DA REGRESSÃO SIMPLES DAS VARIÁVEIS Z

EM U/L

FIGURA 12 - CÁLCULO DA PROBABILIDADE DE ENCONTRAR EMPREGO

(F) PARA OS EUA

FIGURA 13 - CÁLCULO DA PROBABILIDADE DE PERDER EMPREGO (X)

PARA OS EUA.

TABELA 6 - RESULTADO DA REGRESSÃO SIMPLES DAS VARIÁVEIS Z

EM U/L - PARA OS EUA 46

TABELA 7 - ESTATÍSTICAS DESCRITIVAS E CORRELAÇÃO DO HIATO DE F COM HIATO DO PIB E DA TAXA DE DESEMPREGO - EUA, FILTRO HP...46 
TABELA 8 - ESTATÍSTICAS DESCRITIVAS E CORRELAÇÃO DO HIATO DE $X$ COM HIATO DO PIB E DA TAXA DE DESEMPREGO - EUA, FILTRO HP...47

TABELA 9 - LEGENDA PARA AS FIGURAS 14, 15 E 16 .80

FIGURA 14 - RESPOSTA DAS VARIÁVEIS DO MODELO DE MÉDIO PORTE AO CHOQUE DE POLÍTICA MONETÁRIA DE UM DESVIO PADRÃO .81

FIGURA 15 - RESPOSTA DAS VARIÁVEIS DO MODELO DE MÉDIO PORTE AO CHOQUE ESPECÍFICO DE INVESTIMENTO.

FIGURA 16 - RESPOSTA DAS VARIÁVEIS DO MODELO DE MÉDIO PORTE AO CHOQUE TECNOLÓGICO NEUTRO.

TABELA 10 - ESTIMAÇÃO DOS PARÂMETROS COM O PRIMEIRO CONJUNTO DE DADOS

TABELA 11 - ESTIMAÇÃO DOS PARÂMETROS COM O SEGUNDO CONJUNTO DE DADOS

FIGURA 17 - RESPOSTA DAS VARIÁVEIS DO MODELO DE MÉDIO PORTE AO CHOQUE DE POLÍTICA MONETÁRIA.

TABELA 12 - PARÂMETROS ESTIMADOS PARA OS MODELOS I, II E III......98

TABELA 13 - PARÂMETROS ESTIMADOS PARA OS EUA COM DADOS ATÉ 2008.

TABELA 14 - PARÂMETROS ESTIMADOS PARA OS EUA COM DADOS ATÉ 2014 128

FIGURA 18 - FUNÇÕES IMPULSO RESPOSTA A UM CHOQUE DE UM DESVIO PADRÃO DE POLÍTICA MONETÁRIA. 131

FIGURA 19 - FUNÇÕES IMPULSO RESPOSTA A UM CHOQUE PADRONIZADO DE POLÍTICA MONETÁRIA 


\section{ANÁLISE DOS FATORES QUE AFETAM O COMPORTAMENTO CÍCLICO DA TAXA DE DESEMPREGO NO BRASIL}

\subsection{INTRODUÇÃO}

O mercado de trabalho tem sido um assunto recorrente nas discussões da literatura ultimamente. Não há um consenso sobre qual ou quais são os fatores que mais influenciam a dinâmica da taxa de desemprego. E o entendimento de seu funcionamento é muito importante tanto para a tomada de decisões de política pública quanto de política monetária.

Muitos trabalhos acadêmicos procuraram entender quais são os principais fatores que influenciam o mercado de trabalho ao longo do ciclo de negócios (business cycle). Os dois fatores normalmente analisados são (i) a probabilidade de um trabalhador deixar o emprego e, assim, passar a estar desempregado (separation rate - aqui denominada de " $X$ "); e, (ii), a probabilidade de um desempregado passar a ser empregado (job finding rate, denominada doravante de "F").

Recentemente, muitos modelos macroeconômicos com estrutura desagregada para o mercado de trabalho seguem a literatura de matching e searching que, normalmente, tem como hipótese que a separation rate, $\mathrm{X}$, é acíclica. Este comportamento ou é colocado exogenamente ou surge como resultado do modelo. Como exemplo, podemos citar: Gertler e Trigari (2006), Christiano, Eichenbaum e Trabandt (2013), Hall (2005), dentre outros. Esta hipótese implica que para se entender o mercado de trabalho, na frequência cíclica, basta se preocupar com a probabilidade de o trabalhador desempregado encontrar emprego $(F)$, pois sua dinâmica é que vai explicar as flutuações na taxa de desemprego.

Esta hipótese incomoda muitos pesquisadores, pois até pouco tempo atrás, havia certo consenso de que, nos Estados Unidos, o comportamento da probabilidade de um empregado deixar trabalho $(X)$ é que explicava as flutuações na taxa de desemprego. Assim, a análise de seu comportamento é que seria fundamental para se entender a dinâmica cíclica do mercado de trabalho. Blanchard e Diamond (1990), Davis, Haltiwager e Schuh (1996), Bleakley, Ferris e Fuher (1999) e Fujita e Ramey (2009) fazem parte desta linha de argumentação. Portanto, sob esta ótica, a hipótese adotada nos modelos supracitados estaria equivocada e os resultados deixam ser interessantes. 
Por outro lado, parte da literatura dá suporte à hipótese de aciclicalidade de X. Autores como Hall (2005), Elsby et al (2007) e Shimer (2012) concluem que o fator mais importante para explicar as flutuações na taxa de desemprego é, na realidade, a probabilidade com que um desempregado encontra emprego. Ainda, Shimer (2012), usando dados para os EUA entre 1948 e 2012, mostrou que a maior importância da job finding rate é particularmente verdadeira nas últimas duas décadas, quando a probabilidade de sair do emprego declinou expressivamente apesar dos três aumentos na taxa de desemprego. De fato, segundo ele, $90 \%$ da flutuação da taxa de desemprego desde 1987 foi consequência de movimentos na probabilidade em se achar trabalho - job finding rate. Adicionalmente, o artigo conclui que a probabilidade com que um trabalhador deixa o emprego $(X)$ é acíclica. Estes estudos, portanto, deram base teórica e empírica para os modelos macroeconômicos que tem o mercado de trabalho desagregado, consideram a hipótese de aciclicalidade e concedem menor importância à probabilidade de um empregado perder o emprego. Mas esta discussão não está encerrada.

Com relação aos países Europeus, Petrongolo e Pissarides (2008) encontram que a maior importância dos fatores sobre a dinâmica da taxa de desemprego no ciclo de negócios depende do país analisado. No Reino Unido, os autores destacam que o mercado de trabalho era regulado até 1980, quando então houve liberalização. Ao longo deste período, a importância que a probabilidade de desligamento tem sobre a flutuação da taxa de desemprego recuou. Na França, observou-se uma maior importância para a probabilidade de desligamento, o que é condizente com um regime de legislação de proteção ao trabalhador mais estrito. Por fim, no caso da Espanha, os autores mostram que os dois fatores são importantes.

No caso da Espanha ainda, Silva e Vasquez-Grenno (2010) calcularam a taxa de achar emprego e de sair do emprego para os imigrantes e para os espanhóis nativos. Isso porque, desde o final da década de 90, a imigração passou a se intensificar e a se tornar um componente importante para o mercado de trabalho. Seguindo Shimer (2005), os autores mostraram que ambas as taxas são maiores para os imigrantes, sendo que a probabilidade que eles têm de sair do trabalho é, em média, o dobro da encontrada para os nativos. Portanto, o artigo conclui que embora o tempo que os imigrantes ficam desempregos seja menor, eles estão mais frequentemente na situação de desempregado do que os espanhóis nativos. 
Em linha com trabalho de Petrongolo e Pissarides (2008), Smith (2011) mostra para o Reino Unido, usando dados mensais, que ambos os movimentos são importantes para explicar as oscilações na taxa de desemprego. De fato, segundo a autora, em tempos de moderação, a taxa de saída da situação de desemprego é que tem mais influencia sobre a dinâmica do desemprego. Todavia, em período de recessão, a entrada para o desemprego é que explica a variação da taxa de desemprego.

Para o Canadá, Campolieti (2011) encontrou que em termos agregados a taxa de saída do desemprego (finding rate) é mais importante que a de entrada no desemprego (separation rate) para explicar as mudanças nas taxas de desemprego. Além disso, o artigo mostrou que, naquele país, a entrada no desemprego é prócíclica enquanto que a saída é anticíclica.

Para o Brasil, Attuy (2012) encontrou que algo em torno de 37 a 100 pontos percentuais do ciclo da taxa de desemprego no Brasil entre março de 2003 e dezembro de 2010 foram explicados pela margem de separação (separation rate). Silva e Pires (2014) concluem que a probabilidade de desligamento foi responsável por $80 \%$ da queda do desemprego entre 2003 e 2013. Ambos usam dados da Pesquisa Mensal do Emprego do IBGE. A explicação para expressiva redução da taxa de desemprego do período seria a forte redução na probabilidade de um trabalhador deixar o emprego.

Este resultado para o Brasil parece não conversar com o consenso que diz que o mercado de trabalho brasileiro é muito dinâmico e que a rotatividade é muito alta. De fato, dados do Ministério do Trabalho e Emprego mostram que, em 2012, 24,5 milhões de trabalhadores foram demitidos contra um estoque total ao final do ano de 38,9 milhões de trabalhadores. Logo, a taxa de rotatividade bruta foi superior a $62 \%$. Esta mesma taxa em 2003 foi de quase 52\%. Sob esta métrica então, é razoável pensar que a probabilidade que um trabalhador tem de deixar o trabalho tenha aumentado no período, não diminuído. Mas se isso for verdade, tudo o mais constante, também deveria ser observado aumento da probabilidade de encontrar trabalho, pois, caso contrário, o desemprego deveria ter aumentado.

Baseado em todo este contexto, este trabalho, utilizando a metodologia desenvolvida por Shimer (2012), vai calcular a probabilidade com que um trabalhador desempregado encontra trabalho (job finding rate - $\mathrm{F}_{\mathrm{t}}$ ) e a taxa segundo a qual um trabalhador empregado perde o trabalho $\left(X_{t}\right)$ no Brasil. Uma contribuição 
aqui é que serão utilizados, além dos dados normalmente utilizados da PME, os dados o CAGED e da RAIS, tendo como hipótese que existem apenas dois estados para o trabalhador: emprego e desemprego. Esta hipótese é necessária para que se consiga utilizar os dados do CAGED. Os resultados mostram que quando analisamos a dinâmica dos trabalhados formais do CAGED, diferentemente dos resultados a que chegaram os demais trabalhos, a probabilidade de encontrar emprego (F) ganha muita importância para explicar as flutuações do desemprego. Já, a probabilidade de deixar o emprego perde importância, deixando de ser estatisticamente significativa em alguns casos.

Estes resultados estão linha com a leitura de que o mercado de trabalho no Brasil é dinâmico, com uma elevada taxa de rotatividade. Além disso, esses resultados indicam que podemos utilizar, para o caso brasileiro, os modelos de matching e searching que se valem da hipótese de maior importância da job finding rate em detrimento da separation rate.

Além disso, como no Brasil, em média, a qualificação dos trabalhares é muito baixa, é interessante estudar como se comportou a job finding rate e a separation rate entre os grupos de trabalhadores mais qualificados e os menos qualificados. Tendo por base, a mesma metodologia, também vamos fazer isso a fim de ver se o que vale para o todo também vale para as partes. Os resultados apontam para uma resposta afirmativa.

É feita ainda uma comparação com os dados americanos, tendo em vista que o artigo do Shimer (2012) focou naquele país.

O trabalho segue com a metodologia geral utilizada na seção 1.2; com a explicação da base de dados na seção 1.3; com a metodologia para analisar a importância cíclica na seção 1.4; os resultados de $\mathrm{F}$ e $\mathrm{X}$ seguem na parte 1.5; os resultados para a importância cíclica de F e X seguem na seção 1.6; na seção 1.7, temos a análise por grau de escolaridade; na parte 1.8, temos a comparação com os EUA; e, por fim, o artigo termina com a conclusão na seção 1.9.

\subsection{METOdOLOGIA - CÁLCULO DE X $X_{T}$ E F}

Para o cálculo da probabilidade de um trabalhador desempregado encontrar emprego $\left(F_{t}\right)$ e da probabilidade de um trabalhador empregado deixar o emprego $\left(X_{t}\right)$ 
será utilizada a metodologia empregada por Shimer (2012). Nesta metodologia, exante, todos os trabalhadores são idênticos e possuem a mesma probabilidade de achar emprego e de deixar o emprego. Além disso, não são considerados movimentos para dentro e para fora da força de trabalho (População Economicamente Ativa - PEA). Os trabalhadores apenas se movimentam entre os dois estados, um, no qual está empregado e, o outro, no qual está desempregado.

Neste mesmo artigo, Shimer relaxa esta hipótese ao considerar o movimento de transição para dentro e fora da PEA. Parte dos desempregados e dos empregados pode então se movimentar para um terceiro estado que seria de inatividade, ou fora do mercado de trabalho. No presente caso, como se está interessado em analisar os dados do CAGED, tem-se que considerar apenas dois estados: empregado e desempregado. Isso porque não estão disponíveis, nesta base de dados, dados sobre os trabalhadores que deixaram ou entraram na população economicamente ativa (PEA).

Em Shimer (2012), o ambiente é de tempo contínuo no qual os dados estão disponíveis em tempos discretos, $t \in\{1,2,3 \ldots$.$\} . O objetivo é recuperar F_{t}$ e $X_{t}$, ambos $€[0,1]$. Neste modelo, Shimer denomina o intervalo de tempo entre " $t$ " $e$ " $t+1$ " como período "t". Assume-se que durante o período, todos os desempregados encontram trabalho de acordo com um processo Poisson com "arrival rate" $f_{t}=$ $\log \left(1-F_{t}\right)$ e todos os trabalhadores empregados perdem emprego com "arrival rate" $x_{t}$ $=-\log \left(1-X_{t}\right) \cdot f_{t}$ e $x_{t}$ são denominadas respectivamente de job finding rate $\mathrm{e}$ employment exit rate (separation rate), enquanto $F_{t}$ e $X_{t}$ se referem, respectivamente, a probabilidade que um trabalhador desempregado em $t$ encontra trabalho durante o período e a probabilidade que um trabalhador empregado em $t$ perde o trabalho no período.

Fixe $\mathrm{t} \in\{1,2,3 \ldots\}$ e deixe $\mathrm{t} \in[0,1]$ ser o tempo decorrido desde a última averiguação. Define-se $e_{t+\tau} 0$ número de trabalhadores empregados em $t+T, u_{t+\tau} O$ número de desempregados em $\mathrm{t}+\mathrm{T}$, e, $\mathrm{u}_{\mathrm{t}+\mathrm{T}}^{\mathrm{s}}$, os trabalhadores desempregados de curto prazo - trabalhadores que estavam empregados entre $t$ e $t+T$, mas estão desempregados em $\mathrm{t}+\mathrm{T}$. É importante observar que $\mathrm{u}_{(0)}^{\mathrm{s}}=0$ para todo t. Ainda, é conveniente definir $u_{t+1}^{s}=u_{t}^{s}(1)$ como a quantidade total de trabalhadores desempregados de curto prazo ao final do período t. 
Diante destas definições, tem-se que o desemprego e o desemprego de curto prazo evoluem de acordo com as seguintes equações:

$$
\begin{aligned}
& u_{t+\tau}=e_{t+\tau} x_{t}-u_{t+\tau} f_{t} \\
& \dot{u}_{t}^{s}(\tau)=e_{t+\tau} x_{t}-u_{t}^{s}(\tau) f_{t}
\end{aligned}
$$

Portanto, o desemprego aumenta quando empregados deixam seus empregos a taxa instantânea $x_{t}$, e recua quando os desempregados encontram trabalho, à taxa $f_{t}$. O mesmo vale para o desemprego de curto prazo, mas substituindo o estoque de desempregados pelo estoque de desempregados no curto prazo. Para resolver para "job finding probability" Shimer subtrai 1.2 de 1.1, chegando a seguinte equação:

$$
u_{t+\tau}=\dot{u_{t}^{s}}(\tau)-\left(u_{t+\tau}-u_{t}^{s}(\tau)\right) f_{t}
$$

Para t $€[0,1)$. Por construção temos que $u_{t}^{s}(0)=0$, então dada uma condição inicial para $u_{t}$, esta equação diferencial pode ser resolvida para $u_{t+1}$ e para $u_{t+1}^{s}=u_{t}^{s}(1)$ :

$$
u_{t+1}=\left(1-F_{t}\right) u_{t}+u_{t+1}^{s}
$$

Rearranjando os termos chegamos a seguinte expressão que define a probabilidade de um trabalhador desempregado encontrar emprego, em função dos desempregados e dos desempregados de curto prazo.

$$
F_{t}=1-\frac{u_{t+1}-u_{t+1}^{S}}{u_{t}}
$$

Pode-se resolver a equação diferencial (1.1) para frente a fim de obter implicitamente a taxa de saída do emprego $\left(\mathrm{X}_{\mathrm{t}}\right)$ :

$$
u_{t+1}=\frac{\left(1-\exp ^{-f_{t}-x_{t}}\right) x_{t}}{f_{t}+x_{t}} l_{t}+\exp \left(-f_{t}-x_{t}\right) u_{t}
$$

Onde $I_{t}=u_{t}+e_{t}$ é o tamanho da força de trabalho (PEA) no período $t$ que é assumida ser constante, ou seja, não entra nem sai ninguém da PEA. Como $l_{t}>u_{t}, 0$ desemprego em $\mathrm{t}+1$ é crescente na taxa de saída dos trabalhadores empregados $\left(\mathrm{x}_{\mathrm{t}}\right)$.

Vale destacar ainda que esta metodologia em tempo contínuo está imune ao "viés de agregação". Este viés ocorre porque, normalmente, a pesquisa de emprego é feita em tempo discreto, mas, entre dois intervalos de tempo, pode ser que um trabalhador que estava empregado no início do período fique desempregado e rapidamente arrume emprego de forma a não ter seu movimento capitado na estatística. Isso faz com a medida de desemprego de curto prazo seja subestimada. Aqui, dado que o tempo é contínuo, isso não ocorre. 


\subsection{BASE DE DADOS}

Assim como na maioria dos trabalhos sobre o tema, utilizamos os dados da Pesquisa Mensal do Emprego (PME) divulgada pelo Instituto Brasileiro de Geografia e Estatística (IBGE). A PME é uma pesquisa feita em seis regiões metropolitanas, quais sejam: São Paulo, Rio de Janeiro, Belo Horizonte, Curitiba, Porto Alegre, Salvador e Recife. Nela estão presentes tanto os trabalhadores formais como os informais. Nesta pesquisa são divulgadas mensalmente informações como população ocupada, desocupada e população economicamente ativa.

Mas, um dos principais problemas em se trabalhar com a PME consiste no fato dos domicílios serem entrevistados por quatro meses, saírem por oito meses e depois voltarem para mais quatro meses de entrevista, para então saírem definitivamente. Como para calcular o desemprego de curto prazo vamos considerar as pessoas que transitaram do emprego no mês $t$ para o desemprego em $t+1$, conseguimos, a cada período, identificar apenas $75 \%$ dos entrevistados. Porém, eles também não têm identificação direta, uma vez que a identificação na PME é feita pelo domicílio.

A fim de conseguir identificar os indivíduos, seguimos o método de emparelhamento avançado de autoria de Ribas e Soares (2008). Este considera um conjunto grande de variáveis a fim de encontrar as mesmas pessoas ao longo do tempo de um modo bastante preciso. Feito o emparelhamento, isto é, a identificação dos indivíduos para cada um destes anos, vamos então selecionar os indivíduos nos painéis e grupos rotacionais, entre março de 2003 e dezembro de 2013. É importante destacar que a extração dos painéis e a identificação dos indivíduos foram feitas através das ferramentas para STATA disponibilizadas no portal Data Zoom, que foi desenvolvido pela PUC-Rio em parceria com o FINEP.

Outras duas bases de dados utilizadas no presente trabalho são: o cadasto geral de empregados e desempregados (CAGED) e o registro anual de informações sociais (RAIS), que diferentemente da PME considera apenas os empregos formais, aqueles regidos pela consolidação das leis trabalhistas (CLT).

Outras diferenças entre CAGED e a PME são mostradas na tabela 1. Dependendo do objetivo, existem formas para tentar compatibilizar as duas pesquisas. No presente trabalho, não temos essa preocupação, pois queremos analisar as pesquisas separadamente, com objetivo de saber se os resultados se alteram. 
TABELA 1 - DIFERENÇAS ENTRE CAGED E PME

\begin{tabular}{|c|c|c|}
\hline Aspecto considerado & PME & CAGED \\
\hline Variável descrita & Pessoa Ocupada & Vínculo de trabalho \\
\hline $\begin{array}{l}\text { Empregado com carteira assinada e que } \\
\text { tenha mais de um trabalho }\end{array}$ & $\begin{array}{c}\text { Contabilizado como uma pessoa ocupada no trabalho } \\
\text { principal, e número de trabalhos que tinha }\end{array}$ & $\begin{array}{l}\text { Contabilizados os vínculos principal e } \\
\text { adicional }\end{array}$ \\
\hline Abragência geográrfica do levantamento & $\begin{array}{c}\text { Residentes de áreas urbanas de regiões metropolitanas } \\
\text { (São Paulo, Rio de Janeiro, Recife, Salvador, Belo } \\
\text { Horizonte e Porto Alegre) }\end{array}$ & $\begin{array}{l}\text { Estabelecimentos e todo país, de área } \\
\text { urbana e rural }\end{array}$ \\
\hline $\begin{array}{l}\text { Empregado com carteira assinada que } \\
\text { trabalha em região metropolitana, mas } \\
\text { reside fora da região }\end{array}$ & Excluído da amostra & $\begin{array}{l}\text { Contabilizado com víncula na região } \\
\text { metropolitana }\end{array}$ \\
\hline $\begin{array}{l}\text { Empregado com carteira assinada que } \\
\text { trabalha fora região metropolitana, mas } \\
\text { reside na região }\end{array}$ & $\begin{array}{l}\text { Contabilizado como parte dos empregados com carteira } \\
\text { assinada da região metropolitana }\end{array}$ & $\begin{array}{l}\text { Contabilizado com o víncilo fora da } \\
\text { região metropolitana }\end{array}$ \\
\hline Variações associadas aos dados mensais & Amostra mensal & $\begin{array}{c}\text { Depende do numero de empresas que } \\
\text { declararam até a data limite as } \\
\text { movimentações realizadas }\end{array}$ \\
\hline Período de referência do indicadores & Semana Móvel (mês) & mês \\
\hline $\begin{array}{l}\text { Período de referência do levantamento } \\
\text { das informações }\end{array}$ & Semana anterior à da entrevista & mês \\
\hline
\end{tabular}

Fonte: Nota Técnica do Ministério do Trabalho e Emprego: "CAGED e PME" - Diferenças metodológicas e possibilidade de comparação

Portanto, as estimativas foram realizadas se valendo de mais de um conjunto de dados. Chamamos de metodologia de curto prazo (“CP") quando foram usados apenas dados da PME/IBGE. Neste caso, foram utilizadas as séries divulgadas pelo IBGE de população ocupada e desocupada e foram considerados como desempregados de curto prazo as pessoas que saíram da situação de emprego para o desemprego entre t e $\mathrm{t}+1$ - este fluxo foi extraído dos microdados da PME.

Para os dados do CAGED, fizemos dois procedimentos. Em ambos foram considerados o estoque de empregados da RAIS de dezembro de 2000 como a população ocupada inicial e evoluímos este estoque pelo saldo líquido de vagas do CAGED, divulgada mensalmente pelo Ministério do Trabalho e Emprego (MTE). Assim foi construída a série mensal da população ocupada mensal do CAGED.

Como se sabe, o MTE não divulga dados para população desocupada seja junto ao estoque de trabalhadores formais da RAIS seja junto aos valores de admissões e demissões do CAGED. Para conseguir estimar este estoque foram feitos dois procedimentos. O primeiro, denominado de "CAGED_PME", considera a taxa de desemprego divulgada da PME/IBGE para recuperar a população desempregada; enquanto que o segundo, denominado de "PIA", considera como estoque de 
desempregados a diferença entre a população em idade ativa, entre 15 e 64 anos ${ }^{1}$, e o estoque de população ocupada, calculada pelo procedimento descrito anteriormente. A vantagem deste método é que não utilizamos nenhuma informação da PME para construir nossas séries. No primeiro caso, se supõe que se existisse uma taxa de desemprego dos trabalhadores formais ela seria igual a que observamos para taxa de desemprego da PME. Uma hipótese razoável no sentido em que há consenso sobre a melhora expressiva no mercado de trabalho com a consequente diminuição da taxa de desemprego. Por sua vez, nos dois casos, consideramos como desempregado de curto prazo as pessoas que foram demitidas entre dois períodos de tempo, segundo dados do CAGED.

Antes de prosseguir, cabe uma discussão sobre por que usar os dados do CAGED e RAIS ao invés de usar apenas os dados da PME. Primeiramente, eles contêm, sem dúvida nenhuma, informações relevantes sobre o mercado de trabalho brasileiro que podem não estar sendo captadas pela PME. Segundo, os dados da PME são alvo de críticas, embora sejam os mais utilizados por terem uma série mais longa e conterem um maior leque informações.

O que chama a atenção nos dados da PME, por exemplo, é a elevada volatilidade dos dados mesmo quando estamos lidando com estoques, que deveriam ter comportamento bem inercial, suave. De fato, na figura 1, temos a evolução da taxa de crescimento da população ocupada da PME muito mais errática que da taxa de crescimento da população ocupada calculada por nós através da RAIS e evoluída pelo CAGED. Enquanto que na figura 2, a taxa de crescimento do salário de admissão do Caged é muito menos volátil que do rendimento médio nominal de todos os trabalhadores, segundo a $\mathrm{PME}^{2}$. O que chama a atenção é que o estoque da PME é maior que o fluxo de entrantes e, principalmente, que o estoque deve

\footnotetext{
${ }^{1}$ A população em idade ativa entre 15 e 64 anos é divulgada com periodicidade anual pelo IBGE. O que fizemos para tornar a série mensal foi distribuir igualmente entre os meses a diferença entre 0 estoque da PIA em $t+1$ e t.

${ }^{2}$ A taxa média de crescimento do salário de admissão do CAGED é de 9,4\% com desvio padrão de $1,8 \%$ contra média de $7,7 \%$ para o rendimento médio da PME e um desvio padrão de 2,9\%. Portanto, tem-se um desvio padrão bem maior para PME em relação ao dado do CAGED.
} 
sofrer muito menos efeito composição (fluxo mensal de contratações de trabalhadores ganhando mais ou menos) do que o fluxo de admitidos, o que sugere que os dados da PME é que deveriam variar menos. Por isso, é bem razoável querer trabalhar com outros dados além dos da Pesquisa Mensal de Emprego do IBGE.

FIGURA 1 - VARIAÇÃO INTERANUAL DA POPULAÇÃO OCUPADA

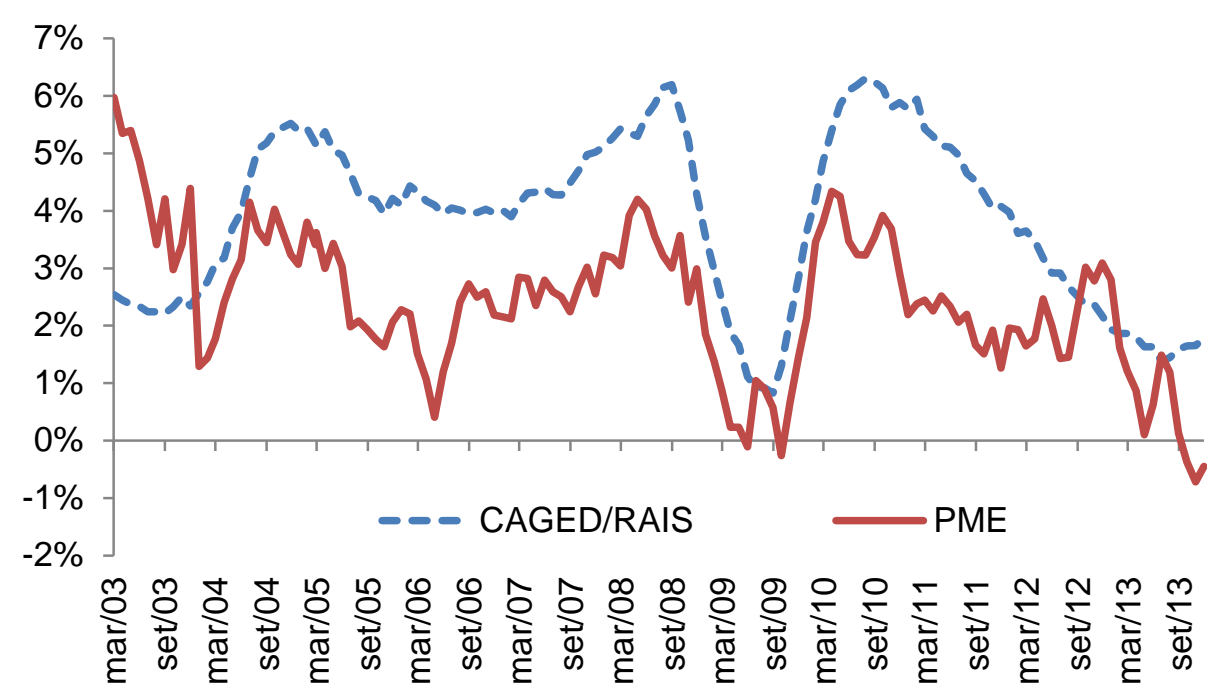

Fonte: Ministério do Trabalho e Emprego e IBGE

FIGURA 2 - CRESCIMENTO INTERANUAL DA RENDA DOS TRABALHADORES

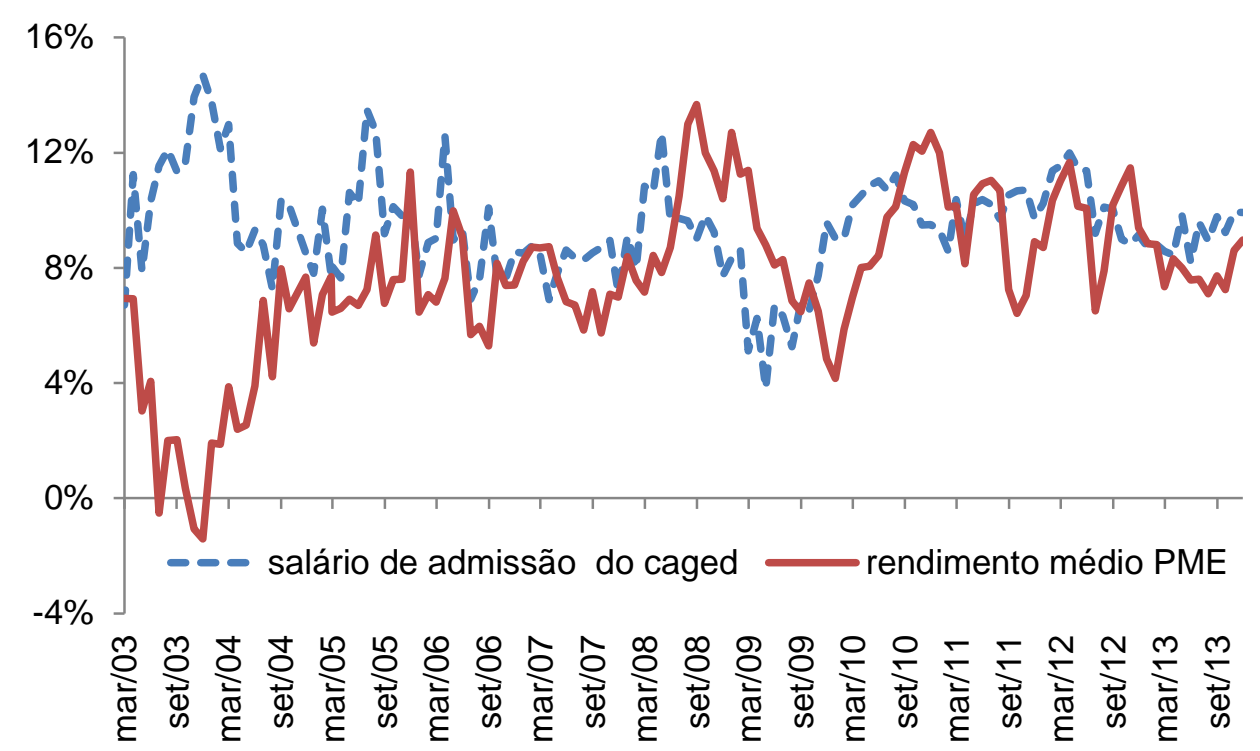

Fonte: Ministério do Trabalho e Emprego e IBGE 
Por sua vez, para o cálculo por grau de escolaridade, mais e menos qualificados, foram criadas utilizando dados da RAIS, do CAGED e da PNAD. Não usaremos dados da PME e não podemos usar os dados de População em Idade Ativa do IBGE, pois não encontramos a quebra por grau de escolaridade. Assim criamos as séries de população ocupada, desocupada e desemprego de curto para prazo tanto para os trabalhadores mais qualificados quanto para os trabalhadores menos qualificados.

No presente trabalho, os empregados mais qualificados (high) são aqueles que possuem no mínimo ensino superior incompleto enquanto que os demais trabalhadores foram chamados de menos qualificados (low).

Para a população ocupada utilizamos a RAIS de 2003 como ponto de partida e evoluímos mês a mês pelo saldo líquido do CAGED. Para o desemprego de curto prazo, consideramos os dados de demitidos do CAGED que também podem ser separados entre mais e menos qualificados seguindo a regra especificada acima. Como estes dados só estão disponíveis no sítio do Ministério do Trabalho e Emprego após 2004, não foi possível construir uma série mais longa.

Por fim, para a população desocupada, neste caso, foram considerados os números de pessoas desocupadas segundo a Pesquisa Nacional de Amostra Domiciliar (PNAD), considerando que quem tem até 11 anos de estudo é menos qualificado e quem tem mais, é mais qualificado. Utilizamos dados da PNAD devido à dificuldade em separar os dados da população brasileira entre 15 e 65 anos entre mais e menos qualificada.

Para os Estados Unidos, assim como Shimer (2012), foram usados os dados do Bureau of Labor Statistics (BLS).

Em todos os casos, temos séries mensais que foram trimestralizadas pela média dos três meses que compõe o trimestre e foram sazonalmente ajustadas pelo X-12 do Eviews. Ainda, para análise cíclica foi aplicado o filtro HP sobre as séries analisadas. 


\subsection{METODOLOGIA DE CÁCULO DAS CONTRIBUIÇÕES DE X E F PARA FLUTUAÇÃO DA TAXA DE DESEMPREGO}

A maior preocupação neste presente trabalho, assim como a de Shimer (2012), é conseguir analisar importância cíclica destes dois componentes. Qual é o mais importante para explicar flutuações na taxa de desemprego?

Para fazer tal análise, inicialmente, se deve lembrar do fato que de acordo com a equação 1.6, se $u_{t+1}=u_{t}$ então $u_{t} / l_{t}=x_{t} /\left(x_{t}+f_{t}\right)$, sendo $u_{t} / l_{t}$ a taxa de desemprego.

Quando se analisa a correlação desta medida de desemprego, $x_{t} /\left(x_{t}+f_{t}\right)$, com a da PME para cada um dos procedimentos anteriormente destacados se tem que a correlação é de 0,946 para o caso da utilização dos dados da RAIS/CAGED/PIA (PIA); de 0,928 para o caso da utilização dos dados da RAIS/CAGED/PME (CAGED_PME); e, de 0,879 quando se utiliza apenas dados da PME (CP). Embora o nível possa ser diferente, como se está preocupado com comportamento cíclico se quer correlações altas. E é isso que temos.

Serão utilizadas estas identidades para se conseguir mensurar a importância tanto de f quanto de $\mathrm{x}$ sobre o comportamento cíclico da taxa de desemprego. Para tanto, foram calculadas duas medidas. Primeiro, $\frac{\bar{x}}{f_{t}+\bar{x}}$, onde $\bar{x}$ é a média de x para o período todo, mostra a importância que a variação de $\mathrm{f}_{\mathrm{t}}$ teve para explicar a variação da taxa de desemprego. Enquanto que a segunda medida $\frac{x_{t}}{x_{t}+\bar{f}}$ mostra qual foi a importância da variável de $x_{t}$ para o comportamento da taxa de desemprego.

Tendo estas medidas, assim como Shimer (2012), serão calculados os hiatos através do filtro HP. A contribuição do primeiro componente será dada pelo coeficiente da regressão simples do hiato dele sobre o hiato da taxa de desemprego calculada, enquanto que a contribuição do segundo componente será dada pelo coeficiente da regressão simples de seu hiato sobre o hiato do desemprego calculado. 


\subsection{RESULTADOS}

\subsubsection{Cáculo de X e F}

Os valores calculados para a probabilidade de um empregado deixar o emprego $\left(X_{t}\right)$ e para probabilidade de um desempregado encontrar trabalho $\left(F_{t}\right)$, ambos para 0 Brasil, seguem abaixo.

\subsubsection{Cálculo de F}

A figura 3 traz o cálculo da probabilidade de um trabalhador desempregado encontrar trabalho entre $t$ e $t+1$ segundo as três metodologias descritas anteriormente. Os dados apresentados são trimestrais e com ajuste sazonal ${ }^{3}$. 0 trimestre se refere à média dos três meses. Como se pode ver, a diferença no cálculo do estoque de desempregados, empregados e desempregados de curto prazo leva tanto a diferença de nível como de trajetória das séries de $F_{t}$ ao longo do tempo.

Como era de se esperar, a série de F considerando dados do CAGED e da PIA ("F_PIA" na figura), por ter uma maior massa de desempregados, é a que leva à menor probabilidade em se achar emprego (linha azul). Embora menor, seu comportamento é parecido com a $F$ resultante da população empregada vinda do CAGED e da população desempregada vinda da taxa de desemprego divulgada da PME (F_CAGED_PME - linha vermelha). Nestes dois casos se tem que a probabilidade de um trabalhador desempregado encontrar trabalho cresceu de modo expressivo entre o início dos anos 2000 e o final de 2013. O que nos parece bastante razoável dada a expressiva redução da taxa de desemprego que ocorreu no período e ao avançado do processo de formalização. Neste ambiente aquecido, é de se esperar que haja mais facilidade em se encontrar empregos, e empregos de melhor qualidade, dentre os quais estão os empregos formais.

\footnotetext{
${ }^{3}$ Método X-12 aditivo do Eviews.
} 
É interessante observar na figura 3 também que, em ambas as séries, $F$ apresenta uma redução significativa no período imediatamente posterior ao estopim da crise econômica-financeira internacional de setembro de 2008. Os impactos fortíssimos da crise afetaram a atividade e também o mercado de trabalho. Mas, assim como a atividade, a recuperação foi rápida entre 2009 e 2010. Mais recentemente a probabilidade para se encontrar emprego estacionou, mas em nível historicamente elevado.

FIGURA 3 - CÁLCULO DA PROBABILIDADE DE ENCONTRAR EMPREGO - F

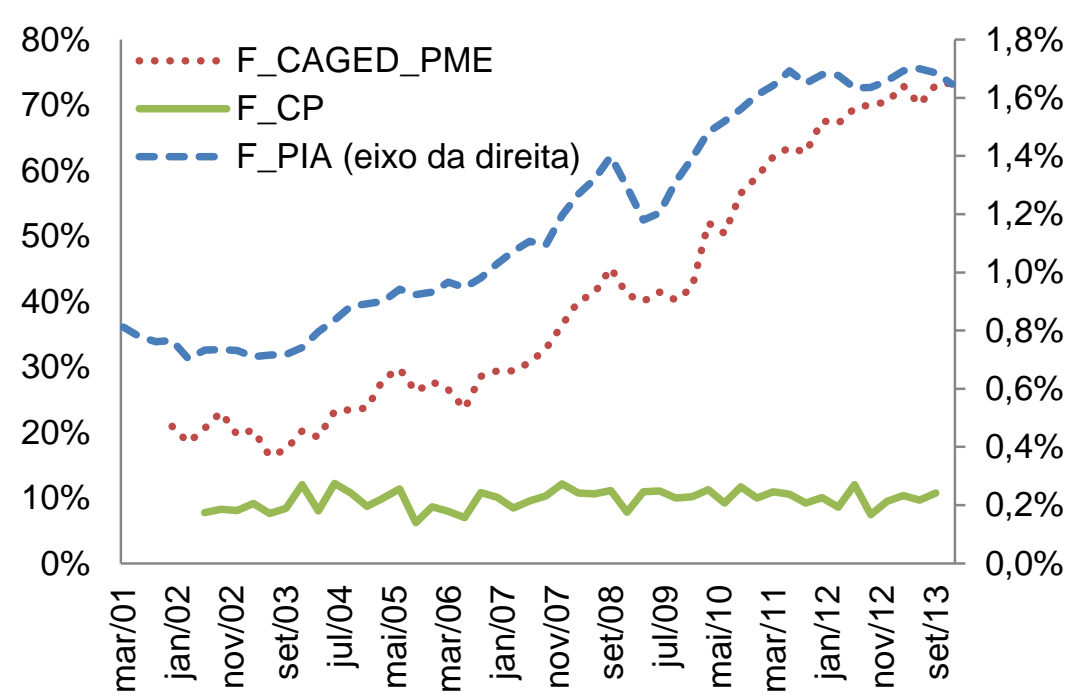

Por sua vez, quando se considera apenas os dados da PME/IBGE, o que se observa (F_CP) é uma $\mathrm{F}$ mais ou menos constante ao longo do tempo. Este comportamento é encontrado na literatura e, provavelmente, é o que faz com que a probabilidade em se encontrar emprego tenha pouca importância para explicar a taxa de desemprego. Esta parece ser uma característica dos dados da PME.

Outro fato que chama atenção na figura 3 é que, no caso da F_CAGED_PME (linha vermelha), o nível está em torno de $70 \%$. Isto ocorre porque quando se considera a população ocupada da RAIS com a taxa de desemprego da PME/IBGE, o total de desemprego de curto prazo (demitidos do CAGED) torna-se apenas pouco menor que o total de desempregados. Neste caso, tem-se uma rotatividade muito grande e a maior parte dos desempregados de curto prazo estaria conseguindo achar emprego (ou trocando de emprego) em cada intervalo de tempo. 
Assim, quando se compara as probabilidades (F) oriundas dos dados do CAGED com a que resulta do cálculo com dado apenas da PME se tem duas situações distintas. No primeiro caso, as probabilidades parecem variar mais e são crescentes ao longo do tempo, enquanto que, no segundo caso, ela varia pouco em torno de uma média. Mas qual será a mais correta? É difícil de dizer, pois o conjunto de dados é diferente e foram feitas aproximações para que se conseguisse calculá-las. No entanto, se levarmos em consideração que há certo consenso que há expressiva rotatividade no mercado de trabalho brasileiro, que tem sido destacada na literatura (por exemplo, Gonzaga (1998 e 2003)) e tem sido fonte de discussões pelo próprio governo, o comportamento da $\mathrm{F}$ parece bastante razoável.

Segundo dados do próprio Ministério do Trabalho e Emprego, referentes à RAIS, em 2012, 24,5 milhões de trabalhadores foram desligados contra um estoque de empregados de 38,9 milhões em 31 de dezembro daquele ano, ou seja, uma taxa de rotatividade superior a $62 \%$ naquele ano. Fazendo este mesmo cálculo pela RAIS de 2003, chegaríamos a 52\%. Portanto, neste contexto de elevadíssimas taxas de desligamentos e de redução significativa do desemprego é de esperar também taxas crescentes para se encontrar trabalho. Num mercado de trabalho aquecido esperase que seja mais fácil para um trabalhador desempregado encontrar trabalho, ou mesmo para um trabalhador empregado trocar de trabalho. Caso contrário, não se consegue entender a redução do desemprego.

\subsubsection{Cálculo de X}

Com relação ao comportamento da probabilidade de um empregado se desligar do trabalho, algo parecido acontece. Os comportamentos das séries oriundas dos dados do CAGED/RAIS são diferentes daquele apresentado pela série resultante dos dados apenas da PME.

Como se pode observar na figura 4, quando foi utilizada a população ocupada do CAGED, tanto com a população desocupada oriunda da PIA (X_PIA - linha azul) quanto com a taxa de desemprego do IBGE/PME (X_CAGED_PME-linha vermelha), tem-se um aumento de $X$ no período. Os movimentos que se destacaram ao longo do tempo foram (i) aumento expressivo da probabilidade de desligamento que ocorreu no auge da crise econômica-financeira em setembro de 2008; (ii) o forte 
crescimento desta probabilidade entre o final de 2009 e o ano de 2012; e, (iii) a desaceleração ao final de 2013.

Ou seja, segundo estes dados, a probabilidade de um trabalhador deixar o trabalho, cresceu de modo mais contido entre o início da série e o início de 2008, cresceu fortemente na crise, reduziu-se, mas posteriormente aumentou consistentemente por um longo período de tempo, quando então se estabilizou. Mais recentemente, esta probabilidade reduziu-se levemente. Portanto, se o motivo do desligamento é a busca por uma melhor opção, segundo estes dados, podemos dizer que o mercado de trabalho parece ter ficado mais aquecido no período pós-crise.

Por outro lado, quando se calculou X apenas com dados da PME/IBGE (X_CP) se tem redução contínua da probabilidade de um trabalhador empregado deixar seu trabalho. Portanto, um resultado contrário ao obtido anteriormente. Outro ponto interessante desta série é que a crise de 2008 pouco afetou a sua dinâmica.

Mas, novamente, parece que este resultado da PME vai na direção contrária da discussão de que havia grande rotatividade no mercado de trabalho brasileiro. Isso porque, está série esta nos dizendo que os trabalhadores estavam ficando, em média, cada vez mais tempo nos seus empregos. Em um mercado de trabalho aquecido, com boas vagas abertas, a não ser que o mercado de trabalho seja muito regulado, não parece razoável supor que os trabalhadores mudem menos de emprego, ainda mais se levarmos em consideração que há um grande contingente de trabalhadores jovens no Brasil.

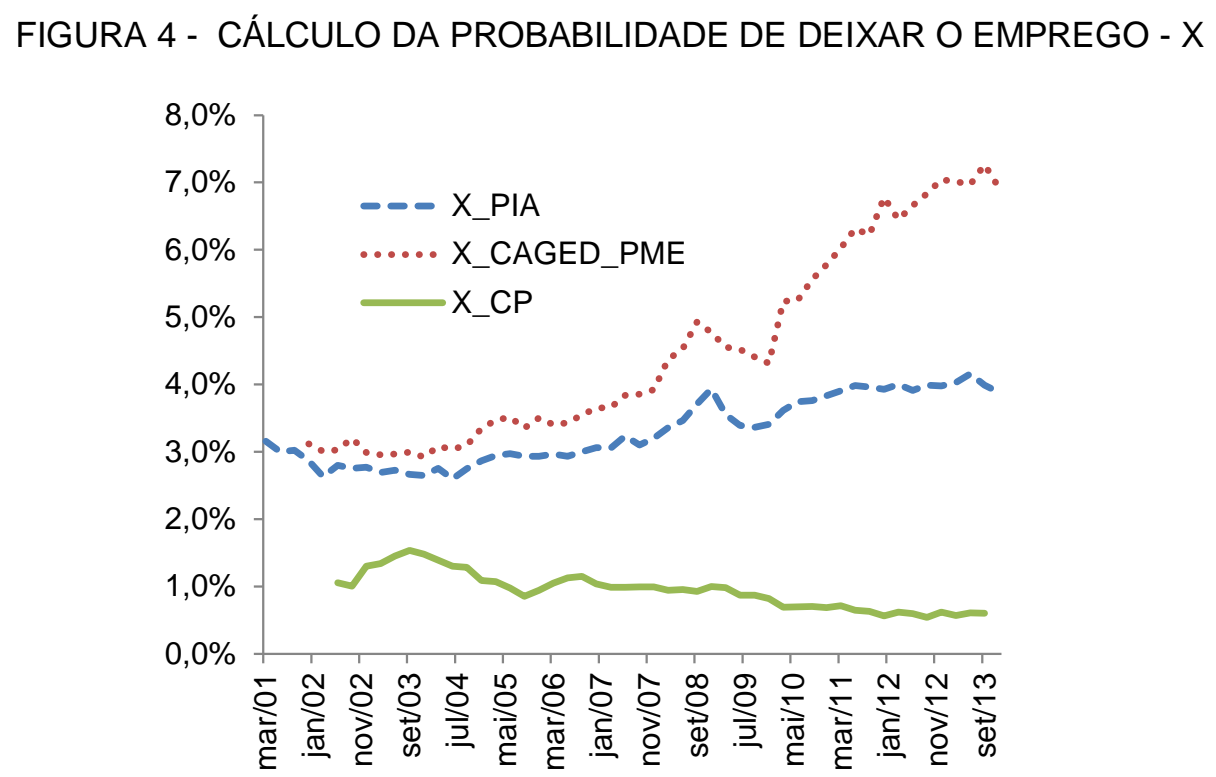


Assim, tendo por base estes resultados, percebe-se que os dados do CAGED/RAIS indicam um mercado de trabalho bem mais dinâmico que o indicado pela análise dos dados da PME/IBGE. O que está de acordo com as discussões sobre elevada rotatividade do mercado de trabalho brasileiro, também referendada pela literatura. Inclusive pela literatura que diz que os mercados de trabalho com percentual significativo de jovens são mercados mais dinâmicos, com mais rotatividade e tendem a ter menor taxa de desemprego (Shimer(2001)).

Por fim, como destacamos anteriormente, a análise simples das figuras de $\mathrm{F}$ e $\mathrm{X}$ pelos dados do CAGED/RAIS mostra que as duas séries parecem ser importantes para explicar o mercado de trabalho enquanto que quando usamos os dados da PME se tem uma maior importância de $X$, dado que $F$ é mais ou menos constante ao longo do tempo.

1.5.2 Cálculo das Contribuições da Probabilidade de Encontrar Emprego e de Deixar o Emprego para Flutuação da Taxa de Desemprego

Como se pode observar na figura 5 , quando construímos as estatísticas tendo por base os dados da PIA/CAGED/RAIS, "PIA", percebemos que quando mantemos $x$ fixo em sua média ( $x$ bbarra no gráfico) e variamos $f$, a série de desemprego gerada é muito próxima da verdadeira, isto é, de $x_{t} /\left(x_{t}+f_{t}\right)$. Enquanto que quando se mantem fixa f na média (f_barra) e se permite a variação de $x$, a série gerada não explica a redução do desemprego no período. Na realidade, na parte final, a variação de $x$ levaria a um aumento da taxa de desemprego. 
FIGURA 5 - CONTRIBUIÇÕES PARA A TAXA DE DESEMPREGO - PIA

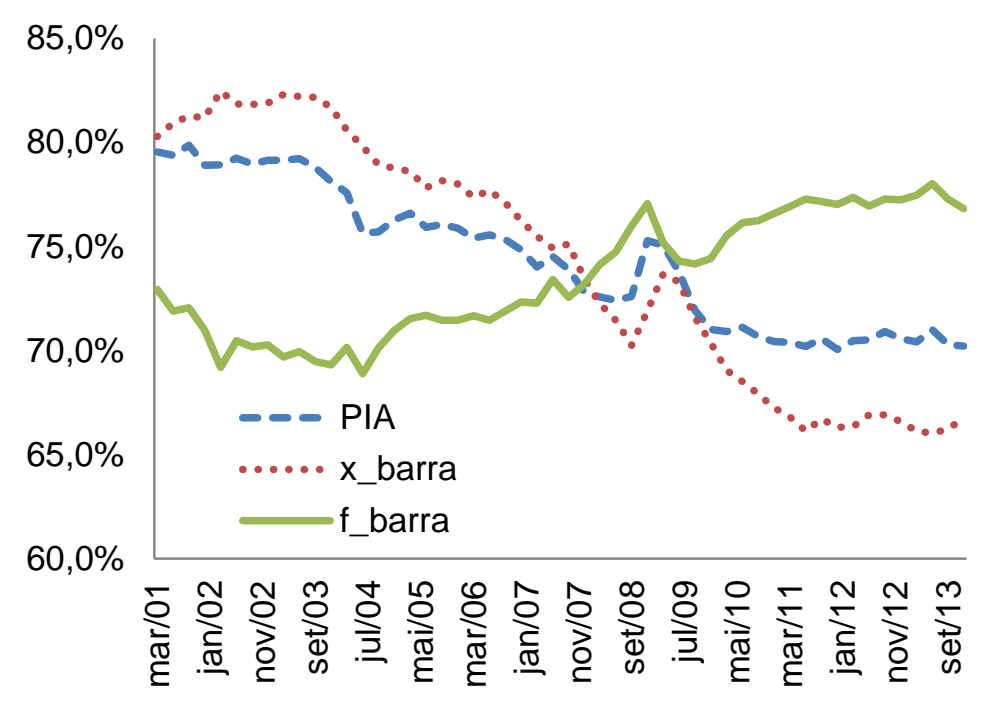

Isso mostra que, sob esta metodologia de análise, o comportamento de f foi mais importante ao longo do tempo para explicar a dinâmica do nível da taxa de desemprego do que o comportamento de $x$.

Quando utilizamos os dados do CAGED, mas com a taxa de desemprego da PME (CAGED_PME, na figura 6), se tem novamente a situação na qual a variação de $f$ (com x fixo na média x_barra) é que explica a redução da taxa de desemprego. Novamente, a variação de x (com f fixo na média - f_barra) levaria a um aumento da taxa de desemprego no final do período.

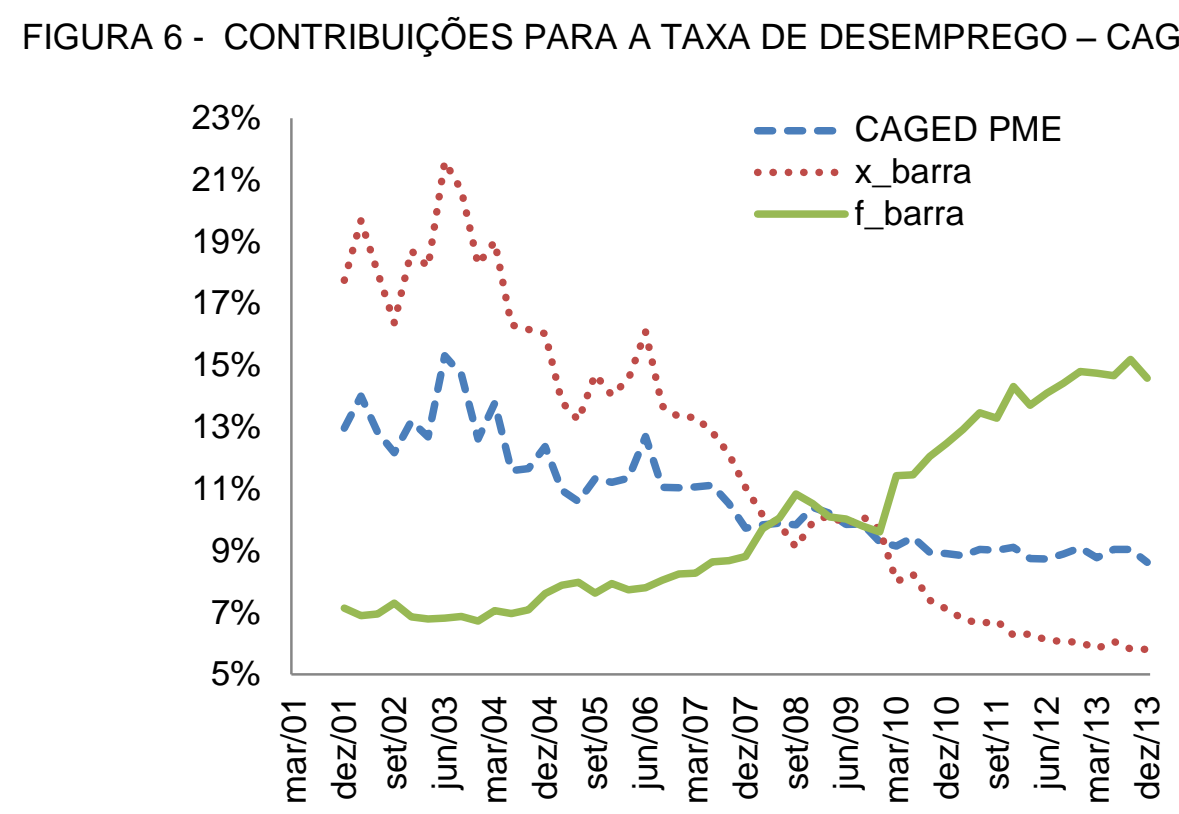

É importante destacar que estes dois resultados, ao mostrar que a fé que tem maior importância, são diferentes daquele encontrado na literatura brasileira que diz que o 
comportamento da taxa de separação é que é o mais relevante para explicar o comportamento da taxa de desemprego. Vale notar ainda que, nestes dois casos, no pós-crise, a maior facilidade em se encontrar emprego é que foi decisiva para redução do desemprego. O que soa bem razoável dadas as condições favoráveis do mercado de trabalho no período.

Por fim, a figura 7 traz os resultados quando foram utilizadas apenas as séries da PME. Como se pode notar, quando fixamos $x$ em sua média ( $x$ barra) e deixamos variar f (linha vermelha), não temos grande explicação do comportamento da taxa de desemprego. A série gerada se descola da série de desemprego (CP, em azul). Já,

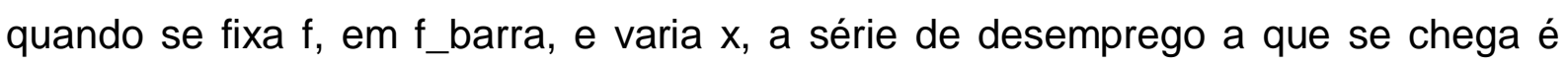
muito próxima à série original. Isso indica que, neste caso, a análise de $x$ é que seria importante para entender o nível da taxa de desemprego e também o mercado de trabalho. Resultado em linha com os encontrados na literatura, que analisam apenas os dados da PME.

FIGURA 7 - CONTRIBUIÇÕES PARA A TAXA DE DESEMPREGO - CP (APENAS PME)

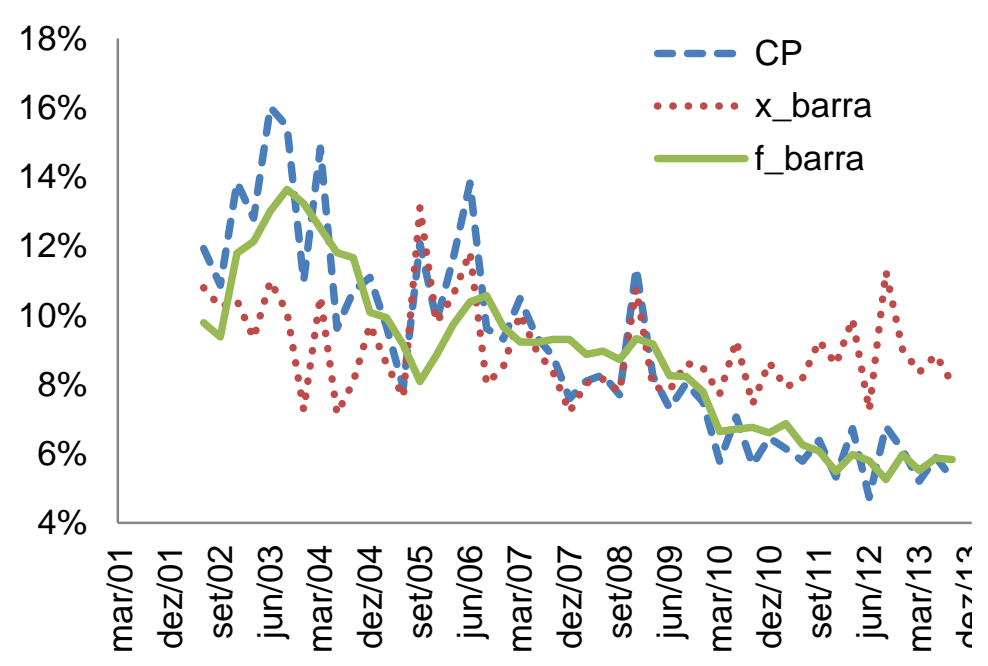

Embora estes exercícios ajudem a entender a importância de cada uma das séries para o desemprego ainda não se consegue mensurar com maior precisão a importância para a dinâmica cíclica que $x$ e f têm para o comportamento cíclico da taxa de desemprego. Isso será realizado a seguir. 


\subsection{IMPORTÂNCIA CÍCLICA DA PROBABILIDADE DE ENCONTRAR EMPREGO E DE DEIXAR O EMPREGO}

Para quantificar a importância cíclica de x e f sobre o desemprego, aplicamos o filtro HP nas séries de desemprego calculadas $\left(\mathrm{x}_{\mathrm{t}} /\left(\mathrm{x}_{\mathrm{t}}+\mathrm{f}_{\mathrm{t}}\right)\right)$ assim como nas duas outras séries de desemprego geradas, com $x$ fixo e com $f$ fixo ${ }^{4}$. Feito isso, utilizamos os hiatos gerados e os regredimos, tanto o hiato da série com $x$ fixo (e $f$ variando) quanto sobre o hiato da série com f fixo (e $x$ variando), sobre o hiato do desemprego calculado para cada uma do conjunto de séries. A ideia é ver qual o percentual da variação cíclica da taxa de desemprego que é explicada por cada uma destas séries (xef).

Os resultados estão na tabela 2. Ela nos mostra que na frequência cíclica, a variação de $f$ (job finding rate) explica a maior parte do comportamento da taxa de desemprego. Ela explica algo entre $62 \%$ e $154 \%$. É interessante notar que, diferentemente da análise gráfica da seção anterior, mesmo na série construída apenas com dados da PME (CP na tabela 1), o poder de explicação do comportamento cíclico de f sobre o comportamento cíclico da taxa de desemprego foi não desprezível, de $62 \%$. Assim, embora pareça que f não dite o nível da taxa de desemprego, ela tem importância para explicar as variações cíclicas.

TABELA 2 - RESULTADO DA REGRESSÃO SIMPLES DAS VARIÁVEIS Z EM U/L

\begin{tabular}{cccc}
\hline \multirow{2}{*}{ Variável Z } & \multicolumn{3}{c}{ Coeficiente } \\
\cline { 2 - 4 } & PIA & CAGED_PME & CP \\
\hline x_barra/(x_barra $+\mathrm{f})$ & 0,8837 & 1,54 & 0,624 \\
$\mathrm{x} /(\mathrm{x}+\mathrm{f}$ bbarra $)$ & $0,01^{* * *}$ & $0,12^{* * *}$ & 0,297 \\
\hline${ }^{* \star *}$ Não é estatisticamente diferente de zero nem a & $10 \%, 5 \%$ ou a $1 \%$ de \\
nível de significância & &
\end{tabular}

A tabela 2 mostra ainda que o entendimento do comportamento de $\mathrm{x}$ não deve ser desprezado apenas quando se analisa os dados da PME, uma vez que ele explica parte ainda importante do comportamento cíclico do desemprego (29,7\%). Já,

\footnotetext{
${ }^{4}$ Utilizamos o Eviews para aplicar o filtro HP. O lambda aplicado foi 10.000 , assim como no artigo do Shimer (2012).
} 
quando os cálculos são feitos com base nos dados do CAGED/RAIS com desemprego da PME (CAGED_PME) e com dados do desemprego levando em consideração toda a população em idade ativa (PIA), a variação do hiato da probabilidade de sair do emprego $(\mathrm{x}$ ) contribuiu muito fracamente para explicar a variação do desemprego sendo que estes valores não são nem estatisticamente diferentes de zero.

Por fim, como se pode notar na tabela 3, o hiato da probabilidade de o trabalhador desempregado encontrar emprego, $F$, é positivamente correlacionado com o hiato do PIB sob as três metodologias de cálculo. Ou seja, esta variável se mostrou prócíclica em relação ao PIB, sendo a pró-ciclicalidade mais forte no caso do cálculo utilizando os dados do CAGED (PIA e CAGED_PME). Portanto, quando a atividade está aquecida (hiato positivo), torna-se mais fácil para um desempregado conseguir emprego.

Com relação à taxa de desemprego, observamos que os hiatos de $\mathrm{F}$ oriundos da série de população ocupada do CAGED e população desocupada via PIA (PIA) ou via PME (CAGED_PME) se mostraram anticíclicos. Assim, quando o ciclo da taxa de desemprego é de baixa, a probabilidade de encontrar trabalho é de alta.

Já, quando se calcula $F$ via os dados da PME (CP no quadro), tem-se o resultado contrário, de pró-ciclicalidade. Isto é, quando o ciclo é de baixa no desemprego, o ciclo também é de baixa na probabilidade de encontrar trabalho.

Com relação às estatísticas descritivas, observa-se que os hiatos têm média zero e em termos de variação, desvio padrão, os hiatos da probabilidade para encontrar emprego CAGED/PME e CP são as que apresentam maior variabilidade.

TABELA 3 - ESTATÍSTICAS DESCRITIVAS E CORRELAÇÃO DOS HIATOS DE F COM HIATO DO PIB E DA TAXA DE DESEMPREGO - FILTRO HP

Correlação

\begin{tabular}{|c|c|c|c|c|c|}
\hline & $\mathrm{CP}$ & PIA & CAGED_PME & $\mathrm{PIB}$ & Tx de desemprego - PME \\
\hline PIB & 0,23 & 0,78 & 0,30 & & \\
\hline Tx de desemprego - & 0,21 & $-0,54$ & $-0,49$ & & \\
\hline \multicolumn{6}{|l|}{ Estatística descritiva } \\
\hline Média & 0,000 & 0,000 & 0,000 & 0,000 & 0,000 \\
\hline Desvio Padrão & 0,014 & 0,001 & 0,049 & 0,015 & 0,005 \\
\hline
\end{tabular}

A tabela 4 traz estas mesmas informações para os cálculos de X. Como podemos observar, o hiato da probabilidade de um trabalhador perder o emprego é pró-cíclico 
em relação ao PIB quando calculado com dados do CAGED (tanto PIA quanto CAGED_PME) e anticíclico quando calculado com dados da PME.

Assim, os cálculos com dados do CAGED indicam que a chance de se deixar o emprego é maior quando a economia está vivendo um período de expansão. Esse resultado é razoável dado que é de se esperar que haja melhores vagas abertas neste período. Isso porque neste contexto as opções de fora para o trabalhador empregado aumentam e melhoram, o que lhe dá incentivo para mudar de emprego. Já, os dados da PME, mostram o contrário, que quanto mais aquecida a economia, menor a chance de o trabalhador deixar o emprego.

Já, no que tange à correlação com a taxa de desemprego, temos que o hiato de $X$ é negativamente correlacionado nas mensurações PIA e CAGED_PME, mas é positivamente correlacionado quando usamos os dados da PME (metodologia denominada (P). Mais uma vez os dados do CAGED/RAIS apontam para um mercado de trabalho mais dinâmico, ao mostrar que quando o ciclo do desemprego é de queda, as pessoas tendem a deixar mais o trabalho, muito provavelmente em buscar de algo melhor para tentar acelerar a ascensão na carreira.

Ademais, com relação às estatísticas descritivas de $\mathrm{x}$ temos que o desvio padrão do componente cíclico das três medidas é pequeno.

TABELA 4 - ESTATÍSTICAS DESCRITIVAS E CORRELAÇÃO DOS HIATOS DE X COM HIATO DO PIB E DA TAXA DE DESEMPREGO - FILTRO HP

Correlação

\begin{tabular}{|c|c|c|c|c|c|}
\hline & $\mathrm{CP}$ & PIA & CAGED_PME & PIB & Tx de desemprego - PME \\
\hline $\mathrm{PIB}$ & $-0,31$ & 0,33 & 0,15 & & \\
\hline Tx de desemprego - & 0,76 & $-0,46$ & $-0,36$ & & \\
\hline \multicolumn{6}{|l|}{ Estatística descritiva } \\
\hline Média & 0,000 & 0,000 & $-0,000$ & 0,000 & 0,000 \\
\hline Desvio Padrão & 0,001 & 0,002 & 0,004 & 0,015 & 0,005 \\
\hline
\end{tabular}

Por fim, as tabelas 3 e 4 ainda nos mostram que no caso tanto do cálculo de $\mathrm{f}$ e $\mathrm{x}$ com dados da PME (CP) como no caso CAGED_PME ${ }^{5}$ o desvio padrão do hiato de $f$

\footnotetext{
${ }^{5}$ Cálculo com dados do CAGED e considerando a taxa de desemprego da PME.
} 
é mais de dez vezes maior que o desvio padrão do hiato de x. Já, no caso $\mathrm{PIA}^{6}$ a situação se inverte e o desvio padrão do hiato de f é pouco menos da metade do desvio padrão do hiato de $x$.

\subsection{CÁlCULO DE F E X POR GRAU DE ESCOLARIDADE}

Como no Brasil, em média, a qualificação dos trabalhares é muito baixa, é interessante estudar como se comportou a job finding rate e a separation rate entre os grupos de trabalhadores mais qualificados e os menos qualificados a fim de poder saber qual dos dois grupos devem ter influenciado mais a dinâmica anteriormente discutida.

A metodologia para cálculo da importância cíclica do job finding rate e da separation rate utilizada aqui é a mesma empregada até agora. Como umas das contribuições do trabalho foi trazer os dados do CAGED e da RAIS para a discussão mais detalhada do mercado de trabalho, vamos fazer esta análise focada apenas nestas bases de dados que julgamos ser a que melhor reflete a dinâmica do mercado de trabalho brasileiro.

A diferença é que temos que criar a séries de população ocupada, desocupada e desemprego de curto prazo tanto para os trabalhadores mais qualificados quanto para os trabalhadores menos qualificados.

Como já explicado, estas séries foram criadas utilizando dados da RAIS, do CAGED e da PNAD. Os trabalhadores mais qualificados (high) são aqueles que possuem no mínimo ensino superior incompleto enquanto que os demais trabalhadores foram chamados de menos qualificados (low).

Para a população ocupada utilizamos a RAIS de 2003 como ponto de partida e evoluímos mês a mês pelo saldo líquido do CAGED. Para o desemprego de curto prazo, consideramos os dados de demitidos do CAGED que também podem ser separados entre mais e menos qualificados seguindo a regra especificada acima.

\footnotetext{
${ }^{6}$ Uso de dados do CAGED e da População em Idade Ativa (PIA) do IBGE.
} 
Como estes dados só estão disponíveis no site do Ministério do Trabalho e emprego após 2004, não foi possível construir uma série mais longa.

Por fim, para a população desocupada, neste caso, foram considerados os números de pessoas desocupadas segundo a Pesquisa Nacional de Amostra Domiciliar (PNAD), considerando que quem tem até 11 anos de estudo é menos qualificado e quem tem mais é mais qualificado. Utilizamos dados da PNAD devido à dificuldade em separar os dados da população brasileira entre 15 e 65 anos entre mais e menos qualificada.

$\mathrm{Na}$ figura 8 temos as probabilidades que os trabalhadores desempregados mais qualificados (high) e menos qualificados (low) tinham para encontrar trabalho entre 0 final de 2003 e o final 2013. Podemos observar, de imediato, que probabilidade para os menos qualificados é bem maior. Isso pode ser explicado, por exemplo, pelo fato deles trabalharem em tarefas que tenham maior rotatividade, como: construção civil e no setor agropecuário.

Ao longo do tempo podemos observar que houve aumento na probabilidade para os dois grupos, mas o incremento na probabilidade de encontrar emprego até o final de 2012 foi maior para os menos qualificados. A expansão forte da economia parece ter contado mais fortemente com a contratação deste tipo de mão de obra.

No período final da análise, em 2013, temos uma forte queda desta probabilidade, com uma redução bem mais acentuada para os menos qualificados. Assim, da mesma forma que este grupo de trabalhadores foi mais beneficiado no período de maior expansão da atividade econômica, que os permitiu uma maior facilidade em encontrar trabalho, no período de desaceleração, este grupo está sofrendo mais que o grupo dos trabalhadores mais qualificados.

Face à esta dinâmica, há uma significativa evidência de que quem parece determinar de modo mais forte a volatilidade da probabilidade em encontrar trabalho (F) agregada, mostrada anteriormente, é o grupo dos trabalhadores menos qualificados.

Por fim, é interessante destacar que, no período mais grave da crise econômicofinanceira, as probabilidades dos dois grupos recuaram, mas voltaram rapidamente à trajetória anterior conforme a economia se recuperou. 
FIGURA 8 - PROBABILIDADE DE ENCONTRAR TRABALHO (F), POR GRAU DE ESCOLARIDADE

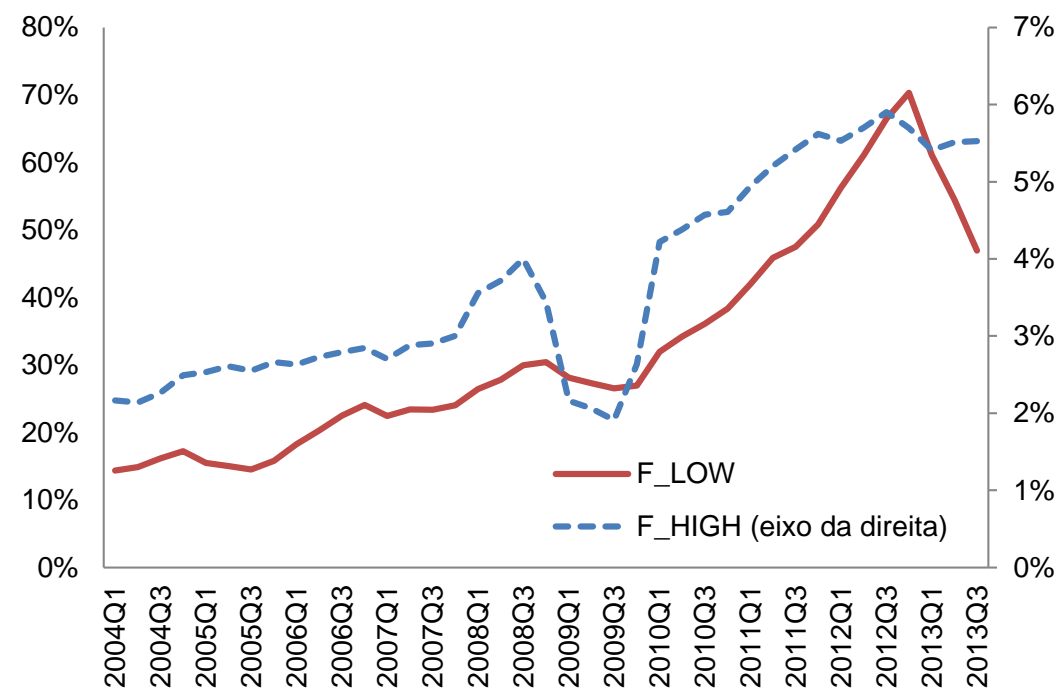

Com relação à probabilidade de um trabalhador empregado poder deixar o trabalho $(\mathrm{X})$, temos na figura 9 que novamente essa probabilidade para o grupo dos trabalhados menos qualificados é maior ao longo de todo o período. Ambas as probabilidades cresceram ao longo do tempo, mas, para o grupo menos escolarizado, ela passou a recuar a partir de meados de 2012. Além disso, entre 2010 e o final de 2012, o aumento da probabilidade foi maior para os menos qualificados do que para os mais qualificados.

Este aumento da probabilidade observada ao longo do período não necessariamente deve ser interpretado como ruim. Isso porque as pessoas podiam estar deixando o trabalho para ir para um emprego melhor. Neste caso, os trabalhadores estariam em melhor condição. Como esta história é bem razoável em momento de expansão da economia, é de esperar que isso tenha ocorrido no Brasil durante o período estudado. E esta dinâmica nos indica que este ganho beneficiou tanto o grupo dos trabalhadores mais qualificados quanto o grupo dos menos qualificados.

Além disso, vale destacar que no período mais agudo da crise, nenhum dos grupos teve alteração drástica da probabilidade de deixar o emprego. 
FIGURA 9 - PROBABILIDADE DE ENCONTRAR TRABALHO (X), POR GRAU DE ESCOLARIDADE

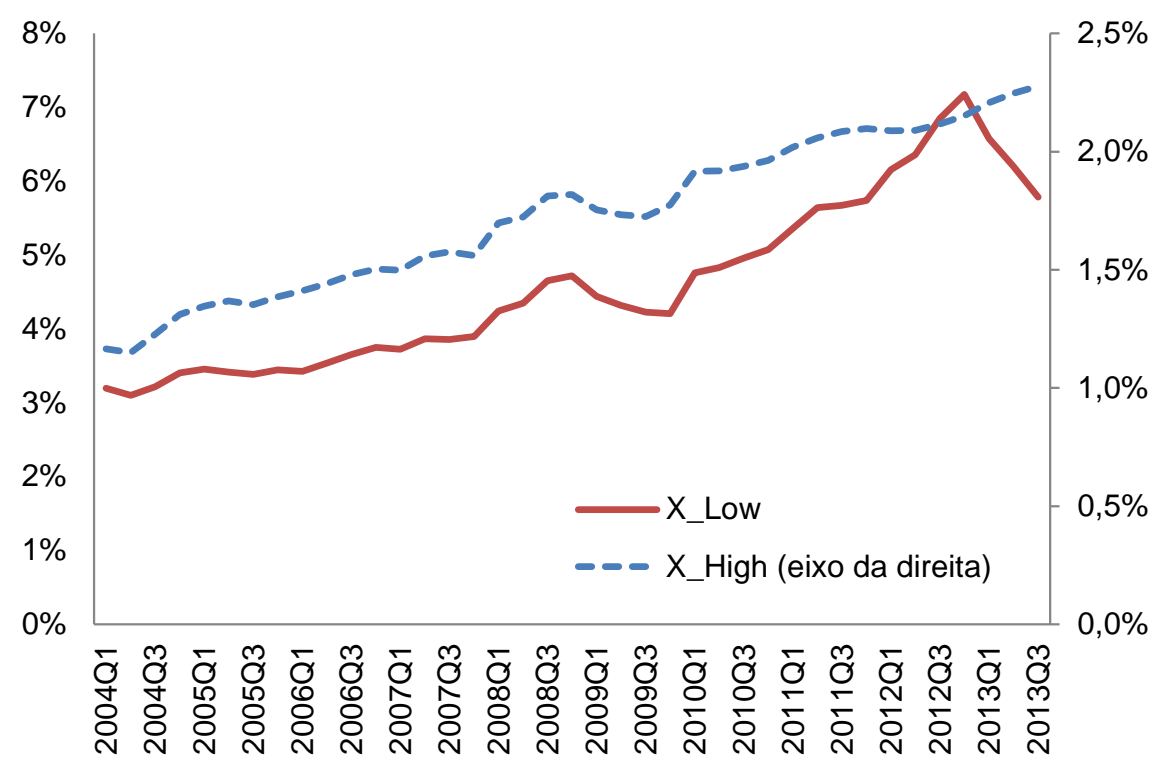

Como vimos, é importante saber as contribuições de x e f para a flutuação da taxa de desemprego. Os resultados seguem abaixo e foram feitos usando a metodologia exposta na seção 1.4 .

Para os trabalhadores mais qualificados, quando fixamos a separation rate na média do período e deixamos livre a job finding rate, é que conseguimos explicar melhor o comportamento da taxa de desemprego, conforme se pode ver na figura 10. Já, quando fixamos a job finding rate na sua média e deixamos livre a separation rate, temos que a taxa de desemprego deveria ter aumentado no período e não diminuído. 
FIGURA 10 - CONTRIBUIÇÃO PARA A TAXA DE DESEMPREGO PARA OS MAIS QUALIFICADOS $(\mathrm{HIGH})$

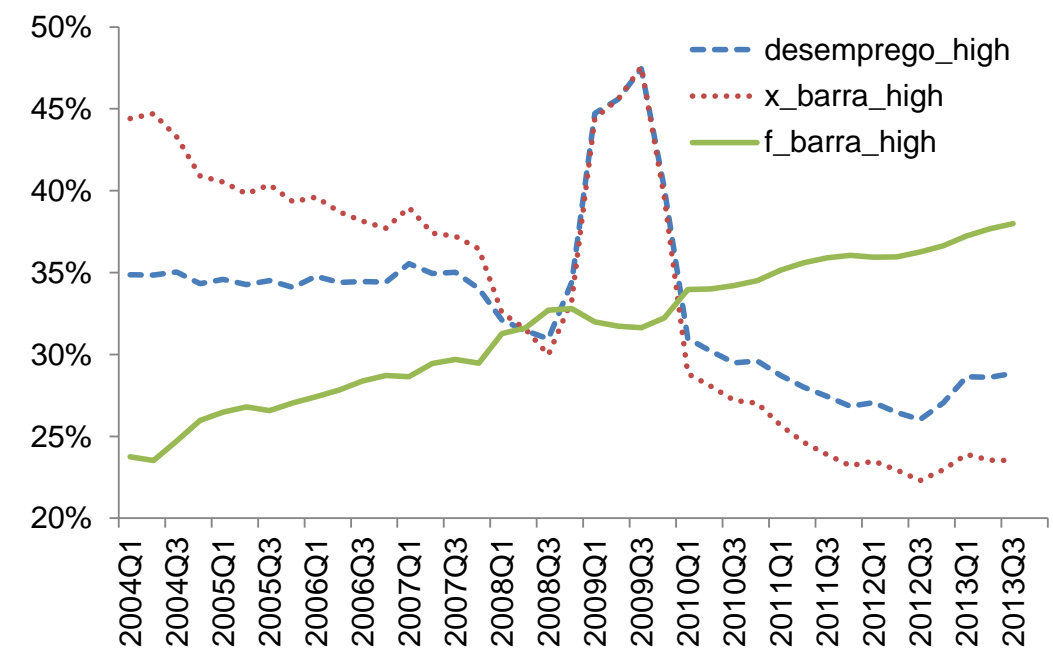

Para os trabalhadores menos qualificados ocorre situação semelhante. Ou seja, conseguimos explicar a queda da taxa de desemprego observada ao longo do período estudado apenas quando fixamos a separation rate $(\mathrm{x})$ na média e deixamos livres a job finding rate, uma vez que quando fazemos o inverso, a separation rate nos indica que a taxa de desemprego deveria ter aumentado no período e não diminuído (figura 11).

FIGURA 11 -CONTRIBUIÇÃO PARA A TAXA DE DESEMPREGO PARA OS MENOS QUALIFICADOS (LOW)

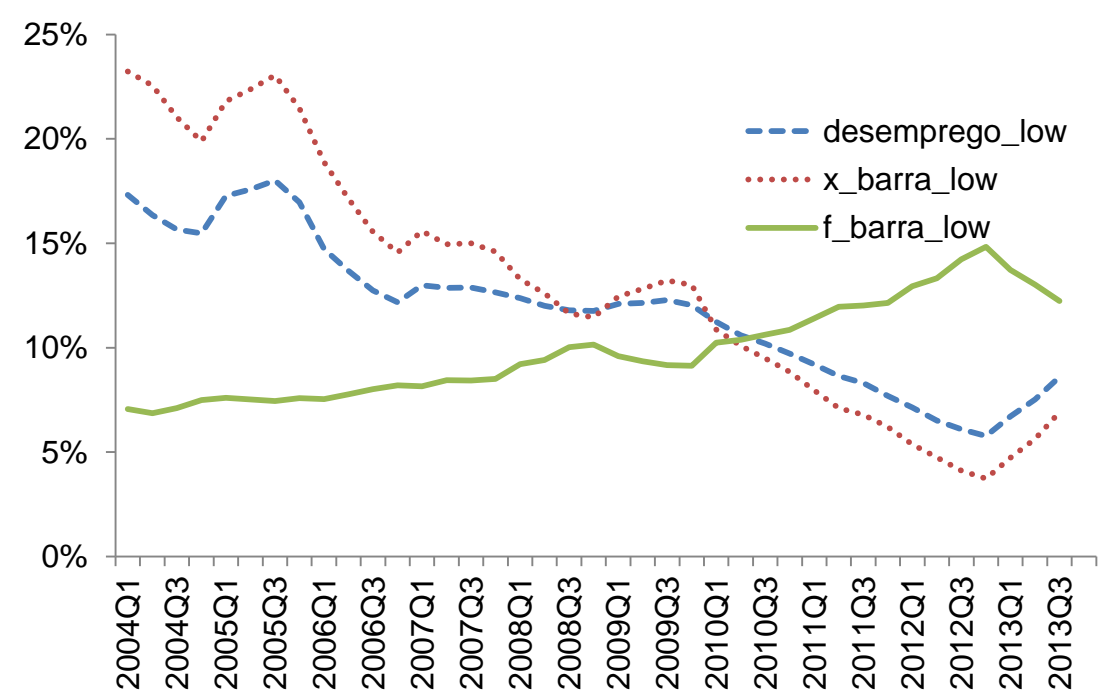

Portanto, assim como para o caso agregado, temos que nos dois casos o comportamento da job finding rate é que explicou o comportamento no nível da taxa de desemprego observada no período. 
Por fim, quando refazemos o exercício de regredir o hiato da taxa de desemprego tanto no hiato da job finding rate quanto na separation rate, novamente, chegamos a resultados parecidos ao encontrado para o agregado para os dois grupos. Como se pode ver na tabela 5 , tanto para os trabalhadores mais qualificados quanto para 0 grupo de trabalhadores menos qualificados, o hiato da job finding rate explica a maior parte do movimento do hiato do desemprego. A contribuição do hiato da separation rate é muito pequena para os mais qualificados e um pouco mais importante para o menos qualificados.

TABELA 5 - RESULTADO DA REGRESSÃO SIMPLES DAS VARIÁVEIS Z EM U/L

\begin{tabular}{ccc}
\hline \multirow{2}{*}{ Variável $Z$} & \multicolumn{2}{c}{ Coeficiente } \\
\cline { 2 - 3 } & High & Low \\
\hline x_barra/(x_barra $+f)$ & 1,06 & 1,23 \\
$x /\left(x+f \_\right.$barra $)$ & $-0,05$ & $-0,31$ \\
\hline${ }^{* * \star}$ Não é estatisticamente diferente de zero nem a $10 \%, 5 \%$ ou a $1 \%$ de \\
nível de significância
\end{tabular}

Portanto, de modo geral, notamos que houve uma dinâmica mais favorável do mercado trabalho tanto para os mais quanto para os menos qualificados ao longo do período estudado. Mas, o ganho maior parece ter sido para os menos qualificados, pelos menos até o final de 2012. A partir de então, quando a economia começa a ter uma dinâmica menos favorável, há uma piora um pouco mais acentuada das condições do mercado para os trabalhadores menos qualificados.

Tudo isso mostra que o comportamento do mercado de trabalho para os menos escolarizados, também pelo seu maior peso, parece dar mais volatilidade ao dado agregado do mercado de trabalho. Além disso, assim como o caso agregado, olhando as partes, os resultados mostram que a probabilidade de achar emprego é que é mais importante para explicar o comportamento da série de desemprego tanto para os mais qualificados quanto para os menos qualificados.

\subsection{COMPARAÇÃO COM OS EUA}

Nas figuras 12 e 13 seguem, respectivamente, os cálculos de F e X entre 1956 e meados de 2014 para os EUA. Para as duas medidas, apresentaremos os resultados de nossos cálculos com dados do BLS assim como os valores disponibilizados por Shimer em seu sítio até 2007. 
FIGURA 12 - CÁLCULO DA PROBABILIDADE DE ENCONTRAR EMPREGO (F) PARA OS EUA

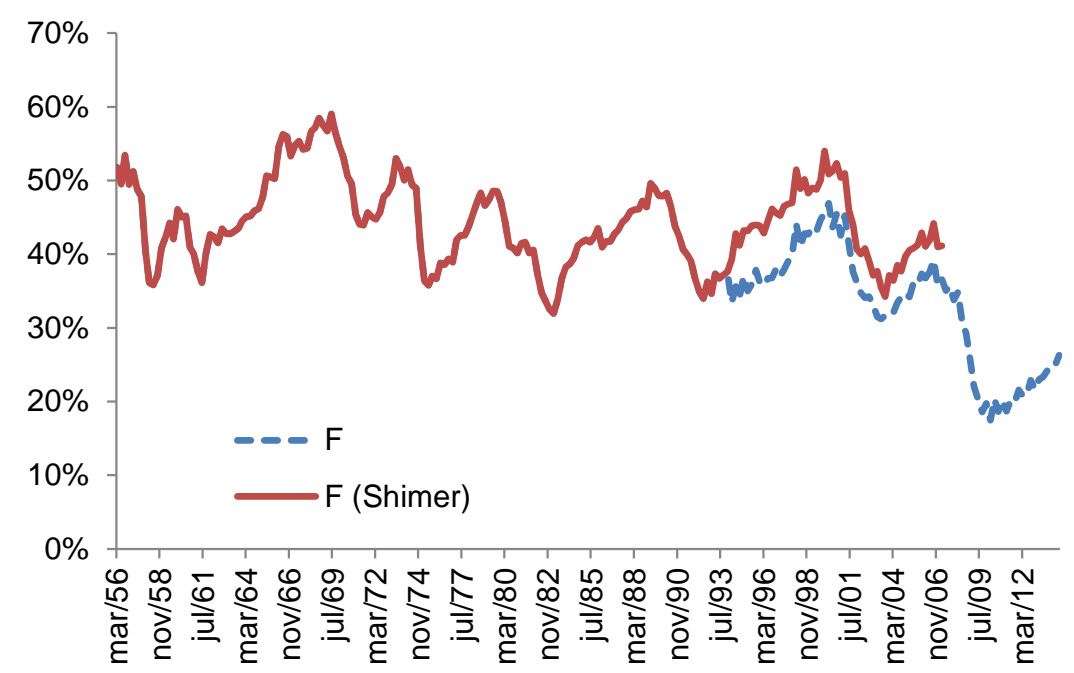

FIGURA 13 - CÁLCULO DA PROBABILIDADE DE PERDER EMPREGO (X) PARA OS EUA

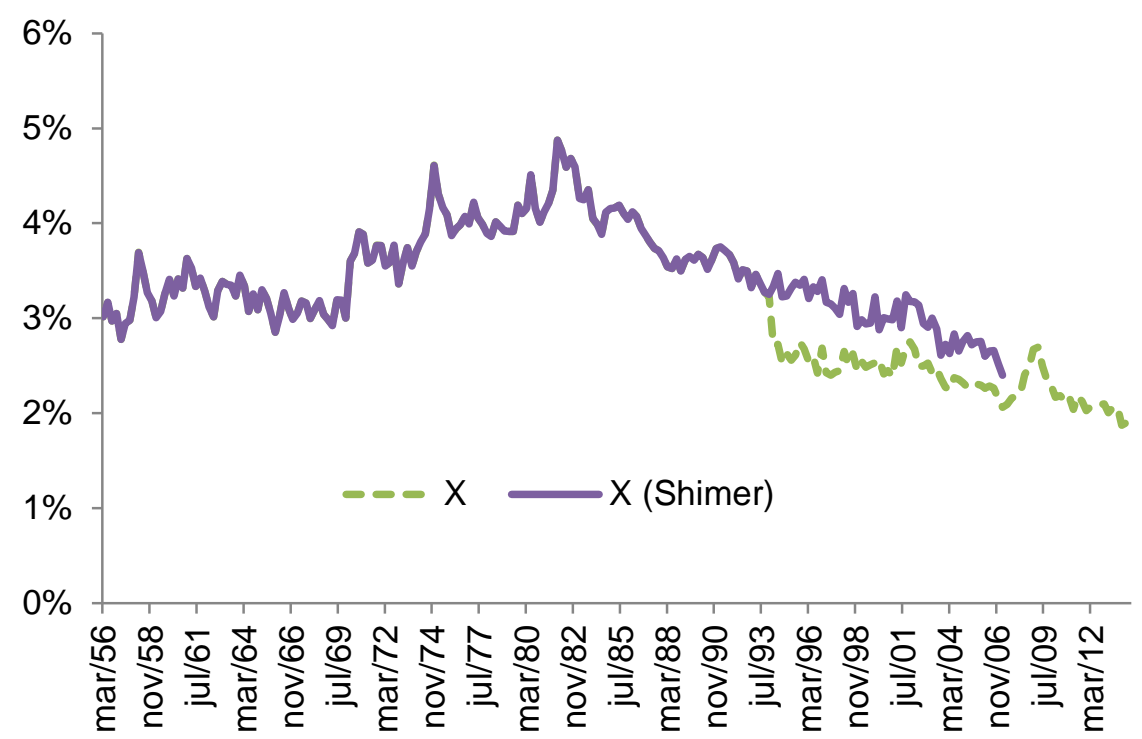

Como podemos observar, até 1994, nossos resultados para $\mathrm{F}$ e $\mathrm{X}$ são iguais aos dele. Mas a partir de então, devido a mudanças metodológicas que o levaram a alterar o modo de cálculo do desemprego de curto prazo, nossos resultados divergem dos dele, principalmente no nível. Como estamos preocupados com ciclo, seguimos analisando as séries calculadas por nós com relação à explicação das flutuações da taxa de desemprego e à ciclicalidade em relação ao PIB e a própria taxa de desemprego.

Como se pode observar na tabela 6 , na frequência cíclica, quem mais explica o comportamento da taxa de desemprego é a variação de f, com mais de $80 \%$. Apesar 
da diferença metodológica a partir de 94, este resultado não está muito distante do encontrado por Shimer (2012). A variação de x responde por cerca de $20 \%$ apenas. O autor destaca em seu artigo que este resultado vai na contramão da literatura que dizia que a taxa de separação, isto é, de saída do emprego, é a que seria a mais importante para explicar o mercado de trabalho.

TABELA 6 - RESULTADO DA REGRESSÃO SIMPLES DAS VARIÁVEIS Z EM U/L - PARA OS EUA

\begin{tabular}{cc}
\hline Variável Z & Coeficiente \\
\hline x_barra/(x_barra $+f)$ & 0,82 \\
x/(x+f_barra $)$ & 0,21 \\
\hline
\end{tabular}

Como vimos anteriormente, o caso brasileiro, seguindo os números do CAGED não se mostra diferente do americano no que tange à importância da job finding rate para se explicar o comportamento cíclico do mercado de trabalho. Este resultado para o caso brasileiro também vai na contramão dos resultados anteriores que concluíam ser a probabilidade em se perder emprego mais importante para se explicar as flutuações nas taxa de desemprego.

Conforme podemos ver nas tabelas 7 e 8, a probabilidade de um desemprego encontrar emprego nos EUA é pró-cíclica em relação ao PIB e anticíclica em relação ao desemprego. Este comportamento em relação ao PIB também foi observado no caso brasileiro. Já, com relação à taxa de desemprego, as medidas oriundas do CAGED foram também anticíclicas enquanto que a da PME foi pró-cíclica.

TABELA 7 - ESTATÍSTICAS DESCRITIVAS E CORRELAÇÃO DO HIATO DE F COM HIATO DO PIB E DA TAXA DE DESEMPREGO - EUA, FILTRO HP

Correlação

\begin{tabular}{lccc}
\hline & $\mathrm{F}$ & $\mathrm{PIB}$ & Tx de desemprego \\
\hline PIB & 0.87 & & \\
Tx de desemprego - PME & -0.92 & & \\
\hline Estatística descritiva & & & \\
\hline \multicolumn{1}{c}{ Média } & 0.00 & 0.00 & 0.00 \\
$\quad$ Desvio padrão & 0.049 & 0.025 & 1.156 \\
\hline
\end{tabular}

Por sua vez, no que tange a probabilidade de um empregado deixar o trabalho, ela é anticíclica em relação ao PIB e pró-cíclica em relação à taxa de desemprego no caso norte-americano. No caso brasileiro, como vimos anteriormente, apenas a medida de $X$ resultante dos dados da PME apresentaram este comportamento enquanto as 
estimativas oriundas do dados do CAGED apontaram que a probabilidade de um empregado deixar o emprego é pró-cíclica com relação ao PIB e anticíclica com relação ao desemprego.

TABELA 8 - ESTATÍSTICAS DESCRITIVAS E CORRELAÇÃO DO HIATO DE X COM HIATO DO PIB E DA TAXA DE DESEMPREGO - EUA, FILTRO HP

\begin{tabular}{lccc} 
Correlação & \multicolumn{1}{c}{ X } & PIB & Tx de desemprego \\
\hline PIB & -0.50 & & \\
Tx de desemprego - PME & 0.53 & & \\
\hline Estatística descritiva & & & -0.00 \\
$\quad$ Média & -0.00 & -0.00 & 1.156 \\
$\quad$ Desvio padrão & 0.002 & 0.025 & \\
\hline
\end{tabular}

Já, o desvio padrão de $\mathrm{F}$ é expressivamente maior que o desvio padrão de $\mathrm{X}$. $\mathrm{O}$ mesmo foi verificado em duas das medidas de $f$ calculadas para o Brasil.

\subsection{CONCLUSÃO}

Este trabalho calculou a probabilidade com que um trabalhador deixa o emprego $(X)$ e a probabilidade com que um desempregado encontra trabalho $(F)$ através da metodologia desenvolvida por Shimer (2012), com objetivo de determinar qual dos dois fatores seria o mais importante para explicar as flutuações da taxa de desemprego, tanto no nível agregado quanto desagregando por grau de qualificação dos trabalhadores (mais e menos qualificados).

Diferentemente dos artigos anteriores de Attuy (2012) e Silva e Pires (2014), utilizamos neste trabalho as séries do CAGED e RAIS divulgadas pelo Ministério do Trabalho e Emprego além das séries da Pesquisa Mensal do Emprego divulgada mensalmente pelo Instituto Brasileiro de Geografia e Estatística.

Segundo estes autores, de modo geral, a probabilidade de separação é a que mais tem influência sobre a dinâmica cíclica da taxa de desemprego. Os resultados aqui apresentados apontam para uma conclusão distinta. Isso porque, os resultados mostram que é a dinâmica da probabilidade de um desempregado encontrar emprego que é fundamental para explicar o comportamento da taxa de desemprego, quando se utiliza os dados do CAGED e da RAIS. 
Ademais, quando se calcula a importância de cada um dos hiatos destas probabilidades para se explicar o comportamento cíclico da taxa de desemprego calculado, conclui-se também que as variações dos hiatos de probabilidade de achar emprego explicam entre $62 \%$ e $154 \%$ do total da variação do hiato da taxa de desemprego. A probabilidade de deixar o emprego tem uma importância muito menor, sendo estatisticamente insignificante na maioria dos casos.

Portanto, assim como Shimer (2012) encontrou para EUA, o presente trabalho mostrou que a probabilidade de um desempregado encontrar trabalho é que é fundamental para se entender a dinâmica cíclica da taxa de desemprego no Brasil.

Por fim, quando analisamos estas probabilidades por grau de escolaridade, qualificação, os resultados não se alteram. $O$ interessante desta análise é que fica claro que embora os dois grupos (mais e menos escolarizados) tenham se beneficiado da dinâmica de forte crescimento econômico, foi o grupo dos menos qualificados que se beneficiou mais. Por outro lado, este grupo é o que está sofrendo de modo mais acentuado a perda de vigor da economia após 2012. 


\section{MODELO DE EQUILÍBRIO GERAL CONSIDERANDO SEARCHING NO MERCADO DE TRABALHO PARA O BRASIL}

\subsection{INTRODUÇÃO}

Há consenso na literatura que emprego e desemprego variam expressivamente ao longo do ciclo de negócios (business cycle) e que os modelos macroeconômicos têm dificuldade em explicar tal comportamento. Esta dificuldade é observada tanto nos modelos de ciclo real de negócios (Real Business Cycle, vide, por exemplo, em Kydland e Prescott (1982) e Hansen (1985)) quanto nos modelos construídos sobre o aparato teórico de busca ou "searching" (Diamond (1982), Mortensen (1985) e Pissarides (1985), denominado modelo $\mathrm{DMP}^{7}$ ).

De fato, Shimer (2005), utilizando um modelo com utilidade linear e sem capital, diz que os modelos de searching não são capazes de gerar variações significativas no desemprego e não são capazes de explicar o comportamento de outras variáveis importantes do mercado de trabalho. Isso porque, sob a hipótese do modelo canônico DMP, a receita marginal é igual a produto marginal do trabalho (mercado competitivo), sendo assim, diante de um choque de produtividade a diferença entre receita marginal e custo do trabalho não varia para firma, uma vez que o salário segue de perto os movimentos da receita marginal. Assim, não há incentivo para se aumentar as contratações. Além disso, o autor destaca que o produto marginal tem pouco comportamento cíclico. Por fim, Shimer argumenta que este problema, que ele denomina como "unemployment volatility puzzle", provavelmente seria resolvido em um contexto com rigidez de salários.

Segundo Rogersen e Shimer (2010), Hall (2005) foi um dos primeiros artigos a analisar se realmente a rigidez de salário seria capaz de contribuir com a solução do puzzle supracitado. Para tanto, o autor utiliza a hipótese de Nash bargaining comumente usada nestes modelos, mas impõe a restrição que os salários não se

7 Nestes modelos DMP, tanto a busca por trabalho por parte do desempregado como a busca do trabalhador pelas empresas são custosas e o acerto entre ambas as partes é determinado por uma função e o salário é determinado nesta negociação (Nash bargaining). 
movimentam em resposta ao choque agregado de produtividade. Neste ambiente, diante de um choque de produtividade positivo, a receita marginal da firma aumenta, mas o custo fica inalterado de forma que o incentivo para contratar novos empregados cresce e o desemprego diminui. Com isso, tem-se um comportamento mais volátil para o emprego.

Ainda segundo Rogersen e Shimer (2010), outra contribuição de Hall (2005) foi entender a negociação salarial entre o desempregado e a empresa como um jogo de soma zero. Como a taxa marginal de substituição entre consumo e lazer é estritamente menor que o produto marginal do trabalho em equilíbrio, há uma diferença estritamente positiva que será chamada de renda oriunda de barganha (match-specific rent). E, dentro deste intervalo, há um conjunto de valores que tanto o trabalhador aceita receber quanto a firma aceita pagar. Outra vantagem de proceder desta forma é que, ao ter a exploração de ganhos bilaterais (negociação), estes modelos não estão sujeitos à crítica de Barro (1977) ${ }^{8}$.

Esta literatura se desenvolveu com alguns autores colocando ad hoc a hipótese de rigidez de salário, enquanto outros deram fundamentação teórica para ela. No primeiro grupo se encaixam Hall (2005), cuja hipótese utilizada previa que os salários eram fixos para sempre, e Blanchard e Gali (2008) que assumiram que os salários eram proporcionais à produtividade e a constante de proporcionalidade era menor do que um.

Já, no segundo grupo, podemos citar como exemplo Hall e Milgrom (2008). Em seu modelo, ao invés de ocorrer o término da negociação quando acontecia um impasse no processo de barganha, ocorria continuidade da negociação e, portanto, havia atraso para o fechamento do acordo. Embora este processo de negociação fosse custoso para ambas às partes, ele ocorria, pois as partes sabiam que havia um excedente a ser negociado. Segundo Christiano, Eichenbaum e Trabandt ( 2013), a principal contribuição desses autores foi perceber que se estes custos associados ao processo fossem insensíveis ao ciclo de negócios, os salários herdariam tal

\footnotetext{
${ }^{8}$ Segundo esta crítica, o desemprego ineficiente surge porque trabalhadores e firmas não são capazes de explorar ganhos bilaterais de trocas.
} 
característica. Portanto, este modelo seria capaz de gerar maiores flutuações para as variáveis do mercado de trabalho.

Outro grupo de modelos que poderia explicar este comportamento das variáveis do mercado de trabalho é o grupo dos modelos novo keynesiano. No entanto, segundo Christiano, Eichenbaum e Trabandt (2013), tais modelos só tem algum sucesso em lidar com estas características ao considerar como hipótese exógena que os salários são rígidos. Não há uma fundamentação teórica para esta rigidez. Além disso, estes autores destacam que nestes modelos as pessoas não conseguem escolher os salários, uma vez que eles são impostos a elas. Além disso, através deste instrumental não se consegue analisar políticas para o mercado de trabalho, como a do seguro desemprego. Por fim, no modelo novo keynesiano, como o de Chistiano, Eichenbaum e Evans (2005), o ajuste no mercado de trabalho (i) se dá sobre horas trabalhadas, de forma que não há desemprego; e, (ii), ocorre instantaneamente e sem custo.

Com relação ao primeiro ponto, Gali (2011) reinterpretou o modelo novo keynesiano tradicional mostrando que a variação do número de horas trabalhadas do agente representativo poderia ser entendida como a variação do número de horas das pessoas trabalhando. Com isso, consegue-se então estudar tanto a força de trabalho quanto o desemprego. Todavia, Christiano (2011) não concorda com isso e, dentre outras coisas, pondera que, agindo desta maneira, a definição de desemprego presente no modelo do Gali (2011) é diferente daquela seguida normalmente pelas agências que calculam desemprego (como o BLS). Além disso, neste ambiente, os desempregados estariam mais felizes que os empregados, o que não parece nada razoável.

Já, no que tange o segundo ponto, Mortensen e Pissarides (1994 e 1999) mostram que não é verdade que o ajuste no mercado de trabalho é rápido, simples e sem custo. Segundo eles, o processo pelo qual os desempregados procuram emprego é complexo, custoso e tem influência sobre o modo pelo qual os choques se propagam na economia ao longo do tempo.

Diante deste contexto, Christiano, Eichenbaum e Trabandt (2013) propuseram um modelo que une a literatura de searching no mercado de trabalho, que prevê um processo complexo e custoso de ajuste, aos modelos novo keynesiano. Nele os autores consideram variáveis do mercado de trabalho (salário, emprego, vagas, 
desemprego entre outras) e não assumem exogenamente que os salários estão sujeitos à rigidez nominal, ao contrário dos preços. Esta rigidez terá fundamentação teórica e ocorrerá em equilíbrio.

Nele, o modelo de mercado de trabalho seguirá o de Hall e Milgrom (2008) descrito anteriormente. Os desempregados e as empresas negociam tendo em mente que há um excedente e a negociação não acaba imediatamente quando ocorre um impasse. A conclusão sofrerá um atraso. Neste caso, a negociação é custosa para os dois lados, mas este custo é insensível ao estado agregado da natureza e esta característica será herdada pelos salários. Portanto, neste arcabouço, diante de um choque positivo, os salários sobem pouco e o incentivo para contratação aumenta e, por conseguinte, o desemprego cai. Como o custo marginal das empresas reage apenas moderadamente, o mesmo ocorre com a inflação, que será bastante inercial mesmo com uma pequena rigidez dos preços.

Nesse artigo vamos estimar bayesianamente este modelo para o Brasil. Mas adotaremos uma estratégia diferente daquela utilizada pelos autores. Até onde temos conhecimento, isto ainda não foi feito para o Brasil. A ideia é comparar os resultados com os oriundos de um modelo novo keynesiano tradicional, com preços e salários rígidos, a fim de verificar se há ganhos. Nesta linha, Rogerson e Shimer (2010) mostraram que os modelos de searching são extremamente úteis para nos ajudar a interpretar o comportamento de algumas séries do mercado de trabalho, como de fluxos, mas que tais fricções de busca não nos ajudam a melhorar o entendimento que temos sobre os agregados macroeconômicos. Veremos se isso também ocorre no caso brasileiro.

Além disso, analisaremos se ao adicionar mercado de trabalho conforme descrito anteriormente conseguimos resultados semelhantes aos esperados diante de um choque de política monetária, mesmo desligando algumas rigidezes que existem no modelo (mais espeficamente working capital channel e utilização do capital).

$\mathrm{Na}$ literatura brasileira encontramos diversos artigos sobre o mercado de trabalho. Gonzaga e Reis (2011) analisam a oferta de trabalho e o ciclo econômico no Brasil e mostram que tanto o efeito desalento quanto o efeito trabalhador adicional são importantes na determinação da taxa de participação no Brasil. Santos (2012) em sua tese utilizou técnicas macroeconométricas bayesianas para investigar problemas específicos. Dentre os pontos estudados está a importância do canal de custo da 
política monetária e a capacidade do modelo dinâmico e estocástico de equilíbrio geral de gerar expectativas de inflação compatíveis com as expectativas coletadas pelo Banco Central do Brasil. O artigo mais relacionado ao nosso tema é o que trata do mercado de trabalho e o insere no modelo seguindo a proposta de Gali (2011). Os resultados mostram que a inclusão do desemprego tem impacto direto sobre os parâmetros do modelo e consequentemente sobre a condução da política monetária. Por fim, Attuy (2012) estudou a macroeconomia e o mercado de trabalho para investigar diversos problemas. Ele (i) concluiu que os dados brasileiros sugerem que a margem de ingresso tem grande relevância para determinar os ciclos da taxa de desemprego no Brasil; (ii) identificou sinais de heterogeneidade no mercado de trabalho (quanto maior a heterogeneidade, menor a correlação do salário real com o desemprego); e, utilizou modelo DSGE proposto por Gali (2011) e mostrou que a inclusão da taxa de desemprego muda a ordem de importância das fricções, dando mais importância para as fricções reais.

O artigo segue com a descrição do modelo DSGE básico na seção 2.2; a seção 2.3 traz as alterações feitas neste trabalho sobre o modelo base; a parte 2.4 traz o modelo DSGE tradicional com rigidez de preços e salários com o qual nosso modelo base será comparado; a parte 2.5 contem a metodologia de estimação, a explicação da base de dados entre outras coisas; na seção 2.6 discutimos os resultados; e, concluímos na parte 2.7. 


\subsection{MODELO DSGE DE MÉDIO PORTE COM ESTRUTURA DE SEARCHING PARA MERCADO DE TRABALHO}

O modelo utilizado neste trabalho foi o modelo desenvolvido por CET (Christiano, Eichenbaum e Trabandt (2013)). O modelo consegue dar conta das respostas dos principais agregados macroeconômicos além de incluir variáveis do mercado de trabalho como salários, emprego, criação de vagas e desemprego. Ele tem uma estrutura parecida ao de CEE (2005), mas foi modificado para incluir a estrutura de modelos de busca (searching) para o mercado de trabalho. Abaixo segue a explicação do modelo.

Uma breve explicação do modelo novo keynesiano tradicional com rigidez de preços e salários com o qual os resultados serão comparados segue na parte 2.4 deste trabalho.

\subsubsection{Famílias e Bens de Produção}

Os autores seguem Andolfatto (1995) e Merz (1996) e assumem que cada família é composta por uma unidade de trabalhadores. Como o trabalho não entra na função utilidade, as pessoas não derivam nem utilidade nem desutilidade do trabalho, por isso, ofertam trabalho inelasticamente. $\mathrm{O}$ trabalhador empregado recebe salário real $\mathrm{w}_{\mathrm{t}}$ enquanto $\mathrm{o}$ desempregado recebe $\mathrm{D}$ bens de consumo do governo como compensação pelo desemprego (espécie de seguro desemprego). Os benefícios dos desempregados são financiados por impostos lump-sum pagos pelas famílias. Os trabalhadores maximizam a renda esperada em troca de um seguro perfeito para o consumo concedido pela família. Todos os trabalhadores têm a mesma preferência côncava sobre o consumo. Neste contexto, o acordo que garante o consumo ótimo é alocar o mesmo nível de consumo, $C_{t}$, para cada pessoa da família.

Cada família maximiza a seguinte preferência:

$$
E_{0} \sum_{t=0}^{\infty} \beta^{t} \ln \left(C_{t}-b C_{t-1}\right)
$$


Dado que há a suavização do consumo por parte das famílias, o parâmetro $b, 0 \leq b$ $<1$, controla o grau de persistência do consumo. Esta maximização é realizada sujeita a seguinte restrição orçamentária:

$P_{t} C_{t}+P_{i, t} I_{t}+B_{t} \leq\left(R_{k, t} u_{t}^{k}-a\left(u_{t}^{k}\right) P_{i, t}\right) K_{t}+\left(1-l_{t}\right) P_{t} D_{t}+W_{t} l_{t}+R_{t-1} B_{t}-T_{t}$

Onde $C_{t}$ é consumo da família; $I_{t}$ é a compra de bens de investimento; $P_{t}$ é o preço do bem de consumo final e $P_{i, t}$ é o preço do bem de investimento; $W_{t}$ é o salário recebido pelos empregados; $T_{t}$ é o tributo lump-sum cobrado líquido de transferências; $D_{t}$ é a compensação recebida pelo trabalhador desempregado, que varia exogenamente no tempo; $\mathrm{B}_{\mathrm{t}+1}$ corresponde aos títulos do governo comprados em $t$ e que pagam taxa de juros $R_{t}$ no início de $t+1 ; e, R_{k, t}$ correspondem a renda nominal recebidas pelos serviços do capital. A variável $a\left(u_{t}^{k}\right)$ representa o custo, em unidades de bens de investimento, para se fazer a utilização $u_{t}^{k}$ do estoque de capital $K_{t}$. Por fim, $l_{t}$ corresponde a fração, $0 \leq l_{t} \leq 1$, das pessoas da família que está empregada.

Neste modelo, fica claro, que a decisão de trabalhar não afeta diretamente a utilidade das famílias, mas afeta sua restrição orçamentária. Com relação à função $a\left(u_{t}^{k}\right)$, ela é definida da seguinte forma:

$$
a\left(u_{t}^{k}\right)=0.5 \sigma_{a} \sigma_{b}\left(u_{t}^{k}\right)^{2}+\sigma_{b}\left(1-\sigma_{a}\right) u_{t}^{k}+\sigma_{b}\left(\frac{\sigma_{a}}{2}-1\right)
$$

Onde $\sigma_{a}$ e $\sigma_{b}$ são escalares positivos. As famílias alugam o estoque de capital que possuem. Ele evolui segundo a seguinte lei:

$$
K_{t+1}=\left(1-\delta_{k}\right) K_{t}+\left[1-S\left(I_{t} / I_{t-1}\right)\right] I_{t}
$$

Com a função $S($.$) , custo de ajustamento do investimento, sendo dada por:$

$$
S\left(I_{t} / I_{t-1}\right)=0.5 \exp \left[\sqrt{S^{\prime \prime}}\left(\frac{I_{t}}{I_{t-1}}-\mu \mu_{\Psi}\right)\right]+0.5 \exp \left[-\sqrt{S^{\prime \prime}}\left(\frac{I_{t}}{I_{t-1}}-\mu \mu_{\Psi}\right)\right]-1
$$

Esta função é crescente e convexa. Os autores assumem que no estado estacionário tanto o valor que $\mathrm{S}($.$) assume quanto o valor de sua primeira derivada é$ zero.

Neste modelo, o bem final é homogêneo e é produzido por firmas idênticas que atuam em um mercado perfeitamente competitivo e usam a seguinte tecnologia: 


$$
Y_{t}=\left[\int_{0}^{1}\left(Y_{j, t}\right)^{\frac{1}{\lambda}} d_{j}\right]^{\lambda}
$$

Onde $\lambda>1$. A firma representativa escolhe insumo especializado $Y_{j, t}$ a fim de maximizar seu lucro:

$$
P_{t} Y_{t}-\int_{0}^{1} P_{j, t} Y_{j, y} d_{j}
$$

sujeita a função de produção (2.6). A condição de primeira ordem para o insumo j é:

$$
Y_{j, t}=\left(P_{t} / P_{j, t}\right)^{\frac{\lambda}{\lambda-1}} Y_{t}
$$

Este insumo especializado é produzido por um varejista com a seguinte tecnologia:

$$
Y_{j, t}=k_{j, t}^{\alpha}\left(z_{t} h_{j, t}\right)^{1-\alpha}-\phi_{t}
$$

Este varejista é um monopolista na produção do bem especializado j, mas compra insumos em mercado de fatores competitivos. Na equação 2.9, $\mathrm{k}_{\mathrm{j}, \mathrm{t}}$ corresponde à quantidade total de serviços de capital comprados pela empresa j. $\phi_{t}$ é o custo fixo de produção, exógeno, que cresce de forma a garantir uma trajetória balanceada de crescimento. Para tanto, este custo fixo é calibrado para se ter uma condição de lucro zero. $z_{t}$ é um choque tecnológico neutro. Por fim, $h_{j, t}$ é a quantidade de bens intermediários comprados pelo varejista j.

O bem intermediário é comprado em um mercado competitivo de um atacadista com o preço, descontados os impostos, $P_{t}^{h}$. O problema enfrentado pelo atacadista será colocado adiante. Assim como em Christiano, Eichenbaum e Evans (2005), Chriastiano, Eichenbaum e Trabandt (2013) assumem que para produzir no período t, o varejista tem que tomar emprestados $P_{t}^{h} h_{j, t}$ no início do período, pagando uma taxa de juros $R_{t}$. $O$ varejista paga este empréstimo no final do período $t$ quando recebe sua receita das vendas. $O$ varejista $j$ estabelece preço $P_{j, t}$ sujeito (i) a curva de demanda dada por (2.9) e, (ii), a fricção de rigidez de preço à la Calvo dada por :

$$
P_{j, t}=\left\{\begin{array}{l}
P_{j, t-1} \text { com probabilidade } \xi \\
\widetilde{P}_{t} \text { com probabilidade } 1-\xi
\end{array}\right.
$$

Em que $\widetilde{P}_{t}$ é o preço ótimo que é escolhido pela fração $1-\xi$ dos varejistas que têm a oportunidade de atualizar o preço. Não há indexação neste modelo, assim, a parcela $\xi$ dos produtores que não reotimizam o preço, mantem o preço vigente. 


\subsubsection{Atacadistas e Mercado de Trabalho}

Christiano, Eichenbaum e Trabandt (2013) têm por hipótese que há um grande número de atacadistas idênticos, competitivos que produzem um bem homogêneo usando trabalho. Seja $v_{t}$ a receita marginal de empregar um trabalhador adicional ${ }^{9}$. No início do período $t, o$ atacadista paga um custo fixo $k_{t}$ que representa o custo para iniciar as negociações com probabilidade 1. Esta variável segue no modelo um processo estocástico exógeno, não correlacionado com os estados da economia. Uma vez que iniciam as negociações começa um processo de barganha bilateral. E se este processo de barganha implicar em acordo, que segundo Christiano, Eichenbaum e Trabandt (2013) sempre ocorrerá em equilíbrio, o empregado começa a produzir imediatamente.

Cada atacadista emprega uma fração dos trabalhadores. $I_{t}$ é força de trabalho do atacadista representativo ao final de t. Esta força de trabalho em t é normalizada para 1. No final do período, aleatoriamente (e exogenamente) uma fração 1- $\rho$ dos empregados são separadas das firmas, ou seja, passam a não ter mais emprego e, assim como os demais desempregados, passam a procurar trabalho. Portanto, ao final do período, uma fração $1-\rho l_{t}$ dos trabalhadores está procurando por trabalho. No período $t+1$ uma fração $f_{t+1}$ encontra uma firma para iniciar a barganha enquanto a fração complementar torna-se desempregada. Com probabilidade $\rho$, um trabalhador que está empregado em $t$ continua empregado na mesma firma em $t+1$. Com probabilidade (1- $\rho) \mathrm{f}_{t+1}$ este trabalhador se move para outra empresa em $t+1$. Enquanto que, com probabilidade $(1-\rho)\left(1-f_{t+1}\right)$, este trabalhador passa a ficar desempregado em $\mathrm{t}+1$.

A medida de desemprego em $t$ utilizada é $1-\mathrm{I}_{\mathrm{t}} \mathrm{O}$ movimento dos empregados que transitam entre uma empresa e outra, entre $t$ e $t+1$, é definida como movimento de emprego para emprego dentre os empregados. Dada esta especificação, os autores

\footnotetext{
${ }^{9}$ ฯt segue um processo estocástico exógeno.
} 
relatam que este movimento é significativo e pró-cíclico, o que seria consistente com os dados para economia dos EUA (Shimer(2005)). Assume-se também que a taxa segundo a qual um trabalhador deixa o emprego (separation rate) é acíclica e o período com o qual se trabalha é trimestral.

Seja $\omega_{t}^{p}$ o valor presente descontado dos salários pagos pelos atacadistas aos trabalhadores contratados:

$$
\omega_{t}^{p}=\omega_{t}+\rho E_{t} m_{t+1} \omega_{t+1}^{p}
$$

Onde $\omega_{\mathrm{t}}$ é o salário em $\mathrm{t}$; e, $\mathrm{m}_{\mathrm{t}+1}$ é a taxa de desconto que será determinada adiante. Seja $J_{t} 0$ valor para o atacadista de empregar um trabalhador adicional no período $t:$

$$
J_{t}=v_{t}^{p}-\omega_{t}^{p}
$$

Onde $v_{t}^{p}$ é o valor presente descontado esperado de $v_{t}$,

$$
v_{t}^{p}=v_{t}+\rho E_{t} m_{t+1} v_{t+1}^{p}
$$

Como há livre entrada no mercado de trabalho, que é competitivo, a firmas auferem lucro zero. Sendo assim, segue que:

$$
\kappa_{t}=J_{t}
$$

Ou seja, o custo e o ganho (valor) para atacadistas para conseguir empregar um novo trabalhador são iguais. Denota-se, também, por $V_{t} O$ valor para um trabalhador ao ser contratado por uma firma que paga $\omega_{t}$ no período $t$ :

$$
V_{t}=\omega_{t}+E_{t} m_{t+1}\left[\rho V_{t+1}+(1-\rho)\left(f_{t+1} \overline{V_{t+1}}+\left(1-f_{t+1}\right) U_{t+1}\right)\right.
$$

Em que $\overline{V_{t+1}}$ denota $o$ valor de trabalhar para outra empresa do período $t+1$. Em equilíbrio, $\overline{V_{t+1}}=V_{t}$. Além disso, $\mathrm{U}_{\mathrm{t}+1}$ representa o valor de estar desempregado em $\mathrm{t}+1$. Rearranjando 2.15, tem-se:

$$
V_{t}=\omega_{t}^{p}+A_{t}
$$

Onde:

$$
A_{t}=(1-\rho) E_{t} m_{t+1}\left(f_{t+1} \overline{V_{t+1}}+\left(1-f_{t+1}\right) U_{t+1}\right)+\rho E_{t} m_{t+1} A_{t+1}
$$

Note que, em 2.16, $\mathrm{V}_{\mathrm{t}}$ é composto por dois componentes: o primeiro representa 0 valor presente esperado dos recebimento por parte de um trabalhador que foi contratado por um firma em t; e, o segundo componente, denota o valor presente esperado dos salários em todos os estados da natureza e em todos os períodos para um trabalhador que deixou a empresa.

O valor do desemprego, $\cup_{t}$, para os trabalhadores é dado por:

$$
U_{t}=D_{t}+\widetilde{U_{t}}
$$


Onde, $D_{t}$ corresponde aos bens recebidos pelos desempregados que segue um processo estocástico exógeno, que é não correlacionado com estados da economia. Já, $\widetilde{U_{t}}$ é o valor de continuar desempregado, qual seja:

$$
\widetilde{U_{t}} \equiv E_{t} m_{t+1}\left[f_{t+1} V_{t+1}+\left(1-f_{t+1}\right) U_{t+1}\right]
$$

Tanto $U_{t}$ quanto $V_{t}$ são definidas em unidades do bem final. $O$ número de trabalhadores empregados evolui assim:

$$
l_{t}=\left(\rho+x_{t}\right) l_{t-1}
$$

Em que $x_{t}$ é a taxa de contratação de trabalhadores em t. Deste modo, o número de novos empregados no período $\mathrm{t}$ é igual a $\mathrm{x}_{\mathrm{t}} \mathrm{l}_{\mathrm{t}-1}$. Para contratar $\mathrm{x}_{\mathrm{t}} \mathrm{t}_{\mathrm{t}-1}$ trabalhadores, 0 atacadista deve colocar $x_{t} t_{t-1} / Q_{t}$ vagas, onde $Q_{t}$ denota a taxa de preenchimento de vagas agregada e os atacadistas a tomam como dada. Assume-se que não há custo para abrir vagas.

A taxa segundo a qual um trabalhador desempregado encontra trabalho (job finding rate), $\mathrm{f}_{\mathrm{t}}$ é dada por:

$$
f_{t}=\frac{x_{t} l_{t-1}}{1-\rho l_{t-1}}
$$

O numerador representa o número pessoas contratadas em $t$, enquanto 0 denominador corresponde ao número de pessoas procurando emprego no final de t1. $x_{t}$ e $I_{t-1}$ afetam as decisões do atacadista, mas são percebidas pelos indivíduos como dadas e fora de seu controle.

\subsubsection{Determinação do Salário}

A especificação básica de Christiano, Eichenbaum e Trabandt (2013) assume barganha período a período. Isto é, trabalhadores e atacadistas barganham no período $t$ sobre a taxa de salário em $t$, pegando como dado o resultado das barganhas futuras que irão acontecer enquanto o trabalhador estiver na empresa. Os acordos dos salários futuros importam para negociação presente através do seu valor presente descontado, $\widetilde{\omega_{t}^{p}}$ :

$$
\widetilde{\omega_{t}^{p}} \equiv E_{t} \sum_{l=1}^{\infty} \rho^{l}\left[m_{t+1} \ldots m_{t+l}\right] \omega_{t+l}=\rho E_{t} m_{t+1} \omega_{t+1}^{p}
$$

O problema de barganha é o mesmo para todos os trabalhadores, independentemente do tempo em eles estão na empresa. Este resultado advém das 
hipóteses de que o custo de contratação é fixo (sunk) no processo de barganha e de que a duração esperada do emprego na empresa que o contratou é independente do tempo que o trabalhador já está na empresa.

Consistente com Hall e Milgrom (2008), Christiano, Eichenbaum e Trabandt (2013) relatam que os salários neste modelo são determinados de acordo com protocolo de barganha onde há alternância de ofertas (alternating offer bargaining protocol) proposto por Rubistein (1982) e Binmore, Rubinstein e Wolinsky (1986). Nele, cada período de tempo (um trimestre) é subdividido em $\mathrm{M}$ períodos de igual tamanho e $\mathrm{M}$ é par. Os atacadistas fazem a oferta de salário no início do primeiro subperíodo, assim como fazem as contrapropostas no início de cada período ímpar, caso a oferta anterior feita por eles tenha sido recusada. Já, os trabalhadores fazem suas ofertas no início dos períodos pares, caso tenham rejeitado a proposta feita pela empresa no período imediatamente anterior. Como $\mathrm{M}$ é par, a última oferta é feita, no estilo tudo ou nada, pelo trabalhador.

Entre 1 e M-1, o receptor das proposta pode aceitá-la ou rejeitá-la. Se a proposta for rejeitada, o trabalhador pode declarar encerrada a negociação ou ele pode fazer uma contra oferta no início do período seguinte. A probabilidade de as negociações serem encerradas ao longo deste período é dada por $\delta$.

Considere um atacadista que faça um proposta salarial $\omega_{\mathrm{s}, \mathrm{t}}$ no subperíodo $\mathrm{s}<\mathrm{M}$ e $\mathrm{s}$ é ímpar. Este estabelece o menor salário possível sujeito à restrição de que o trabalhador não rejeitará a oferta. A firma quer que o trabalhador aceite a proposta uma vez que a falta de acordo acarreta no atraso do início da produção. Então, é ótimo para o atacadista oferecer o menor salário sujeito ao fato de o trabalhador não o rejeitar. Assim, o salário ofertado satisfaz a seguinte condição de indiferença:

$$
V_{s, t}=\delta U_{s, t}+(1-\delta)\left[\frac{1}{M} D+V_{s+1, t}\right]
$$

Quando o trabalhador esta indiferente entre aceitar ou rejeitar, ele aceita a proposta. O lado esquerdo de 2.23 corresponde ao valor para o trabalhador aceitar a oferta:

$$
V_{s, t}=\omega_{s, t}+\widetilde{\omega_{t}^{p}}+A_{t}
$$

Em que $\widetilde{\omega_{t}^{p}}$ e $A_{t}$ são tomados como dados pelo par trabalhador-atacadista. Por sua vez, o lado direito de 2.23 corresponde ao payoff que o trabalhador terá caso rejeite a proposta e faça uma contra oferta. 
O primeiro termo do lado direito de $2.23\left(\delta U_{s, t}\right)$ representa a possibilidade de a negociação acabar exogenamente o que implicará que 0 trabalhador ficará desempregado. O valor de ficar desempregado dado que houve o fim das negociações em um subperíodo $s$ é dado por $\mathrm{U}_{\mathrm{s}, \mathrm{t}}$ :

$$
U_{s, t}=\frac{M-s+1}{M} D_{t}+\widetilde{U_{t}}
$$

Onde a primeira parte representa a hipótese segundo a qual os desempregados recebem seguro-desemprego (benefícios) no período t na proporção do número de subperíodos que eles ficaram desempregados.

Já, o segundo termo do lado direito da equação 2.23, por sua vez, reflete o fato de que com probabilidade $(1-\delta)$ o trabalhador receberá os benefícios como desempregado pelo período $1 / \mathrm{M}$ dado que ele fez uma contraproposta $\omega_{s+1, t}$ e ele espera que a empresa aceite.

A equação 2.23 traz uma importante condição de indiferença assumindo que o payoff dos trabalhadores quando as negociações continuam excede o valor da opção de fora (no caso, de desemprego), que é obtido se houver o fim das negociações.

Pelo lado dos trabalhadores, considere o problema de um trabalhador que faz uma oferta $\omega_{s, t}$ no subperíodo $s$, onde $s<M$ e $s$ é par. Os trabalhadores querem que 0 atacadista aceite a proposta, pois o atraso no acordo fará com que eles não recebam salário, cujo valor esperado excede o valor esperado dos benefícios recebidos pelos desempregados. Neste caso, é ótimo para os trabalhadores pedirem o maior salário possível restritos à condição de que a empresa não rejeite a oferta. A oferta resultante $\omega_{\mathrm{s}, \mathrm{t}}$ satisfaz a seguinte condição de indiferença por parte da firma:

$$
J_{s, t}=\delta * 0+(1-\delta)\left[-\gamma_{t}+J_{s+1, t}\right]
$$

O lado esquerdo da equação 2.26 denota o valor para empresa ao aceitar a oferta $\omega_{s, t}$

$$
J_{s, t}=\frac{M-s+1}{M} \vartheta_{t}+\widetilde{\vartheta_{t}^{p}}-\left(\omega_{s, t}+\widetilde{\omega_{t}^{p}}\right)
$$

Onde,

$$
\widetilde{\vartheta_{t}^{p}} \equiv E_{t} \sum_{l=1}^{\infty} \rho^{l}\left[m_{t+1} \ldots m_{t+l}\right] \vartheta_{t+l}=\rho E_{t} m_{t+1} \vartheta_{t+1}^{p}
$$


O termo do lado direito da equação 2.27 representa o valor para a empresa ao aceitar a oferta proposta pelo trabalhador de forma que a produção comece imediatamente. Já, o termo $\frac{M-s+1}{M}$ reflete a hipótese segundo a qual o trabalhador produz 1/M bens em cada subperíodo em que há produção. Por sua vez, o termo $\widetilde{\vartheta_{t}^{p}}$ representa o valor presente esperado da receita marginal associada com 0 trabalhador, enquanto que $\left(\omega_{s, t}+\widetilde{\omega_{t}^{p}}\right)$ corresponde ao valor esperado pela firma dos salários a serem pagos para o trabalhador caso ela aceite a proposta $\omega_{\mathrm{s}, \mathrm{t}}$

A expressão do lado direito da equação 2.26 é o payoff da empresa ao não aceitar a oferta. Se a empresa não aceita a proposta feita pelo trabalhador com a intenção de fazer uma contraproposta, há uma probabilidade $\delta$ de a negociação ser encerrada $e$, neste caso, a firma vai para a opção de fora, que é produzir zero e cujo valor, portanto, é zero. Com probabilidade 1- $\delta$ a empresa fará uma nova oferta, $\omega_{\mathrm{s}+1, t}$,ao trabalhador no próximo subperíodo. Mas, para fazê-la, a empresa terá que arcar com custo $\mathrm{Y}$. Entretanto, neste caso, há um benefício, $J_{s+1, t}$, associado ao sucesso desta contraoferta.

Assim, a equação 2.26 representa uma condição de indiferença relevante que governa a oferta de salários por parte dos trabalhadores assumindo que o payoff para firma com a continuidade da negociação, mesmo que sem acordo, excede o payoff obtido pelo fim da negociação.

Finalmente, considere o último subperíodo, M, no qual o trabalhador faz a proposta do tipo tudo ou nada. Novamente, o trabalhador escolhe o maior salário possível sujeito a condição de que a empresa não o rejeite e vá para sua opção de fora. Como esta opção implica em valor zero, pode-se escrever a condição de indiferença da firma como:

$$
J_{M, t}=0
$$

Onde,

$$
J_{M, t}=\frac{1}{M} \vartheta_{t}+\widetilde{\vartheta_{t}^{p}}-\left(\omega_{M, t}-\widetilde{\omega_{t}^{p}}\right)
$$

A taxa de salário de equilíbrio será determinada da seguinte maneira: note que $\omega_{\mathrm{s}, \mathrm{t}} \mathrm{e}$ $\widetilde{\omega_{t}^{p}}$ sempre aparecem como uma soma nas condições de equilíbrio 2.23, 2.24, 2.26, $2.27,2.29$ e 2.30 ,

$$
\omega_{s, t}^{p} \equiv \omega_{s, t}+\widetilde{\omega_{t}^{p}}
$$


Para $s=1, \ldots$, M. Segundo Christiano, Eichenbaum e Trabandt (2013), pode-se resolver para $\omega_{M}^{p}$ dadas as variáveis que são exógenas ao par trabalhador-empresa. Então, 2.23 para $s=M-1$ pode ser resolvida para $\omega_{M-1}^{p}$ e 2.26 pode ser resolvida para $\omega_{M-2}^{p}$. Assim, as condições de equilíbrio podem ser usadas para se resolver unicamente para um conjunto de valores:

$$
\omega_{1, t}^{p}, \omega_{2, t}^{p}, \omega_{3, t}^{p}, \ldots, \omega_{M, t}^{p}
$$

condicional nas variáveis que são exógenas ao par trabalhador-empresa. $O$ valor presente descontado para o salário no equilíbrio, $\omega_{t}^{p}$, é $\omega_{1}^{p}$. Como as equações de equilíbrio anteriormente destacadas são equações lineares, elas podem ser resolvidas analiticamente para $\omega_{t}^{p}$ :

$$
\omega_{t}^{p}=\frac{1}{\alpha_{1}+\alpha_{2}}\left[\alpha_{1} \vartheta_{t}^{p}+\alpha_{2}\left(U_{t}-A_{t}\right)+\alpha_{3} \gamma-\alpha_{4}\left(\vartheta_{t}-D_{t}\right)\right]
$$

Com

$$
\begin{gathered}
\alpha_{1}=1-\delta+(1-\delta) M \\
\alpha_{2}=1-(1-\delta)^{M} \\
\alpha_{3}=\alpha_{2}\left(\frac{1-\delta}{\delta}\right)-\alpha_{1} \\
\alpha_{4}=\frac{1-\delta}{2-\delta} \frac{\alpha_{2}}{M}+1-\alpha_{2}
\end{gathered}
$$

$\mathrm{E} \alpha_{i}$, para $\mathrm{i}=1,2,3,4$, são estritamente positivos $^{10}$.

Por fim, utilizando-se as equações 2.11 e 2.22 se computa o salário $\omega_{t}$ para o período $\mathrm{t}$, condicional em $\omega_{t}^{p}$ e dadas crenças sobre os salários futuros $\widetilde{\omega_{t}^{p}}$. Christiano, Eichenbaum e Trabandt (2013) comenta que suas análises indicaram que $\omega_{t}^{p}$ é unicamente determinado condicional nas variáveis que são exógenas ao par empresa-trabalhador, quais sejam: $\vartheta_{t}, \vartheta_{t}^{p}, U_{t} e A_{t}$. Em princípio, a decomposição aditiva de $\omega_{t}^{p}$ entre salário corrente, $\omega_{\mathrm{t}}$, e pagamentos futuros, sintetizados por $\widetilde{\omega_{t}^{p}}$, não é unicamente determinada. Este potencial problema de falta de unicidade foi

\footnotetext{
${ }^{10}$ Para maiores detalhes vide Anexo A do artigo Christiano, Eichenbaum e Trabandt (2013).
} 
resolvido no artigo assumindo que os salários em cada período de tempo são a mesma função invariante no tempo de um conjunto pequeno de variáveis de estado. Dadas as leis de movimento para $\vartheta_{t}$ e $\mathrm{m}_{\mathrm{t}+1}$, um equilíbrio de barganha período a período é um processo estocástico para dez variáveis,

$$
J_{t}, \omega_{t}^{p}, V_{t}, U_{t}, l_{t}, f_{t}, x_{t}, A_{t}, \widetilde{\omega_{t}^{p}}, \omega_{t}
$$

que satisfazem as seguintes condições de equilíbrio: (i) as primeiras oito variáveis em 2.37 satisfazem as oito equações, 2.12, 2.14, 2.16, 2.17, 2.18, 2.20, 2.21 e 2.32; (ii) o processo estocástico $\widetilde{\omega_{t}^{p}}$ em 2.37 satisfaz 2.22; e, (iii) $\omega_{\mathrm{t}}$ satisfaz 2.11.

$$
\omega_{t}=\omega_{t}^{p}-\widetilde{\omega_{t}^{p}}
$$

Por fim, é importante destacar que dentro do arcabouço tradicional DMP, $\omega_{t}^{p}$ é determinado pela seguinte Nash sharing rule:

$$
J_{t}=\frac{1-\eta}{\eta}\left(V_{t}-U_{t}\right)
$$

Em que $0 \leq \eta \leq 1$ é a parcela do total do excedente dada aos trabalhadores. Tendo por base a equação 2.32, os autores mostram que se consegue rearranjá-la de forma a se chegar a seguinte equação, interpretada como alternatating offer bargaining sharing rule:

$$
J_{t}=\beta_{1}\left(V_{t}-U_{t}\right)-\beta_{2} \gamma_{t}+\beta_{3}\left(\vartheta_{t}-D_{t}\right)
$$

Onde $\beta_{i}=\frac{\alpha_{i+1}}{\alpha_{1}}$,para $i=1,2,3$. Então, assim como na Nash sharing rule, $\omega_{t}^{p}$ depende de $J_{t}$ e de $\left(V_{t}-U_{t}\right)$, com pesos determinados por parâmetros que descrevem 0 ambiente econômico do modelo. Entretanto, há dois termos constante envolvendo $\mathrm{Y}$ e D que, por hipótese,não são uma função do estado na economia e são separados em $\vartheta_{t}$.

\subsubsection{Equilíbrio no Mercado de Trabalho}

Segundo Christiano, Eichenbaum e Trabandt (2013), em equilíbrio, o atacadista representativo emprega $I_{t}$ trabalhadores com os quais ele negociou (barganha) ao salário $\omega_{t}$. A produção começa imediatamente após a conclusão das negociações sobre o salário e o atacadista vende seu bem intermediário ao preço real $\vartheta_{t} \equiv \frac{P_{t}^{h}}{P_{t}}$. As condições de equilíbrio do mercado de trabalho são as estabelecidas em 2.37. 


\subsubsection{Implicações para o Salário}

No modelo Christiano, Eichenbaum e Trabandt (2013), a barganha ocorre período a período. Os autores mostram que a alocação a que se chega sob este arcabouço é a mesma da alocação a que se chega quando se trabalha com o valor presente descontado de barganha. De fato, a proposição 2.1 de Christiano, Eichenbaum e Trabandt (2013) diz que o equilíbrio de barganha período a período é um equilíbrio de barganha considerando o valor presente descontado ${ }^{11}$.

Ademais, Christiano, Eichenbaum e Trabandt (2013) concluem que o equilíbrio a que se chega nestes casos é consistente com os seguintes resultados empíricos: (i) os trabalhadores e firmas incumbentes não negociam salário todos os período; (ii) o salário nominal do trabalhador incumbente é normalmente constante por um prolongado período de tempo; e, (iii) a volatilidade dos salários pagos para os novos contratados é maior di que a volatilidade dos salários pagos aos trabalhadores incumbentes.

\subsubsection{Market Clearing, Política Monetária e Formas Funcionais.}

A quantidade total de bens intermediários comprados pelos varejistas dos atacadistas é:

$$
h_{t} \equiv \int_{0}^{1} h_{j, t} d_{j}
$$

Como a quantidade de bens intermediários produzida pelo atacadista é igual ao número de trabalhadores empregados, tem-se que esta quantidade total produzida é $\mathrm{I}_{\mathrm{t}}$. Assim, a condição de Market clearing para o mercado de bens intermediário é: $h_{t}$ $=$ I $_{\mathrm{t}}$ Já, a condição para o mercado de serviços do capital é dada por:

$$
u_{t}^{k} K_{t}=\int_{0}^{1} k_{j, t} d_{j}
$$

Para o mercado de bens finais, por sua vez, tem-se a seguinte condição:

\footnotetext{
${ }^{11}$ Página 12 do artigo.
} 


$$
C_{t}+\frac{I_{t}+a\left(u_{t}^{k}\right) K_{t}}{\psi_{t}}+\kappa_{t} x_{t} l_{t-1}+G_{t}=Y_{t}
$$

Em que, o lado direto, $Y_{t}$, representa $o$ total de bens finais produzidos enquanto $o$ lado esquerdo representa suas utilizações. Como se pode observar na identidade 2.43 , os bens finais são usados para o consumo das famílias $\left(C_{t}\right)$; para o consumo do governo $\left(\mathrm{G}_{\mathrm{t}}\right)$; para o custo de utilização do capital $\left(\frac{a\left(u_{t}^{k}\right) K_{t}}{\psi_{t}}\right)$; para custo de se empregar novos trabalhadores $\left(\kappa_{t} x_{t} l_{t-1}\right)$; e, para se produzir bens de investimento segundo a função que transforma 1 bem de consumo final em $\psi_{t}$ bens de investimentos $\left(\frac{I_{t}}{\psi_{t}}\right)$.

A perfeita competição na produção de bens de investimento implica que:

$$
P_{I, t}=P_{t} / \Psi_{t}
$$

O fator estocástico de desconto, $\mathrm{m}_{\mathrm{t}+1}$, foi construído usando a utilidade marginal do consumo $\left(\mathrm{u}_{\mathrm{c}, \mathrm{t}}\right)$ :

$$
U_{c, t}=\left(C_{t}-b C_{t-1}\right)^{-1}-\beta b E_{t}\left(C_{t+1}-b C_{t}\right)^{-1}
$$

Portanto,

$$
m_{t+1}=\beta \frac{u_{c, t+1}}{u_{c, t}}
$$

Com relação à política monetária, ela é guiada pela seguinte especificação:

$$
\ln \left(\frac{R_{t}}{R}\right)=\rho_{R} \ln \left(\frac{R_{t-1}}{R}\right)+\left(1-\rho_{R}\right)\left[r_{\pi} \ln \left(\frac{\pi_{t}}{\pi}\right)+r_{y} \ln \left(\frac{Y_{t}}{Y}\right)\right]+\sigma_{R} \varepsilon_{R, t}
$$

Onde m é a meta de inflação; $R$ e $Y$ são os valores de estado estacionário da taxa de juro e do produto, respectivamente; e; $\varepsilon_{R, t}$ é o choque de política monetária com média zero e variância 1. $Y_{t}$ denota o produto interno bruto da economia que é dado por:

$$
Y_{t}=C_{t}+\frac{I_{t}}{\Psi_{t}}+G_{t}
$$

Por hipótese, $G_{t}$ cresce exogenamente de forma consistente com crescimento balanceado da economia. Christiano, Eichenbaum e Trabandt(2013) também trabalham com a hipótese segundo a qual a taxa de crescimento da produtividade total dos fatores é descrita por um processo i.i.d. Assume-se que $\ln \left(\mu_{z, t}\right) \equiv \ln \left(\frac{z_{t}}{z_{t-1}}\right)$ e que $\ln \left(\mu_{\Psi, t}\right) \equiv \ln \left(\frac{\Psi_{t}}{\Psi_{t-1}}\right)$ segue um processo $\mathrm{AR}(1)$. Os parâmetros que controlam o 
desvio padrão de cada um deles são definidos, respectivamente, por $\sigma_{z} e \sigma_{\Psi}$. Já, $\rho_{\Psi}$ é o coeficiente de autocorrelação de $\ln \left(\mu_{\psi, t}\right)$.

Neste modelo, as duas fontes de crescimento são os choques neutro $\left(z_{t}\right)$ e específico $\left(\psi_{t}\right)$ de investimento, ou de progresso tecnológico. As variáveis $\frac{Y_{t}}{\Phi_{t}}, \frac{C_{t}}{\Phi_{t}}, \frac{\omega_{t}}{\Phi_{t}}$ e $I_{t} /\left(\Psi_{t} \Phi_{t}\right)$ convergem para um estado estacionário não estocástico, no qual

$$
\Phi_{t}=\left(\Psi_{t}\right)^{\alpha /(1-\alpha)} z_{t}
$$

é a média ponderada entre as duas fontes de progresso tecnológico. Se as variáveis como o custo fixo de produção, o custo de contratação, o custo para se fazer uma contra oferta, as compras do governo e os benefícios dos desempregados, definidos respectivamente por $\left(\phi_{t}, \kappa_{t}, \gamma_{t}, G_{t} e D_{t}\right)$, são constantes, eles se tornam irrelevantes ao longo do tempo. Para evitar isso, Christiano, Eichenbaum e Trabandt (2013), seguindo a literatura, colocaram a hipótese que estas variáveis têm a mesma taxa de crescimento do produto, que no presente caso é dada por $\Phi_{t}$. No entanto, uma implicação negativa desta hipótese é que os dois tipos de choque tecnológico afetam imediatamente este conjunto de variáveis. O que é difícil de justificar. Para contornar este problema, os autores procederam como em Christiano, Trabandt e Walentin (2012) e Schmitt-Grohé e Uribe (2012) e assumiram que as compras do governo $\left(G_{t}\right)$ são defasadas e são distribuídas de acordo com um processo que tem raiz unitária. Deste modo, tem-se que $G_{t}$ é cointegrada com $Y_{t}$ mas tem uma tendência estocástica suavizada.

Em particular, Christiano, Eichenbaum e Trabandt(2013) assumem, então, que :

$$
\left(\phi_{t}, \kappa_{t}, \gamma_{t}, G_{t} e D_{t}\right)^{\prime}=\left(\phi_{t}, \kappa_{t}, \gamma_{t}, G_{t} e D_{t}\right)^{\prime} \Omega_{t}
$$

Onde $\Omega_{t}$ é a diagonal $\left(\Omega_{i, t}\right)$ com $i \epsilon\left(\phi_{t}, \kappa_{t}, \gamma_{t}, G_{t} e D_{t}\right)$ e $\Omega_{i, t}$ corresponde a uma distribuição dos valores passados defasados de $\Phi_{t}$ definida por:

$$
\Omega_{i, t}=\left(\Phi_{t-1}\right)^{\theta_{i}}\left(\Omega_{t-1}^{i}\right)^{\left(1-\theta_{i}\right)}
$$

Onde $0<\theta_{i} \leq 1$ são parâmetros a serem estimados. Note que $\Omega_{t}^{i}$ cresce no longo prazo a mesma taxa que $\Phi_{t}$. Quando $\theta_{i}$ é muito próximo de zero, $\Omega_{t}^{i}$ responde muito pouco no curto prazo a qualquer tipo de inovação tecnológica. Na prática, os autores colocaram a restrição de que os quatro primeiros valores de $\theta_{i}$ deveriam ser iguais, podendo ser diferente apenas $\theta_{D}$. 
Com relação à equação que define o custo de ajustamento (2.5), temos que $\mu$ e $\mu_{\Psi}$ representam as taxas de crescimento incondicional de $\Phi_{t} e \Psi_{t}$. O valor de $\mathrm{I}_{t} / \mathrm{I}_{\mathrm{t}-1}$ no estado estacionário não estocástico é dado por $\mu \mu_{\Psi}$. Adicionalmente, S" é um parâmetro que coincide com a segunda derivada de $S($.$) avaliado no estado$ estacionário.

No que tange a equação que define a utilização do capital (2.3), temos que no estado estacionário $u_{t}^{k}$ é normalizado para 1.

Por fim, cabe a discussão sobre como as contratações são determinadas. Os autores utilizam uma função de matching padrão, qual seja:

$$
x_{t} l_{t-1}=\sigma_{m}\left(1-\rho l_{t-1}\right)^{\sigma}\left(l_{t-1} v_{t}\right)^{(1-\sigma)}
$$

Onde $l_{t-1} v_{t}$ corresponde ao total de vagas abertas e $v_{t}$ representa a taxa de vagas abertas. Dados $\mathrm{x}_{\mathrm{t}}$ e $\mathrm{I}_{\mathrm{t}-1}$, usa-se 2.52 para resolver para $v_{t}$. É importante lembrar que o número total de vagas foi definido por $\left.x_{t}\right|_{t-1} / Q_{t}$. Portanto, temos que:

$$
Q_{t}=\frac{x_{t}}{v_{t}}
$$

Christiano, Eichenbaum e Trabandt (2013) destacam que o equilíbrio a que se chega tem uma estrutura recursiva particular. Pode-se primeiro resolver para todas as variáveis do modelo, exceto $\mathrm{Q}_{\mathrm{t}}$ e $v_{t}$, que são resolvidas usando 2.52 e 2.53 .

\subsection{ALTERAÇÕES DO MODELO ORIGINAL, CONJUNTO DE EQUAÇÕES UTILIZADAS E LOG-LINEARIZAÇÃO}

Christiano, Eichenbaum e Trabandt (2013) trabalham com três choques no modelo, quais sejam: choque de política monetária, choque de investimento tecnológico $\left(\psi_{\mathrm{t}}\right)$ e choque neutro de investimento $\left(z_{t}\right)$. Além disso, eles utilizam o modelo no nível. No presente trabalho, as equações apresentadas no apêndice técnico B.1 de Christiano, Eichenbaum e Trabandt (2013) para o modelo de médio porte foram loglinearizadas e estimadas bayesianamente. O processo de estimação será explicado em uma próxima seção. 
2.3.1 Conjunto de Equações do Modelo e o Resultado da Log-linearização.

As equações presentes no apêndice técnico e a sua forma log-linearizada serão apresentadas abaixo respeitando a ordem do apêndice técnico B.1 de Christiano, Eichenbaum e Trabandt (2013).

\subsubsection{Equações Originais do Modelo}

Condição de Primeira Ordem para o consumo:

$$
\psi_{\mathrm{t}}=\left(\mathrm{c}_{\mathrm{t}}-\frac{\mathrm{bc}_{\mathrm{t}}}{\mu_{\mathrm{t}}}\right)^{-1}-\beta \mathrm{cE}_{\mathrm{t}}\left(\mathrm{c}_{\mathrm{t}+1} \mu_{\mathrm{t}+1}-\mathrm{bc}_{\mathrm{t}}\right)^{-1}
$$

Condição de Primeira Ordem para os títulos:

$$
\psi_{\mathrm{t}}=\frac{\beta \mathrm{E}_{\mathrm{t}} \psi_{\mathrm{t}+1} \mathrm{R}_{\mathrm{t}}}{\pi_{\mathrm{t}+1} \mu_{\mathrm{t}+1}}
$$

Condição de Primeira Ordem para o investimento:

$$
1=p_{k^{\prime}, t}\left[1-S_{t}-\frac{S_{t}^{\prime} \mu_{t} \mu_{\Psi, t} i_{t}}{i_{t-1}}\right]+\frac{\beta E_{t} \psi_{t+1}}{\psi_{t}} p_{k^{\prime}, t+1} S_{t+1}^{\prime}\left(\frac{i_{t+1}}{i_{t}}\right)^{2} \mu_{\Psi, t+1} \mu_{t+1}
$$

Condição de Primeira Ordem para o capital:

$$
\psi_{t}=\frac{\beta E_{t} \psi_{t+1} R_{t+1}^{k}}{\pi_{t+1} \mu_{t+1}}
$$

Lei de movimento do capital:

$$
\mathrm{k}_{\mathrm{t}}=\frac{\left(1-\delta^{\mathrm{k}}\right)}{\mu_{\mathrm{t}} \mu_{\Psi, \mathrm{t}}} \mathrm{k}_{\mathrm{t}-1}+\left(1-\mathrm{S}_{\mathrm{t}}\right) \mathrm{i}_{\mathrm{t}}
$$

Minimização do custo:

$$
0=\frac{a^{\prime}\left(u_{t}^{k}\right) u_{t}^{k} k_{t-1}}{\mu_{\Psi, t} \mu_{t}}-\frac{\alpha}{1-\alpha} \vartheta_{t}\left[v^{f} R_{t}+1-v^{f}\right] l_{t}, \operatorname{com} v^{\mathrm{f}}=1
$$

Produção:

$$
\mathrm{y}_{\mathrm{t}}=\dot{\mathrm{p}}^{\frac{\lambda}{1-\lambda}}\left[\left(\frac{\mathrm{u}_{\mathrm{t}}^{\mathrm{k}} \mathrm{k}_{\mathrm{t}-1}}{\mu_{\mathrm{t}} \mu_{\Psi, \mathrm{t}}}\right)^{\alpha} \mathrm{l}_{\mathrm{t}}^{1-\alpha}-\eta_{\phi, t} \phi\right.
$$

Recursos da Economia:

$$
y_{t}=\eta_{g, t} g_{t}+c_{t}+i_{t}+\frac{a\left(u_{t}^{k}\right) k_{t-1}}{\mu_{t} \mu_{\Psi, t}}+\eta_{k, t} k_{t-1}
$$

Regra de Taylor: 


$$
\ln \left(\frac{R_{t}}{R}\right)=\rho_{R} \ln \left(\frac{R_{t-1}}{R}\right)+\left(1-\rho_{R}\right)\left[r_{\pi} \ln \left(\frac{\pi_{t}}{\pi}\right)+r_{y} \ln \left(\frac{Y_{t}}{Y}\right)\right]+\sigma_{R} \varepsilon_{R, t} / 400
$$

Equação do preço 1:

$$
F_{t}=\psi_{t} y_{t}+\beta \xi E_{t}\left(\frac{\pi}{\pi_{t+1}}\right)^{\frac{1}{1-\lambda}} F_{t+1}
$$

Equação do preço 2:

$$
K_{t}=\lambda \psi_{t} y_{t} m c_{t}+\beta \xi E_{t}\left(\frac{\pi}{\pi_{t+1}}\right)^{\frac{\lambda}{1-\lambda}} K_{t+1}
$$

Equação do preço 3:

$$
(1-\xi)\left(\frac{K_{t}}{F_{t}}\right)^{\frac{1}{1-\lambda}}=1-\xi\left(\frac{\pi}{\pi_{t}}\right)^{\frac{1}{1-\lambda}}
$$

Dispersão de preços:

$$
\dot{p}_{t^{\frac{\lambda}{1-\lambda}}}=(1-\xi)^{1-\lambda}\left[1-\xi\left(\frac{\pi}{\pi_{t}}\right)^{\frac{\lambda}{1-\lambda}}\right]^{\lambda}+\xi\left[\frac{\pi}{\pi_{t}} \dot{p_{t}}\right]^{\frac{\lambda}{1-\lambda}}
$$

Valor presente dos salários:

$$
\omega_{t}^{p}=\omega_{t}+\rho \beta E_{t} \frac{\psi_{t+1}}{\psi_{t}} \omega_{t+1}^{p}
$$

Valor presente da receita:

$$
\vartheta_{t}^{p}=\vartheta_{t}+\rho \beta E_{t} \frac{\psi_{t+1}}{\psi_{t}} \vartheta_{t+1}^{p}
$$

Condição de livre entrada:

$$
\eta_{\kappa, t} \kappa=J_{t}
$$

Valor para a firma:

$$
J_{t}=\vartheta_{t}^{p}-\omega_{t}^{p}
$$

Valor para o trabalhador:

$$
\begin{gathered}
V_{t}=\omega_{t}^{p}+A_{t} \\
A_{t}=(1-\rho) \beta E_{t}\left\{\left(\frac{\psi_{t+1}}{\psi t}\right)\left[f_{t+1} V_{t+1}-\left(1-f_{t+1}\right) U_{t+1}\right]\right\}+\rho \beta E_{t}\left(\frac{\psi_{t+1}}{\psi_{t}}\right) A_{t+1}
\end{gathered}
$$

Valor do desemprego:

$$
U_{t}=\eta_{D, t} D+\beta E_{t}\left\{\left(\frac{\psi_{t+1}}{\psi t}\right)\left[f_{t+1} V_{t+1}+\left(1-f_{t+1}\right) U_{t+1}\right]\right\}
$$

Regra de divisão do excedente:

$$
\alpha_{1} J_{t}=\alpha_{2}\left(V_{t}-U_{t}\right)-\alpha_{3} \eta_{\gamma, t} \gamma+\alpha_{4}\left(\vartheta_{t}-\eta_{D, t} D\right)
$$

PIB real: 


$$
Y_{t}=\eta_{g, t} g_{t}+c_{t}+i_{t} \quad, \text { com } g_{t}=g \text { para todo } t
$$

Taxa de desemprego:

$$
u_{t}=1-l_{t}
$$

Taxa com que o desempregado encontra emprego (finding rate):

$$
f_{t}=\left(\frac{x_{t} l_{t-1}}{1-\rho l_{t-1}}\right)
$$

Função de matching:

$$
x_{t} l_{t-1}=\sigma_{m}\left(1-\rho l_{t-1}\right)^{\sigma} v_{t}^{t o t}(1-\sigma)
$$

Vagas:

$$
v_{t}^{\text {tot }}=v_{t} l_{t-1}
$$

Taxa de preenchimento de vagas:

$$
Q_{t}=\frac{x_{t}}{v_{t}}
$$

Lei de movimento do emprego:

$$
l_{t}=\left(\rho+x_{t}\right) l_{t-1}
$$

Tecnologia composta:

$$
\ln \mu_{t}=\frac{\alpha}{1-\alpha} \ln \left(\mu_{\Psi, t}\right)+\ln \mu_{z, t}
$$

Tecnologia neutra:

$$
\ln \mu_{z, t}=\left(1-\rho_{\mu_{z}}\right) \ln \mu_{z}+\rho_{\mu_{z}} \ln \mu_{z, t-1}+\frac{\sigma_{\mu_{z}} \varepsilon_{\mu_{z}, t}}{100}
$$

Tecnologia do Investimento:

$$
\ln \mu_{\Psi, t}=\left(1-\rho_{\mu_{\Psi}}\right) \ln \mu_{\Psi}+\rho_{\mu_{\Psi}} \ln \mu_{\Psi, t-1}+\frac{\sigma_{\mu_{\Psi}} \varepsilon_{\mu_{\Psi}, t}}{100}
$$

Difusão da tecnologia:

$$
\eta_{i, t}=\eta_{i, t-1}^{1-\theta_{i}} \mu_{t}^{-1} \text { para } i \epsilon\{\phi, \kappa, \gamma, g, D\}
$$

Retorno do capital:

$$
R_{t}^{k}=\frac{\pi_{t}}{\mu_{\Psi, t} p_{k^{\prime}, t-1}}\left[u_{t}^{k} a^{\prime}\left(u_{t}^{k}\right)-a\left(u_{t}^{k}\right)+\left(1-\delta^{k}\right) p_{k^{\prime}, t}\right]
$$

Custo Marginal:

$$
m c_{t}=\frac{\left(\mu_{\Psi, t} \mu_{t}\right)^{\alpha} \vartheta_{t}\left[v^{f} R_{t}+1-v^{f}\right]\left(\frac{u_{t}^{k} k_{t-1}}{l_{t}}\right)^{-\alpha}}{1-\alpha} \quad, c o m v^{f}=1
$$




\subsubsection{Log-linearização}

As variáveis com barra $\left(^{-}\right)$indicam que elas estão no estado estacionário enquanto as variáveis $\left(^{\sim}\right)$ indicam a diferença do logaritmo da variável em relação ao valor do logaritmo quando ela está no estado estacionário.

Condição de Primeira Ordem para o consumo:

$$
\begin{gathered}
\widetilde{\psi_{t}}=\left(\frac{\bar{\mu} \overline{\Gamma_{c}}}{(\bar{\mu}-\beta b)}\right)\left[\frac{b}{\bar{\mu}-b} \widetilde{\mu_{t}}-\frac{\bar{\mu}}{\bar{\mu}-b} \widetilde{c_{t}}+\frac{b}{\bar{\mu}-b} \widetilde{c_{t-1}}\right] \\
-\left(\frac{\beta b \overline{\Gamma_{c}}}{\bar{\mu}-\beta b}\right) E_{t}\left[\left(\frac{\bar{\mu}}{\bar{\mu}-b}\right)\left(\widetilde{c_{t+1}}+\widetilde{\mu_{t+1}}\right)+\left(\frac{b}{\bar{\mu}-b}\right) \widetilde{c_{t}}\right]
\end{gathered}
$$

Condição de Primeira Ordem para os títulos:

$$
\widetilde{\psi_{t}}=E_{t}\left[\widetilde{\psi_{t+1}}+\widetilde{R_{t+1}}-\widetilde{\pi_{t+1}}-\widetilde{\mu_{t+1}}\right]
$$

Condição de Primeira Ordem para o investimento:

$$
0=\widetilde{p_{k^{\prime}, t}}-\left(\overline{\mu \mu_{\Psi}}\right)^{2} S^{\prime \prime}\left[\widetilde{\mu_{t}}+\widetilde{\mu_{\Psi, t}}+\widetilde{\imath_{t}}-\widetilde{\imath_{t-1}}-\beta E_{t}\left(\widetilde{\mu_{t+1}}+\widetilde{\mu_{\Psi, t+1}}+\widetilde{l_{t+1}}-\widetilde{\imath_{t}}\right)\right](2
$$

Condição de Primeira Ordem (CPO) para o capital:

$$
\widetilde{\psi_{t}}=E_{t}\left[\overline{\psi_{t+1}}+\widetilde{R_{t+1}^{k}}-\widetilde{\pi_{t+1}}-\widetilde{\mu_{t+1}}\right]
$$

Lei de movimento do capital:

$$
\widetilde{k_{t}}=\frac{1-\delta^{k}}{\overline{\mu \mu_{\Psi}}}\left[\widetilde{k_{t-1}}-\widetilde{\mu_{t}}-\widetilde{\mu_{\Psi}, t}\right]+\frac{\bar{l}}{\bar{k}} \widetilde{l_{t}}
$$

Minimização do custo:

$$
\begin{aligned}
& 0=\left(\frac{\bar{k}}{\bar{\mu} \overline{\mu_{\Psi}}}\right)\left[\sigma_{b}\left(\widetilde{k_{t-1}}-\widetilde{\mu_{t}}-\widetilde{\mu_{\Psi}, t}\right)+\left(\sigma_{b}-\sigma_{a} \sigma_{b}\right) \widetilde{u_{t}^{k}}\right] \\
& -\left(\frac{\alpha}{1-\alpha}\right) \bar{\vartheta} \bar{l}\left[(\bar{R})\left(\widetilde{\vartheta_{t}}+\widetilde{l_{t}}\right)+\bar{R} \widetilde{R_{t}}\right]
\end{aligned}
$$

Produção:

$$
\begin{aligned}
\bar{y} \widetilde{y_{t}}=\overline{\dot{p}}^{\left(\frac{\lambda}{\lambda-1}\right)}\left\{\left(\frac{\bar{k}}{\overline{\mu \mu_{\Psi}}}\right)^{\alpha}\left[\left(\frac{\lambda}{\lambda-1}\right) \widetilde{\dot{p}_{t}}+\alpha *\left(\widetilde{u_{t}^{k}}+\widetilde{k_{t-1}}-\widetilde{\mu_{t}}-\widetilde{\mu_{\Psi}, t}\right)+(1-\alpha) \widetilde{l_{t}}\right]\right. \\
\left.-\left[\overline{\eta_{\phi}}\left(\left(\frac{\lambda}{\lambda-1}\right) \widetilde{\dot{p}_{t}}+\widetilde{\eta_{\phi, t}}\right)\right]\right\}
\end{aligned}
$$

Recursos da Economia:

$\bar{y} \widetilde{y_{t}}=\left(\overline{\eta_{g}} \bar{g}\right)\left(\widetilde{\eta_{g}, t}+\widetilde{g_{t}}\right)+\bar{c} \widetilde{c_{t}}+\widetilde{\imath \tau_{t}}+\left(\frac{\sigma_{b} \bar{k}}{\overline{\mu \mu_{\Psi}}}\right) \widetilde{u_{t}^{k}}+\kappa\left(\overline{\eta_{\kappa, t}} \bar{x} \vec{l}\right)\left(\widetilde{\eta_{\kappa, t}}+\widetilde{x_{t}}+\widetilde{l_{t-1}}\right)$

Regra de Taylor: 


$$
\widetilde{R_{t}}=\rho_{R} \widetilde{R_{t-1}}+\left(1-\rho_{R}\right)\left[r_{\pi} \widetilde{\pi_{t}}+r_{y} \widetilde{Y}_{t}\right]+\sigma_{R} \varepsilon_{R, t} / 400
$$

Equação do preço 1:

$$
\widetilde{F_{t}}=\left(1-\beta \xi\left(\frac{1}{\bar{\pi}}\right)^{\frac{1}{1-\lambda}}\right)\left[\widetilde{\psi_{t}}+\widetilde{y_{t}}\right]+\beta \xi\left(\frac{1}{\bar{\pi}}\right)^{\frac{1}{1-\lambda}} \widetilde{E_{t}} \widetilde{F_{t+1}}-\left(\frac{\beta \xi}{1-\lambda}\right)\left(\frac{1}{\bar{\pi}}\right)^{\frac{1}{1-\lambda}} E_{t} \widetilde{\pi_{t+1}}
$$

Equação do preço 2:

$$
\begin{aligned}
\widetilde{K_{t}}=\left(1-\beta \xi\left(\frac{1}{\bar{\pi}}\right)^{\left(\frac{\lambda}{1-\lambda}\right)}\right)\left(\widetilde{\psi_{t}}+\widetilde{y_{t}}+\widetilde{m_{t}}\right) \\
+\beta \xi\left(\frac{1}{\bar{\pi}}\right)^{\left(\frac{\lambda}{1-\lambda}\right)} E_{t}\left[\left(-\frac{\lambda}{1-\lambda}\right) \widetilde{\pi_{t+1}}+\widetilde{K_{t+1}}\right]
\end{aligned}
$$

Equação do preço 3:

$$
\widetilde{K_{t}}-\widetilde{F_{t}}=\frac{\xi\left(\frac{1}{\bar{\pi}}\right)^{\frac{1}{1-\lambda}} \widetilde{\pi_{t}}}{1-\xi\left(\frac{1}{\bar{\pi}}\right)^{\frac{1}{1-\lambda}}}
$$

Dispersão de preços:

$$
\begin{aligned}
\dot{\dot{p}}^{\lambda /(1-\lambda)} \widetilde{\dot{p}_{t}}=\xi & (1-\xi)^{1-\lambda}\left[1-\xi\left(\frac{1}{\bar{\pi}}\right)^{\left(\frac{1}{1-\lambda}\right)}\right]^{\lambda-1}\left(\frac{1}{\overline{\bar{\pi}}}\right)^{\left(\frac{1}{1-\lambda}\right)} \widetilde{\pi_{t}} \\
& +\xi\left(\frac{\overline{\dot{p}}}{\bar{\pi}}\right)^{\lambda /(1-\lambda)}\left[\widetilde{p_{t-1}}-\widetilde{\pi_{t}}\right]
\end{aligned}
$$

Valor presente dos salários:

$$
\widetilde{\omega_{t}^{p}}=(1-\rho \beta) \widetilde{\omega_{t}}+\rho \beta E_{t}\left[\widetilde{\psi_{t+1}}-\widetilde{\psi_{t}}+\widetilde{\omega_{t+1}^{p}}\right]
$$

Valor presente da receita:

$$
\widetilde{\vartheta_{t}^{p}}=(1-\rho \beta) \widetilde{\vartheta_{t}}+\rho \beta E_{t}\left[\widetilde{\psi_{t+1}}-\widetilde{\psi_{t}}+\widetilde{\vartheta_{t+1}^{p}}\right]
$$

Condição de livre entrada:

$$
\widetilde{\eta_{\kappa, t}}=\widetilde{J_{t}}
$$

Valor para a firma:

$$
\widetilde{J_{t}}=\left(\overline{\frac{\vartheta^{p}}{\bar{J}}}\right) \widetilde{\vartheta_{t}^{p}}-\left(\overline{\frac{\omega^{p}}{\bar{J}}}\right) \widetilde{\omega_{t}^{p}}
$$

Valor para o trabalhador: 


$$
\begin{aligned}
& \widetilde{V_{t}}=\left(\frac{\overline{\omega^{p}}}{\bar{V}}\right) \widetilde{\omega_{t}^{p}}+\left(\frac{\bar{A}}{\bar{V}}\right) \widetilde{A_{t}} \\
& \bar{A} \widetilde{A_{t}}=(1-\rho) \beta \bar{f} \bar{V} E_{t}\left[\widetilde{\psi_{t+1}}-\widetilde{\psi_{t}}+\widetilde{V_{t+1}}+\widetilde{f_{t+1}}\right]+(1-\rho) \beta \bar{U} E_{t}\left[\widetilde{\psi_{t+1}}-\widetilde{\psi_{t}}+\widetilde{U_{t+1}}\right] \\
& -(1-\rho) \beta \bar{f} \bar{U} E_{t}\left[\widetilde{\psi_{t+1}}-\widetilde{\psi_{t}}+\widetilde{f_{t+1}}+\widetilde{U_{t+1}}\right] \\
& +\bar{A} \bar{f} \beta E_{t}\left[\overline{\psi_{t+1}}-\widetilde{\psi_{t}}+\widetilde{A_{t+1}}\right]
\end{aligned}
$$

Valor do desemprego:

$$
\begin{gathered}
\widetilde{U_{t}}=\left(\frac{\overline{\eta_{D}} D}{\bar{U}}\right) \widetilde{\eta_{D, t}}+\left(\frac{\beta \bar{f} \bar{V}}{\bar{U}}\right) E_{t}\left[\widetilde{\psi_{t+1}}-\widetilde{\psi_{t}}+\widetilde{f_{t+1}}+\widetilde{V_{t+1}}\right]+\beta E_{t}\left[\widetilde{\psi_{t+1}}-\widetilde{\psi_{t}}+\widetilde{U_{t+1}}\right] \\
-\beta \bar{f} E_{t}\left[\widetilde{\psi_{t+1}}-\widetilde{\psi_{t}}+\widetilde{f_{t+1}}+\widetilde{U_{t+1}}\right] \quad(2,106)
\end{gathered}
$$

Regra de divisão do excedente:

$$
\widetilde{J_{t}}=\left(\frac{\alpha_{2} \bar{V}}{\alpha_{1} \bar{J}}\right)\left(\widetilde{V_{t}}-\widetilde{U_{t}}\right)-\frac{\alpha_{3} \overline{\eta_{\gamma} \gamma}}{\alpha_{1} \bar{J}}\left(\widetilde{\eta_{\gamma, t}}\right)+\frac{\alpha_{4} \bar{\vartheta}}{\alpha_{1} \bar{J}}\left(\widetilde{\vartheta_{t}}\right)-\frac{\alpha_{4} \overline{\eta_{D}} D}{\alpha_{1} \bar{J}} \widetilde{\eta_{D}, t}
$$

PIB real:

$$
\widetilde{Y_{t}}=\frac{\overline{\eta_{g}} \bar{g}}{\bar{Y}} \widetilde{\eta_{g, t}}+\frac{\bar{c}}{\overline{\bar{Y}}} \widetilde{c_{t}}+\frac{\bar{\imath}}{\overline{\bar{Y}}} \widetilde{l_{t}}
$$

Taxa de desemprego:

$$
\widetilde{u_{t}}=\left(\frac{\bar{l}}{\bar{l}-1}\right) \widetilde{l_{t}}
$$

Taxa com que o desempregado encontra emprego (finding rate):

$$
\widetilde{f}_{t}=\widetilde{x}_{t}+\left(\frac{1}{1-\rho \bar{l}}\right) \widetilde{l_{t-1}}
$$

Função de matching:

$$
\widetilde{x_{t}}=(1-\sigma) \widetilde{v_{t}^{t o t}}-\left(1+\frac{\sigma \rho \bar{l}}{1-\rho \bar{l}}\right) \widetilde{l_{t-1}}
$$

Vagas:

$$
\widetilde{v_{t}^{t o t}}=\widetilde{v_{t}}+\widetilde{l_{t-1}}
$$

Taxa de preenchimento de vagas:

$$
\widetilde{Q_{t}}=\widetilde{x_{t}}-\widetilde{v_{t}}
$$

Lei de movimento do emprego:

$$
\widetilde{l_{t}}=\widetilde{l_{t-1}}+\bar{x} \tilde{x_{t}}
$$


Tecnologia composta:

$$
\widetilde{\mu_{t}}=\left(\frac{\alpha}{1-\alpha}\right) \widetilde{\mu_{\Psi, t}}+\widetilde{\mu_{z, t}}
$$

Tecnologia neutra:

$$
\widetilde{\mu_{z, t}}=\widetilde{\rho_{\mu_{z}}} \widetilde{\mu_{z, t-1}}+\frac{\sigma_{\mu_{z}} \varepsilon_{\mu_{z}, t}}{100}
$$

Tecnologia do Investimento:

$$
\widetilde{\mu_{\Psi, t}}=\rho_{\mu_{\Psi}} \widetilde{\mu_{\Psi, t-1}}+\frac{\sigma_{\mu_{\Psi}} \varepsilon_{\mu_{\Psi}, t}}{100}
$$

Difusão da tecnologia:

$$
\widetilde{\eta_{l, t}}=\left(1-\theta_{i}\right) \widetilde{\eta_{l, t-1}}-\widetilde{\mu_{t}}, \text { para } i \epsilon\{\phi, \kappa, \gamma, g, D\}
$$

Retorno do capital:

$$
\begin{gathered}
\overline{R^{k}} \widetilde{R_{t}^{k}}=\frac{\bar{\pi} \sigma_{b}}{\overline{\mu_{\Psi} p_{k^{\prime}}}}\left[\widetilde{\pi_{t}}-\widetilde{\mu_{\Psi, t}}-\widetilde{p_{k^{\prime}, t-1}}\right]+\frac{\bar{\pi}}{\overline{\mu_{\Psi} p_{k^{\prime}}}}\left[\sigma_{b}+\sigma_{b} \sigma \sigma_{a}\right] \widetilde{u_{t}^{k}}-\frac{\bar{\pi} \sigma_{b}}{\overline{\mu_{\Psi} p_{k^{\prime}}}} \widetilde{u_{t}^{k}} \\
+\frac{\left(1-\delta^{k}\right) \bar{\pi}}{\overline{\mu_{\Psi}}}\left[\widetilde{\pi_{t}}+\widetilde{p_{k^{\prime}, t}}-\widetilde{p_{k^{\prime}, t-1}}-\widetilde{\mu_{\Psi}, t}\right]
\end{gathered}
$$

Custo Marginal:

$$
\begin{gathered}
\overline{m c} \widetilde{m c_{t}}=\overline{\Gamma_{m c}}\left(\overline{\mu \mu_{\Psi}}\right)^{\alpha} \bar{\vartheta} \bar{R}\left(\frac{\bar{k}}{\bar{l}}\right)^{-\alpha}\left(\frac{1}{1-\alpha}\right)\left[\widetilde{R_{t}}+\alpha \widetilde{\mu_{\Psi}, t}+\alpha \widetilde{\mu_{t}}+\widetilde{\vartheta_{t}}-\alpha \widetilde{u_{t}^{k}}-\alpha \widetilde{k_{t-1}}\right. \\
\left.+\alpha \widetilde{l_{t}}\right] \quad(2.120)
\end{gathered}
$$

\subsection{MODELO DE MÉDIO PORTE COM RIGIDEZ DE PREÇOS E SALÁRIOS}

Como destacado anteriormente, comparamos os resultados do modelo com estrutura para mercado de trabalho com o modelo novo keynesiano mais tradicional com rigidez de preços e salários que segue mais de perto Christiano, Eichenbaum e Evans (2005).

Para ter este novo formato, em relação ao modelo de Christiano, Eichenbaum e Trabandt (2013) apresentado anteriormente, foram alteradas as características do setor atacadista de produção. Agora, os bens finais homogêneos, $Y_{t}$, são produzidos por firmas competitivas e idênticas usando a tecnologia dada pela equação 2.6. Os insumos especializados usados na produção de $Y_{t}$ são produzidos por varejistas que utilizam serviços de capital e o fator trabalho que é homogêneo. O produtor de bens finais compra insumo especializado $\mathrm{j}, \mathrm{Y}_{\mathrm{j}, \mathrm{t}}$, do varejista que produz $\mathrm{o}$ insumo usando 
tecnologia dada por 2.9. Serviços de capital são comprados em mercados competitivos. Em 2.9, $\mathrm{h}_{\mathrm{j}, \mathrm{t}}$ se refere a quantidade de trabalho homogêneo que a firma j compra dos fornecedores de mão de obra (“labor contractors”). Estes fornecedores produzem o insumo de trabalho homogêneo combinando um conjunto diferente de insumos de trabalho, $h_{i, t}$, usando a seguinte tecnologia:

$$
h_{t}=\left[\int_{0}^{1} h_{i, t}^{1 / \lambda_{w}} d i\right]^{\lambda_{w}}, \lambda_{w}>1
$$

Os fornecedores de trabalho atuam num mercado de concorrência perfeita e tomam o salário $W_{t}$ de $h_{t}$ como dado. Eles também tomam o salário $W_{i, t}$ do tipo de trabalho $i$ como dado. A maximização de lucro destes agentes produz a seguinte curva de demanda por trabalho:

$$
h_{i, t}=\left(\frac{W_{t}}{W_{i, t}}\right)^{\frac{\lambda_{w}}{1-\lambda_{w}}} h_{t}
$$

Substituindo 2.121 em 2.122 e rearranjando, obtemos:

$$
W_{t}=\left[\int_{0}^{1} W_{i, t}^{\frac{1}{1-\lambda_{w}}} d i\right]^{1-\lambda_{w}}
$$

Os trabalhos especializados são ofertados por um grande número de domicílios/famílias idênticas. O domicílio representativo é composto por um grande número de membros de cada tipo i de trabalho especializado e fornece um seguro completo para todos os membros em troca dos salários. Sua restrição orçamentária é dada por 2.2 mas considerando que neste caso $D_{t}$ é igual a zero. Esta restrição reflete a hipótese que as famílias possuem o estoque de capital, escolhem seu nível de utilização e fazem as decisões de investimento.

É ótimo para as famílias designar uma quantidade igual de consumo para cada membro. A função utilidade é dada por:

$$
\ln \left(C_{t}-b C_{t-1}\right)-A \int_{0}^{1} \frac{h_{i, t}^{1+\psi}}{1+\psi} d i
$$

Onde A é uma constante positiva e $h_{i, t}$ corresponde as horas trabalhadas pelo membro i da família. O salário do tipo de trabalho i é $\mathrm{W}_{\mathrm{i}, \mathrm{t}}$ e é determinado fora do domicílio/família representativa por um sindicato monopolista que representa todos os tipos i de trabalho entre todos os domicílios. 
O sindicato monopolista enfrenta rigidez nominal de salário à la Calvo. Com probabilidade $1-\xi_{w} \circ$ sindicato pode atualizar e otimizar o salário $W_{i, t}$ e com probabilidade $\xi_{w}$ ele não pode. Não há indexação dos salários, então, neste último caso, o salário nominal é dado por:

$$
\mathrm{Wi}, \mathrm{t}=\mathrm{Wi}, \mathrm{t}-1
$$

Por fim, o sindicato maximiza o bem estar de seus membros.

\subsection{METODOLOGIA, DADOS E PARÂMETROS}

\subsubsection{Metodologia Econométrica}

O presente modelo foi estimado utilizando métodos bayesianos. De posse dos modelo log-linearizados, este procedimento permite que as informações disponíveis a priori (distribuições priors) sejam atualizadas pelos dados e forneçam a distribuição posterior dos parâmetros de interesse. Isso ocorre através do Filtro de Kalman que leva à função de máxima verossimilhança que é então estimada pelo método de mesmo nome (qual seja, máxima verossimilhança).

Uma vantagem de assim proceder ocorre porque se tem muitos parâmetros nestes tipos de modelos de forma que a identificação fica comprometida. Esta situação se agrava no caso do Brasil dado que as séries históricas são muito curtas. Uma saída seria usarmos a calibragem pura dos parâmetros, mas neste caso nosso conjunto de dados não estaria dizendo nada sobre eles. Através destas técnicas econométricas, conseguimos então atualizar estes parâmetros calibrados, que seguem uma distribuição a priori, com os dados que temos disponíveis.

Maiores detalhes sobre esta metodologia constam tanto no livro de Canova (2007) quanto no livro de Dejong e Dave (2011). O programa utilizado para estimação foi o Dynare e o Matlab.

\subsubsection{Dados, parâmetros e distribuições a priori utilizadas}

O modelo por nós utilizado tem três choques de forma que conseguimos estimar o modelo utilizando apenas três variáveis observáveis. Utilizamos dois conjuntos de variáveis. O primeiro tem PIB, inflação e taxa de juro Selic. Utilizamos o 
comportamento cíclico (hiato) em torno do estado estacionário (valor da variável no potencial) calculado pelo filtro HP da série da Selic média trimestral, da série com ajuste sazonal do IPCA trimestral e do logaritmo neperiano da série de PIB também com ajuste sazonal. Enquanto o segundo conjunto traz as mesmas séries de hiato para o PIB e Selic, mas traz a série do comportamento cíclico com ajuste sazonal do logaritmo neperiano do salário real trimestral médio de admissão do CAGED. O modelo utiliza dados trimestrais e o início é o primeiro trimestre de 2001 e o último dado se refere ao quarto trimestre de 2013.

Com relação aos valores calibrados, os valores no estado estacionário e as distribuições priors das variáveis temos para a taxa de crescimento do produto interno bruto e para o investimento, ambos per capta, usamos o valor médio encontrado em nossa base de dados para o Brasil de 1,7\% ao ano e 3,2\% ao respectivamente.

Com relação aos demais parâmetros e as nossas distribuições priors, de maneira geral, seguimos os valores do artigo que explica o modelo SAMBA (Stochastic Analytical Model with a Bayesian Approach) do Banco Central do Brasil (Castro, Gouvea, Minella, Santos e Souza-Sobrinho(2011)). A média da distribuição beta considerada para o parâmetro de hábito de consumo foi de 0,85 . Já, a taxa estocástica de desconto foi de 0,989\%.

$\mathrm{Na}$ regra de Taylor, o coeficiente da inércia do juro tem média 0,6 enquanto que os coeficientes da reação em relação ao desvio da inflação tem média 2,0 e, ao desvio do hiato, 0,25. No primeiro caso a distribuição utilizada foi a beta, no segundo, a normal e, no terceiro, a distribuição gamma. Com relação à taxa de depreciação do capital, consideramos $1,5 \%$ ao trimestre. A participação do capital no PIB foi de $44,8 \%$.

Por fim, com relação aos parâmetros de rigidez e de mark-up de preço e de salários, consideramos como priors as distribuições beta e gamma com média 0,65 e 1,1 no primeiro caso, 0,75 e 1 no segundo caso, que foi usado para o modelo sticky wage. Neste caso ainda, consideramos que o inverso da elasticidade da oferta de trabalho é igual a um.

Para os demais parâmetros e aqueles ligados ao mercado de trabalho construído sob o arcabouço dos modelos de searching seguimos os valores que constam no artigo que serviu como base para o presente trabalho. Os custos de ajustamento do 
capital assim como o custo de ajustamento do investimento seguem uma distribuição gamma com média 0,5 e 8 respectivamente. A probabilidade de matching não ocorrer segue uma distribuição gamma cuja média é $0,005(0,5 \%)$. O replacement ratio tem distribuição prior beta com média 0,4 enquanto que o custo para empresa contratar através do processo de searching segue distribuição gamma com média 1. Já, o parâmetro da função matching segue distribuição beta com média 0,5.

A taxa segundo a qual as vagas são preenchidas é de 0,7, seguindo CET (2013), Haan, Ramey e Watson (2000) e Ravena e Walsh (2008). O intervalo de tempo M foi estabelecido em 60 e a probabilidade de sobrevivência (job survivor probability) é 0.9. E, por fim, em linha com os dados das contas nacionais, consideramos que no estado estacionário do consumo do governo representa cerca de $20 \%$ do PIB.

\subsection{RESULTADOS}

\subsubsection{Funções Impulso Resposta}

Nas figuras 14, 15 e 16 temos as respostas das variáveis do modelo aos choques de um desvio padrão de política monetária, tecnológico neutro e específico de investimento. Vale lembrar que calibramos vários parâmetros para a realidade brasileira, conforme descrito na seção anterior e usamos a versão por nós loglinearizada do modelo ${ }^{12}$.

${ }^{12}$ Para que não houvesse problema de indeterminação, com relação aos parâmetros da regra de Taylor tivemos que utilizar a média da posterior encontrada pelos autores do modelo SAMBA para 0 parâmetro de suavização (que é 0,79 ) e de reação para inflação $(2,43)$ e o valor de 0,10 para a reação com relação ao hiato do produto. Este valor de 0,1 está no intervalo de confiança entre 0,06 e 0,25 dado para estimação realizada por eles. 
TABELA 9 - LEGENDA PARA AS FIGURAS 14, 15 E 16

\begin{tabular}{|c|c|}
\hline Variáveis & Nome das variáveis \\
\hline psi & Multiplicador de Lagrange \\
\hline c & Consumo \\
\hline $\mathrm{mi}$ & Fator tecnológico composto \\
\hline $\mathrm{R}$ & Taxa de juros \\
\hline pi & Inflação \\
\hline mipsi & Choque investimento/tecnológico específico \\
\hline $\mathrm{i}$ & Investimento \\
\hline $\mathrm{K}$ & Capital \\
\hline uk & Utilização do capital \\
\hline v & Receita marginal de um trabalhador adicional \\
\hline I & Emprego \\
\hline netaphi & Custo para produção \\
\hline po & Dispersão de preços \\
\hline y & Produção \\
\hline netag & Governo \\
\hline$x$ & Taxa de contratação \\
\hline netak & Custo para negociação \\
\hline Q & Taxa de preenchimento de vagas \\
\hline Yy & PIB real \\
\hline $\mathrm{F}$ & Variável ligada à inflação 1 \\
\hline $\mathrm{mc}$ & Custo Marginal \\
\hline wp & Valor presente dos salários \\
\hline vp & Valor presente para empresas contratarem \\
\hline$J$ & Valor líquio para as empresas \\
\hline A & Parte do valor do trabalho \\
\hline$U$ & Valor do desemprego \\
\hline$f$ & Finding rate \\
\hline netad & Benefício do Desemprego \\
\hline $\mathrm{u}$ & Taxa de desemprego \\
\hline V & Valor do trabalho \\
\hline vtot & Contratados \\
\hline $\operatorname{miz}$ & Choque tecnológico neutro \\
\hline pklinha & Preço do investimento \\
\hline w & Salário real \\
\hline netagamma & Custo de contra-oferta \\
\hline $\mathrm{Kg}$ & Variável ligada à inflação 2 \\
\hline vzin & Vagas \\
\hline Rk & Taxa de juro do capital \\
\hline
\end{tabular}


FIGURA 14 - RESPOSTA DAS VARIÁVEIS DO MODELO DE MÉDIO PORTE AO CHOQUE DE POLÍTICA MONETÁRIA DE UM DESVIO PADRÃO
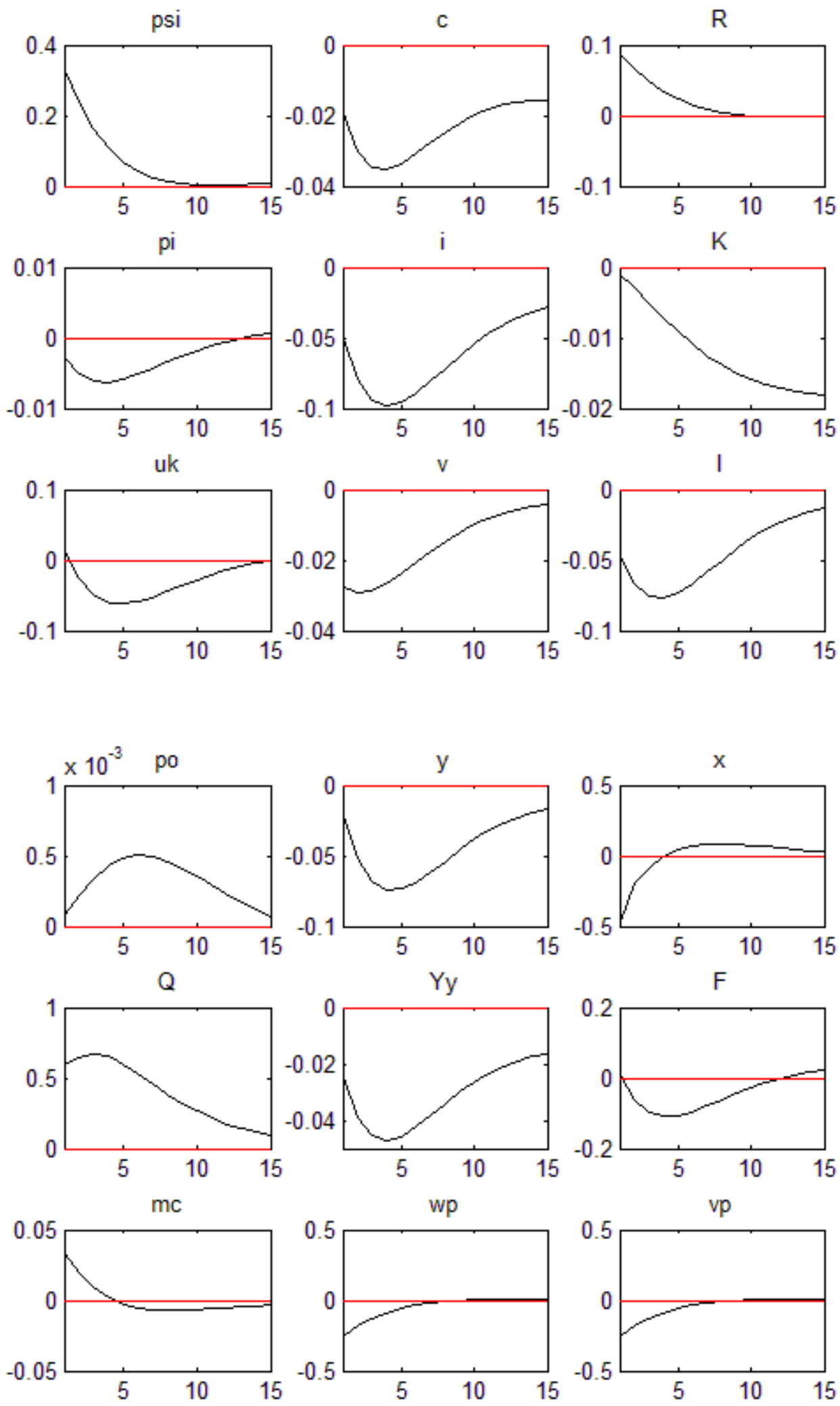

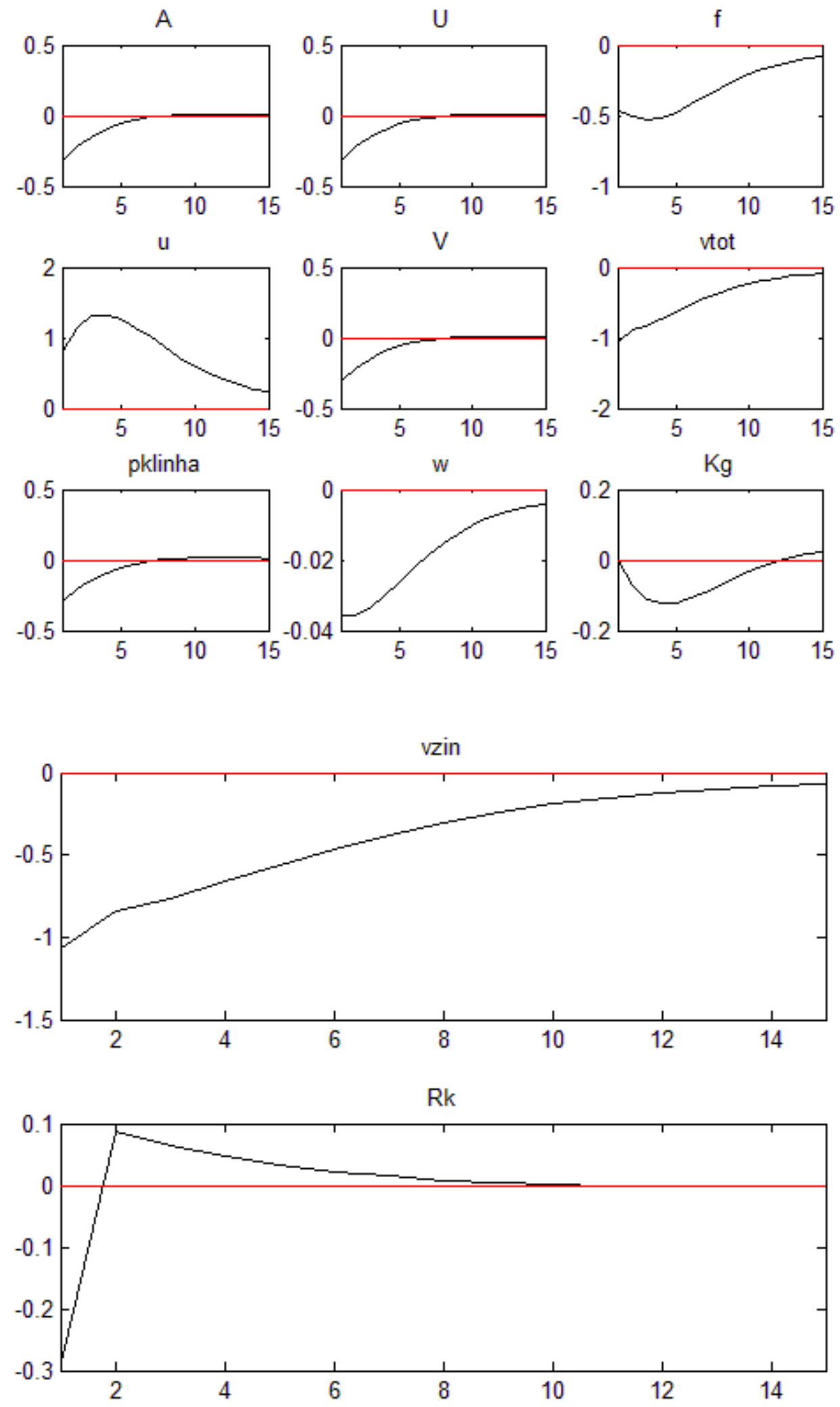
Quando temos um choque contracionista de um desvio padrão de política monetária, a taxa de juro da economia $(R)$ sobe, o produto interno bruto real (Yy) e as horas trabalhadas/emprego (I) recuam e o desemprego sobe conforme o choque se propaga. Depois de atingir um vale, estas condições melhoram ao longo do tempo. Por sua vez, o salário real (w) responde menos que as horas trabalhadas/emprego. Já, a inflação apresenta queda ao longo do tempo, em reação ao aumento dos juros. Ou seja, o modelo consegue dar conta dos movimentos observados empiricamente para PIB real e inflação assim como os modelos canônicos novos keynesianos.

Ainda, neste contexto, o custo marginal $(\mathrm{mc})$ sobe e os valores presentes dos salários (wp) e da receita por parte das firmas (vp) caem. Deste modo, como é menos interessante para as firmas empregarem para expandir a produção ocorre redução no job fiding rate (f) e no número de vagas (vtot). Mas como o efeito negativo sobre o número de novas vagas (vzin) é maior que sobre as contratações $(\mathrm{x})$, a taxa de preenchimento $(\mathrm{Q})$ sobe por um período de tempo. Mas esta melhora, como se viu, se dá por uma piora na dinâmica na margem do mercado de trabalho. Ainda, neste cenário de menor incentivo a produção, a utilização da capacidade instalada diminuiu ao longo do tempo.

Estes movimentos são semelhantes, mas em sentidos opostos, ao reportados por Christiano, Eichenbaum e Trabandt(2013). Isso porque lá o choque foi expansionista e aqui é contracionista.

Com relação ao choque específico de tecnologia, a figura 15 nos mostra que quando ocorre um choque aumentando o preço relativo do investimento (mpsi), tanto o investimento quanto o consumo recuam assim como o PIB. Para estimular a economia, a autoridade monetária diminui os juros $(\mathrm{R})$ que tem impacto para reduzir o custo marginal das empresas (mc), o que as estimula a aumentar as vagas e as contratações ao longo do tempo. Por isso, o desemprego (u) que inicialmente sobe, passa a recuar. Ainda, dado que está mais caro investir e há capacidade ociosa, o nível de utilização da capacidade instalada aumenta ao longo do tempo e, conforme este nível vai aumentando, vai pressionando a inflação. Por isso, os juros voltam a subir após algum tempo. 
FIGURA 15 - RESPOSTA DAS VARIÁVEIS DO MODELO DE MÉDIO PORTE AO CHOQUE ESPECÍFICO DE INVESTIMENTO.
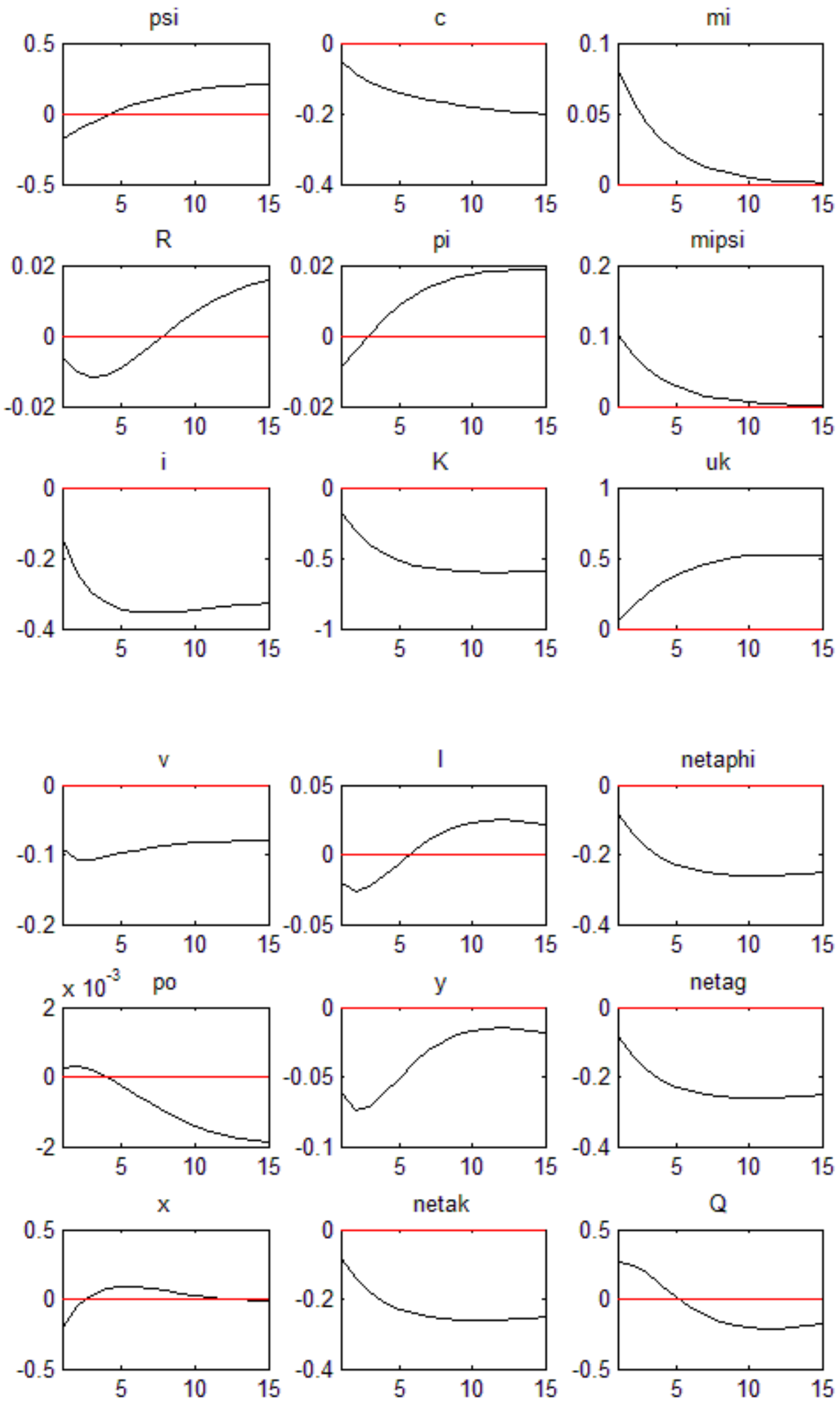

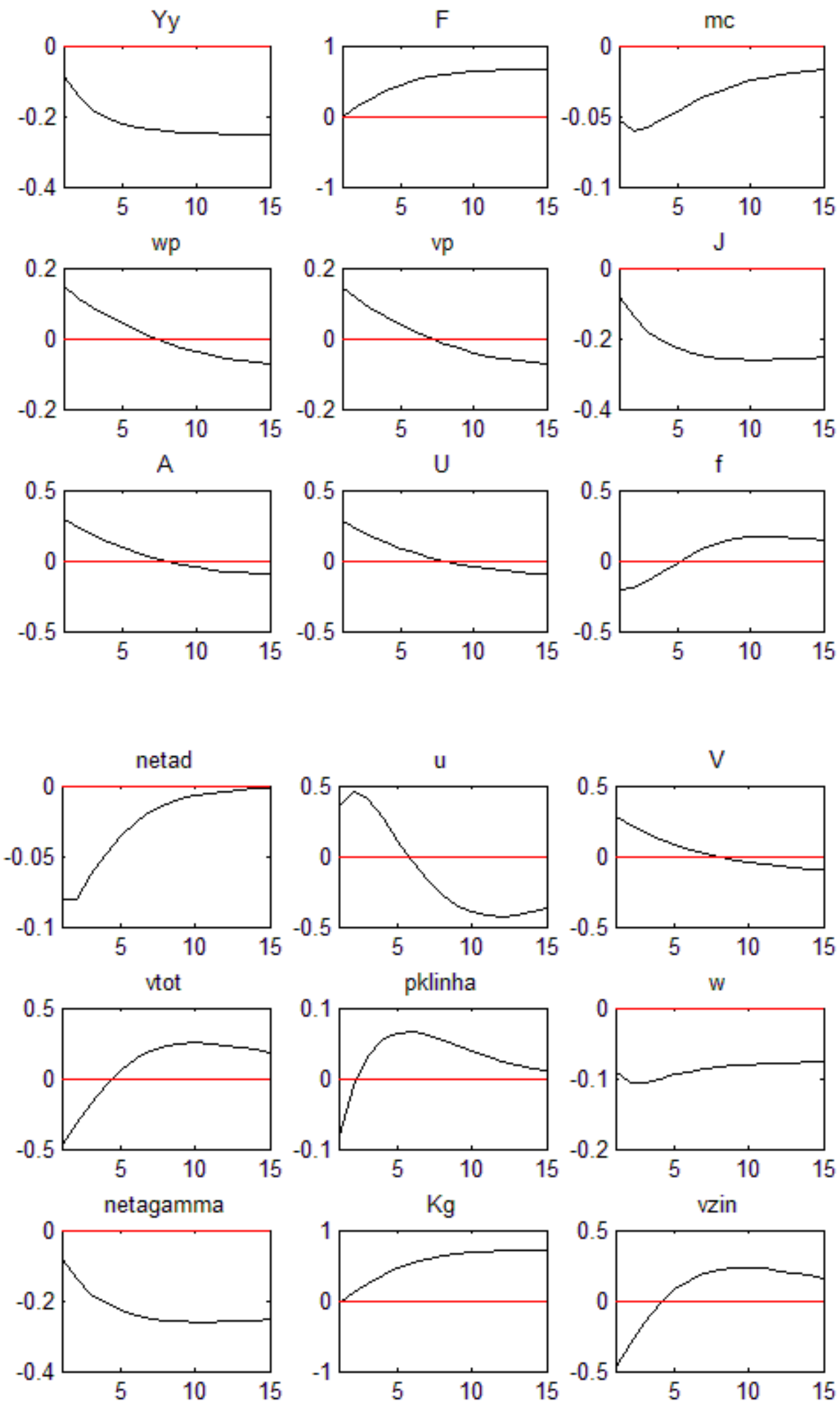


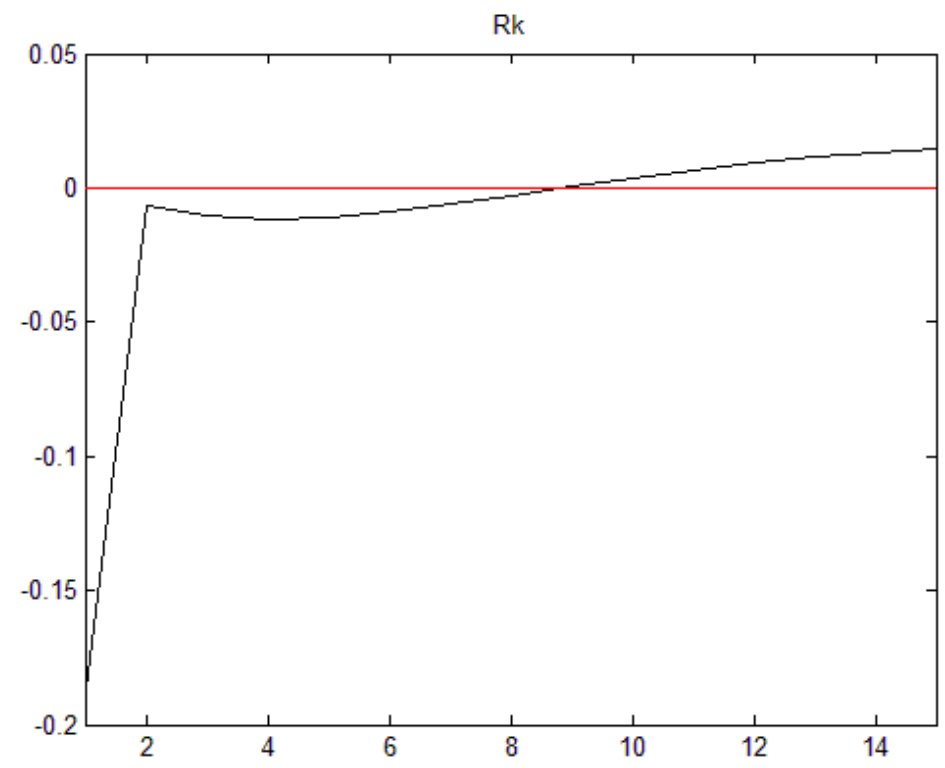

$\mathrm{Na}$ figura 16, temos as repostas ao choque neutro de investimento/tecnologia. Assim como em Christiano, Eichenbaum e Trabandt (2013) observamos que há uma forte queda da inflação (pi) e um movimento de redução significativo do desemprego (u) ao longo do tempo puxado pelo aumento do job finding rate (f) e da criação de vagas (vzin). Com este choque positivo, o valor para firma (vp) sobe e isso a incentiva a contratar mais e a produzir mais ao longo do tempo.

Com relação à redução da inflação, este movimento é encontrado em Altig, Christiano, Eichenbaum e Linde (2011) e Paciello (2009). A redução do custo marginal $(\mathrm{mc})$ deve ajudar a explicar ao menos em parte este movimento. 
FIGURA 16 - RESPOSTA DAS VARIÁVEIS DO MODELO DE MÉDIO PORTE AO CHOQUE TECNOLÓGICO NEUTRO.
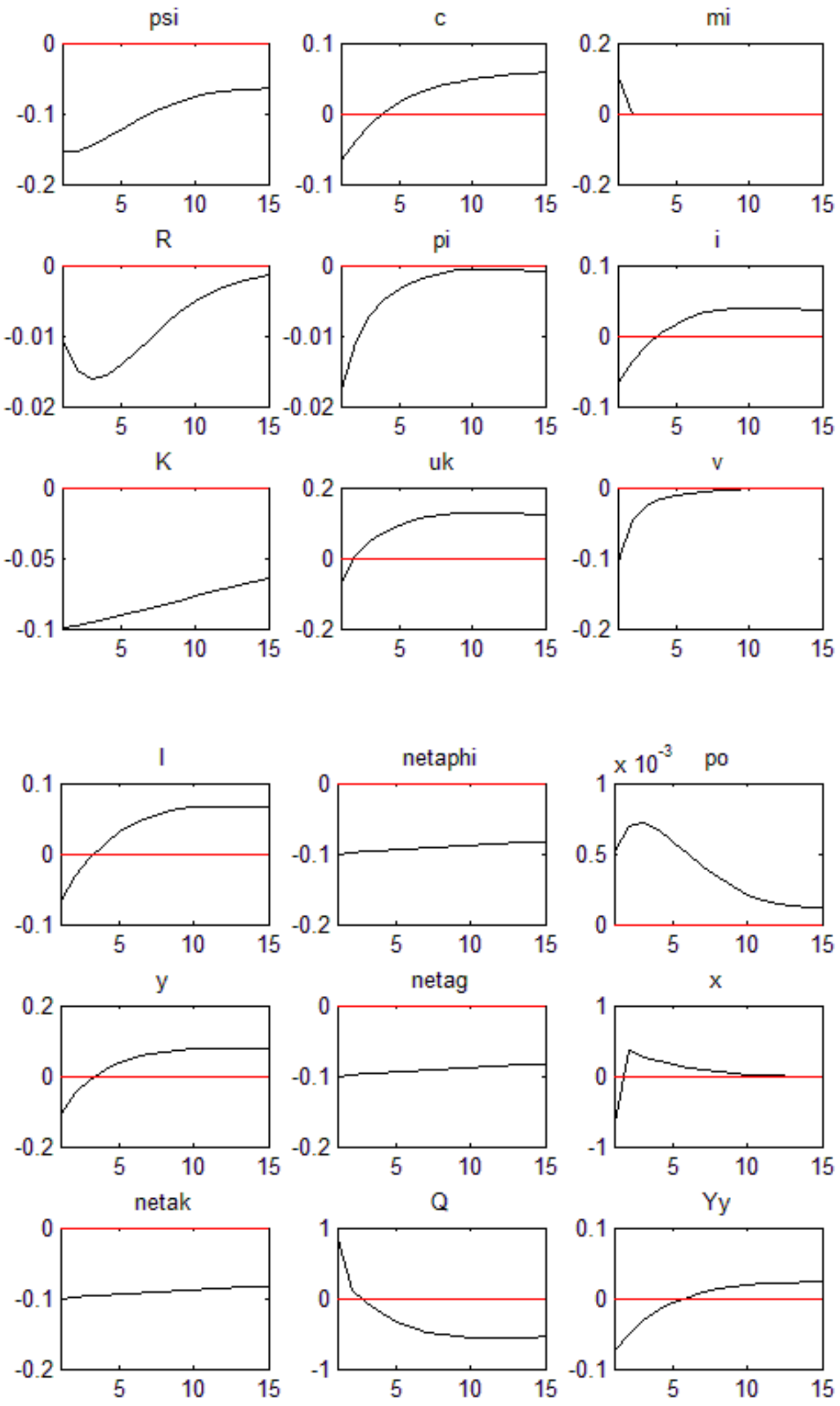

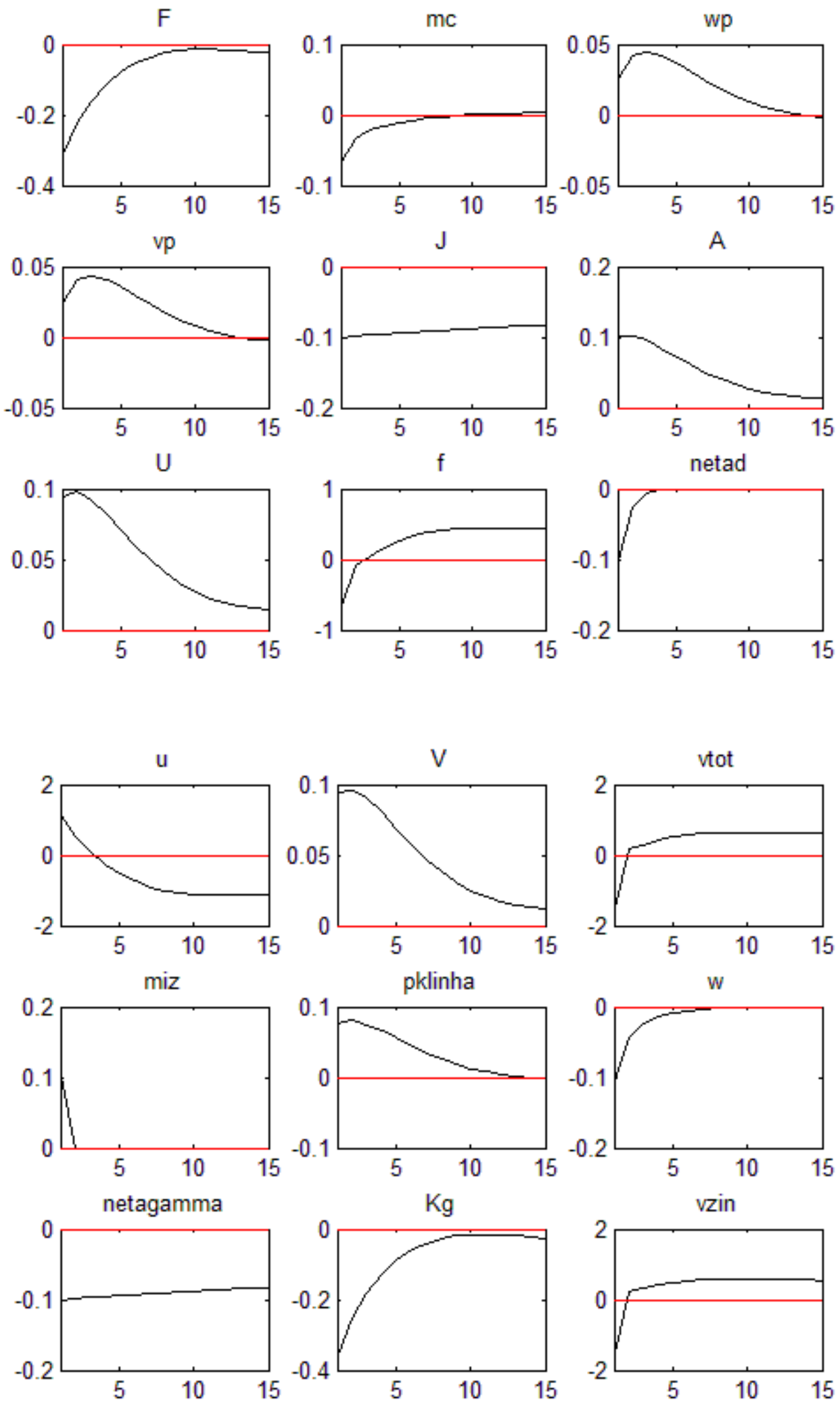


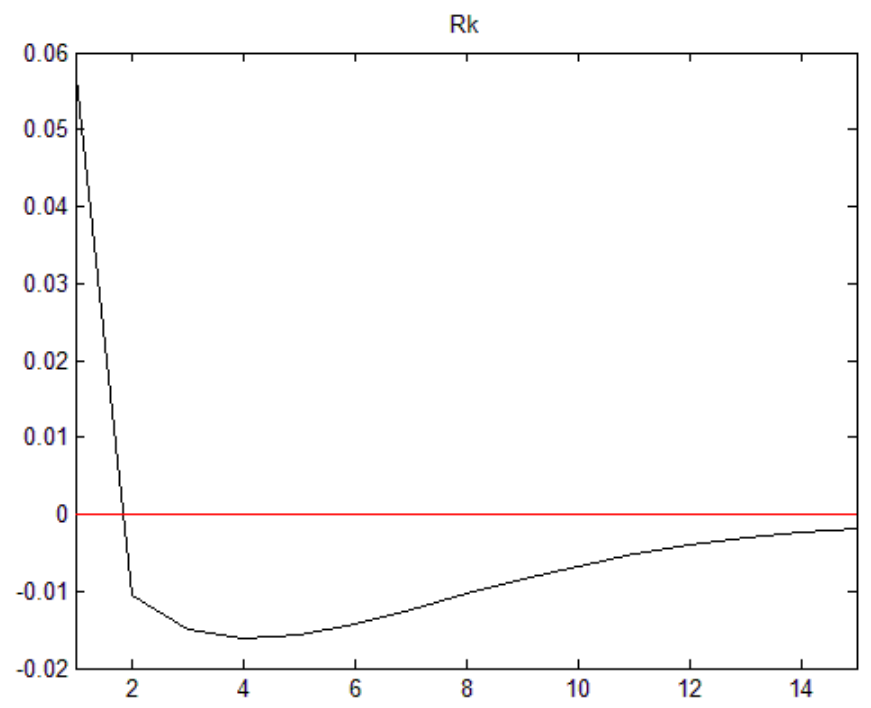

\subsubsection{Estimação Bayesiana dos Parâmetros}

Como destacamos anteriormente, fizemos as estimações bayesianas para nosso modelo básico cuja estrutura do mercado de trabalho fora construída sob o arcabouço dos modelos de searching (Alternating Offer Bargaining, aqui também chamado de Alt) e para o modelo novo keynesiano tradicional com rigidez de preços e salários (Sticky Wage, aqui também chamado de SW). As estimações foram feitas considerando dois conjuntos de dados, PIB real, inflação e taxa de juros (Selic) no primeiro caso (tabela 10) e PIB real, salários e taxa de juros (Selic) no segundo caso (tabela 11).

Conforme se pode notar na tabela 10, o valor estimado para a rigidez de preço foi de 0,58 para nosso modelo básico e de 0,75 para o modelo $S W$, com rigidez de preço e salário. Isso quer dizer que, no primeiro caso, em média, se observa reajuste de preços a cada 2,4 trimestres enquanto que no segundo caso (SW) se prevê, em média, que o reajuste de preços ocorra a cada três trimestres. Portanto, no caso do modelo com arcabouço mais detalhado para o mercado de trabalho se prevê uma maior frequência de alterações de preço, ou uma menor rigidez de preços.

TABELA 10 - ESTIMAÇÃO DOS PARÂMETROS COM O PRIMEIRO CONJUNTO DE DADOS

A PRIMEIRA COLUNA TRAZ OS NOMES DOS PARÂMETROS ENQUANTO A SEGUNDA OS DESCREVE. AS COLUNAS DE 3 A 5 MOSTRAM AS DISTRIBUIÇÕES PRIORS USADAS PARA CADA UM DOS PARÂMETROS, ASSIM COMO A MÉDIA O DESVIO PADRÃO DELAS. AS DUAS ÚLTIMAS COLUNAS, $8 \mathrm{E}$ 9, MOSTRAM A MODA E O DESVIO PADRÃO DAS DISTRIBUIÇÕES POSTERIORES DOS PARÂMETROS, 
ORIUNDA DA ESTIMAÇÃO BAYESIANA, PARA NOSSO MODELO BASE DENOMINADO "ALTERNATING OFFER BARGAINING" (ALT). POR FIM, AS COLUNAS 6 E 7 TRAZEM TAMBÉM A MODA E O DESVIO PADRÂO DAS DISTRIBUIÇÕES POSTERIORES PARA OS PARÂMETROS ESTIMADOS PARA O MODELO DE STICKY WAGE TRADICIONAL SEM INDEXAÇÃO (SW). NESTES DOIS CASOS, O CONJUNTO DE DADOS USADO PARA ESTIMAÇÃO FOI O HIATO ESTIMADO PELO FILTRO HP DA TAXA DE JUROS SELIC, DA TAXA DE INFLAÇÃO TRIMESTRAL COM AJUSTE SAZONAL E DO PRODUTO INTERNO BRUTO COM AJUSTE SAZONAL.

\begin{tabular}{|c|c|c|c|c|c|c|c|c|}
\hline \multirow{2}{*}{ parâmetros do modelo } & \multirow{2}{*}{ descrição } & \multicolumn{3}{|c|}{ Distribuições PRIORS } & \multicolumn{2}{|c|}{ Sticky Wage (SW) } & \multicolumn{2}{|c|}{ Alternating Offer Bargaining (Alt) } \\
\hline & & Distribuição & Média & Desvio padrão & moda & desvio padrão & moda & desvio padrão \\
\hline eps & price stickiness & beta & 0,65 & 0,1 & 0,75 & 0,076 & 0,58 & 0,034 \\
\hline lambda & price markup parameter & gamma & 1,1 & 0,1 & 1,133 & 0,050 & 1,049 & 0,011 \\
\hline rhor & taylor rule: smoothing & beta & 0,6 & 0,15 & 0,642 & 0,087 & 0,594 & 0,057 \\
\hline $\mathrm{rpi}$ & taylor rule: inflation & normal & 2 & 0,35 & 1,382 & 0,125 & 1,386 & 0,111 \\
\hline ry & taylor rule: gdp & gamma & 0,25 & 0,1 & 0,229 & 0,066 & 0,033 & 0,013 \\
\hline b & consumption habit & beta & 0,85 & 0,05 & 0,752 & 0,075 & 0,855 & 0,041 \\
\hline sigmaa & capacity utilization adj cost & gamma & 0,5 & 0,3 & 0,208 & 0,249 & 0,179 & 0,148 \\
\hline Spp & Investimento adj cost & gamma & 8 & 2 & 7,725 & 1,581 & 5,603 & 1,582 \\
\hline alpha & capital share & beta & 0,448 & 0,025 & 0,329 & 0,021 & 0,422 & 0,018 \\
\hline rhog & technology difussion - gov & beta & 0,5 & 0,2 & 0,355 & 0,172 & 0,460 & 0,066 \\
\hline rhod & technology difussion - D & beta & 0,5 & 0,2 & & & 0,703 & 0,132 \\
\hline deltapercent & $\begin{array}{l}\text { Probability of Bargaing } \\
\text { breakup }\end{array}$ & gamma & 0,5 & 0,4 & & & 0,181 & 0,113 \\
\hline D & replacement ratio & beta & 0,4 & 0,1 & & & 0,388 & 0,065 \\
\hline recsharepercent & hiring-search $\cos t / Y$ & gamma & 1 & 0,3 & & & 0,966 & 0,181 \\
\hline sigma & matching function parameter & beta & 0,5 & 0,1 & & & 0,487 & 0,066 \\
\hline sig_epsR & $\begin{array}{c}\text { Standard deviation monetary } \\
\text { policy } \\
\text { Standard deviation neutral }\end{array}$ & gamma & 0,65 & 0,05 & 0,455 & 0,047 & 0,457 & 0,033 \\
\hline $\begin{array}{l}\text { Sigmamiz } \\
\text { sigmamipsi }\end{array}$ & $\begin{array}{c}\text { tech } \\
\text { Standard deviation investiment } \\
\text { tech }\end{array}$ & gamma & $\begin{array}{l}0,1 \\
0,1\end{array}$ & $\begin{array}{l}0,05 \\
0,05\end{array}$ & $\begin{array}{l}0,146 \\
0,134\end{array}$ & $\begin{array}{l}0,034 \\
0,034\end{array}$ & $\begin{array}{l}0,203 \\
0,156\end{array}$ & $\begin{array}{l}0,024 \\
0,023\end{array}$ \\
\hline rhomipsi & AR(1) investiment tech & beta & 0,75 & 0,1 & 0,957 & 0,026 & 0,946 & 0,018 \\
\hline sigmal & Inv. Labor suply elasticity & gamma & 1 & 0,25 & 0,940 & 0,231 & & \\
\hline epsw & wage stickiness & beta & 0,75 & 0,1 & 0,486 & 0,068 & & \\
\hline $\begin{array}{l}\text { log data density [Laplace } \\
\text { aproximation] }\end{array}$ & & & & & & 365,74 & & 348,34 \\
\hline $\begin{array}{c}\text { Aceitação das cadeias de } \\
\text { markov }\end{array}$ & & & & & 2 cadeia & $(28,39 \%$ e $28,13 \%)$ & 2 cadeic & $31,85 \%$ e $32,20 \%)$ \\
\hline
\end{tabular}

Com relação aos parâmetros que estão na função de reação do banco central, temos que o termo de suavização é de 0,59 para o modelo base (Alt) e de 0,64 para o modelo SW. Já, o coeficiente de reação à inflação e o hiato do produto foi de 1,386 e 0,03 no primeiro caso e de 1,38 e 0,229 no segundo caso. Logo, observamos que nosso modelo Alt prevê uma suavização um pouco menor do movimento dos juros, 
uma reação significativamente menor ao hiato do produto e uma reação semelhante com relação à inflação, sempre comparando com modelo SW.

Comparando com o modelo SAMBA do Banco Central do Brasil temos: (i) o parâmetro de rigidez dos preços livres estimado pelos autores foi de 0,74, contra 0,75 por nós no caso do SW e 0,58 no Alt; ii) o parâmetro de suavização da regra de taylor é 0,79 , um pouco maior que os encontrados aqui; (iii) a reação ao hiato do produto tem coeficiente 0,16 , um pouco mais fraco que estimado por nós para SW e mais forte que o encontrado para o modelo Alt; e (iv), o coeficiente de reação à inflação é de 2,43, mais alto que os valores estimados por nós. Vale destacar ainda que parte destas diferenças, principalmente em relação à reação à inflação, pode ser explicada pelo fato de estarmos usando dados mais recentes na estimação, pois, neste período mais recente, a inflação ficou persistentemente acima do centro da meta de $4,5 \%$.

No que tange a participação do capital, o modelo SW estima 0,329 enquanto que o modelo Alt estima 0,42 , mais perto do valor de 0,448 calibrado para o modelo SAMBA.

No caso de nosso modelo base (Alt), podemos ainda destacar que a moda da posterior indica que há $0,18 \%$ de probabilidade de haver um fim exógeno nas negociações caso a oferta seja rejeitada. Este percentual é menor que a média da distribuição prior de 0,5\% e também menor que o 0,3\% encontrado por Christiano, Eichenbaum e Trabandt(2013), indicando que para o caso brasileiro parece ocorrer, em média, menos términos de negociações.

Por sua vez, a moda da posterior para o replacement ratio foi de 0,388 , menor que o 0,67 encontrado por Christiano, Eichenbaum e Trabandt(2013). Esta variável captura a renda necessária, em relação à renda que ele tinha no trabalho, para que um desempregado consiga manter mais ou menos o mesmo padrão de vida. Segundo Gertler, Sala e Trigari (2008) o intervalo entre 0,4 e 0,7 é razoável para esta variável. Como no Brasil, a taxa de poupança é bem pequena e as pessoas tem que se sustentar apenas com o seguro desemprego e/ou com trabalho informais, parece razoável um número baixo. Se fosse considerada a parte informal, provavelmente, teríamos um percentual maior.

Já, com relação ao parâmetro de rigidez de salário do modelo com stlcky wage, a moda da posterior foi de quase 0,49 , ou seja, o resultado indica que ocorre reajuste 
de salário praticamente a cada dois trimestres. No modelo do Banco Central do Brasil, a estimativa para este parâmetro foi de 0,75 , indicando que o reajuste ocorre com uma frequência menor.

Por fim, em termos de aceitação das cadeias de Markov, temos que ambas as estimativas tiveram êxito. Já, no que se refere ao valor da verossimilhança marginal, percebemos que o modelo SW levou ligeira vantagem sobre nosso modelo básico, indicando que ele se adequa um pouco melhor ao mesmo conjunto de dados.

Como nosso modelo base tem o mercado de trabalho desagregado, a ausência de uma variável observável do mercado de trabalho na estimação pode ter contribuído para o fato de nosso modelo Alt ter tido uma verossimilhança pior do que a do modelo clássico de sticky wage. Por isso, optamos por fazer uma estimação com salário a fim de ver como a diferença entre os modelos reagem. Assim, a tabela 11 traz a moda e o desvio padrão para os mesmos parâmetros considerando ambos os modelos, mas agora fazendo a estimativa considerando o PIB real, a taxa de juro (Selic) e o salário real ao invés da inflação. 
TABELA 11 - ESTIMAÇÃO DOS PARÂMETROS COM O SEGUNDO CONJUNTO DE DADOS

A PRIMEIRA COLUNA TRAZ OS NOMES DOS PARÂMETROS ENQUANTO A SEGUNDA OS DESCREVE. AS COLUNAS DE 3 A 5 MOSTRAM AS DISTRIBUIÇÕES PRIORS USADAS PARA CADA UM DOS PARÂMETROS, ASSIM COMO A MÉDIA E O DESVIO PADRÃO DELAS. AS DUAS ÚLTIMAS COLUNAS, 8 E 9, MOSTRAM A MODA E O DESVIO PADRÃO DAS DISTRIBUIÇÕES POSTERIORES DOS PARÂMETROS, ORIUNDA DA ESTIMAÇÃO BAYESIANA, PARA NOSSO MODELO BASE DENOMINADO "ALTERNATING OFFER BARGAINING" (ALT). POR FIM, AS COLUNAS 6 E 7 TRAZEM TAMBÉM A MODA E O DESVIO PADRÃO DAS DISTRIBUIÇÕES POSTERIORES PARA OS PARÂMETROS ESTIMADOS PARA O MODELO DE SITCKY WAGE TRADICIONAL SEM INDEXAÇÃO (SW). NESTES DOIS CASOS, O CONJUNTO DE DADOS USADO PARA ESTIMAÇÃO FOI O HIATO ESTIMADO PELO FILTRO HP DA TAXA DE JUROS SELIC, DOS SALÁRIOS E DO PRODUTO INTERNO BRUTO COM AJUSTE SAZONAL.

\begin{tabular}{|c|c|c|c|c|c|c|c|c|}
\hline \multirow{2}{*}{ parâmetros do modelo } & \multirow{2}{*}{ descrição } & \multicolumn{3}{|c|}{ Distribuições PRIORS } & \multicolumn{2}{|c|}{ Sticky Wage (SW) } & \multicolumn{2}{|c|}{ Alternating Offer Bargaining (Alt) } \\
\hline & & Distribuição & Média & Desvio padrão & moda & desvio padrão & moda & desvio padrão \\
\hline eps & price stickiness & beta & 0,65 & 0,1 & 0,888 & 0,051 & 0,679 & 0,117 \\
\hline lambda & price markup parameter & gamma & 1,1 & 0,1 & 1,202 & 0,045 & 1,143 & 0,083 \\
\hline rhor & taylor rule: smoothing & beta & 0,6 & 0,15 & 0,515 & 0,106 & 0,693 & 0,091 \\
\hline rpi & taylor rule: inflation & normal & 2 & 0,35 & 1,855 & 0,141 & 2,232 & 0,257 \\
\hline ry & taylor rule: gdp & gamma & 0,25 & 0,1 & 0,067 & 0,040 & 0,149 & 0,057 \\
\hline$b$ & consumption habit & beta & 0,85 & 0,05 & 0,568 & 0,099 & 0,796 & 0,040 \\
\hline sigmaa & capacity utilization adj cost & gamma & 0,5 & 0,3 & 0,191 & 0,297 & 0,052 & 0,032 \\
\hline Spp & Investimento adj cost & gamma & 8 & 2 & 9,202 & 2,100 & 8,063 & 3,052 \\
\hline alpha & capital share & beta & 0,448 & 0,025 & 0,355 & 0,026 & 0,434 & 0,008 \\
\hline rhog & technology difussion - gov & beta & 0,5 & 0,2 & 0,412 & 0,180 & 0,743 & 0,152 \\
\hline rhod & technology difussion - $\mathrm{D}$ & beta & 0,5 & 0,2 & & & 0,044 & 0,017 \\
\hline deltapercent & Probability of Bargaing breakup & gamma & 0,5 & 0,4 & & & 0,179 & 0,313 \\
\hline D & replacement ratio & beta & 0,4 & 0,1 & & & 0,391 & 0,102 \\
\hline recsharepercent & hiring-search cost/Y & gamma & 1 & 0,3 & & & 0,912 & 0,270 \\
\hline sigma & matching function parameter & beta & 0,5 & 0,1 & & & 0,499 & 0,106 \\
\hline sig_epsR & $\begin{array}{l}\text { Standard deviation monetary } \\
\text { policy }\end{array}$ & gamma & 0,65 & 0,05 & 0,480 & 0,043 & 0,469 & 0,036 \\
\hline sigmamiz & Standard deviation neutral tech & gamma & 0,1 & 0,05 & 0,151 & 0,056 & 0,151 & 0,087 \\
\hline sigmamipsi & $\begin{array}{c}\text { Standard deviation investiment } \\
\text { tech }\end{array}$ & gamma & 0,1 & 0,05 & 0,197 & 0,057 & 0,170 & 0,049 \\
\hline rhomipsi & $\mathrm{AR}(1)$ investiment tech & beta & 0,75 & 0,1 & 0,804 & 0,039 & 0,857 & 0,033 \\
\hline sigmal & Inv. Labor suply elasticity & gamma & 1 & 0,25 & 0,976 & 0,370 & & \\
\hline epsw & wage stickiness & beta & 0,75 & 0,1 & 0,921 & 0,051 & & \\
\hline $\begin{array}{l}\text { log data density [Laplace } \\
\text { aproximation] }\end{array}$ & & & & & & 326,08 & & \\
\hline $\begin{array}{c}\text { Aceitação das cadeias de } \\
\text { markov }\end{array}$ & & & & & 2 cadeia & $32,99 \%$ e $34,82 \%)$ & 2 cadeias & $\%$ e $31,70 \%)$ \\
\hline
\end{tabular}

Como esperado, a diferença entre as verossimilhanças do modelo base (Alt) e do SW diminuiu significativamente, embora o SW ainda seja maior, indicando melhor adequação aos dados. Provavelmente, a inclusão de uma variável do mercado de 
trabalho levou à uma melhor identificação do nosso modelo com maior estrutura do mercado de trabalho.

Com relação aos parâmetros, como se pode observar, quando comparamos o modelo Alternating Offer Bargainging aqui estimado com o estimado anteriormente, temos que com este conjunto de dados os preços são reajustados a cada 2,7 trimestres, ou seja, um pouco mais frequentemente que o anterior.

Por sua vez, o parâmetro de suavização dos juros é maior $(0,69)$ assim como a resposta da autoridade monetária ao PIB real $(0,149)$ e à inflação $(2,23)$. Portanto, neste segundo caso, a autoridade monetária reage mais aos desvios da inflação e do produto. Com relação aos parâmetros do mercado de trabalho, temos estimativas semelhantes para o fim das negociações quando a oferta é rejeitada $(0,179 \%)$, para o replacement ratio (D) e para o parâmetro da função matching (sigma).

Por fim, quando olhamos os valores estimados para os parâmetros do modelo SW, notamos grandes alterações em relação aos valores estimados usando o primeiro conjunto de dados. Primeiro tanto a rigidez de preços (eps) quanto a de salários (epsw) aumentaram significativamente. De fato, em média, ocorre reajuste integral de preço a cada 8,9 trimestres enquanto que os salários se reajustam a cada 12 trimestres. Tais frequências de atualizações estão muito acima daquelas encontras na literatura. Por exemplo, Santos (2013) encontrou reajuste de preços a cada 3,7 trimestres e de salários a cada 2,8 trimestres. Segundo, o parâmetro de suavização da taxa de juro (rhor) é menor enquanto que a autoridade monetária reage mais à inflação (rpi) e menos ao produto (ry).

\subsection{DESABILITANDO ALGUMAS RIGIDEZES}

Outro objetivo do trabalho é saber se ao introduzirmos esta estrutura mais completa e complexa para o mercado de trabalho há algum ganho na propagação de uma choque de política monetária. Isto é, queremos saber se com tal aparato podemos desligar algumas rigidezes que existem no modelo e mesmo assim garantir que a propagação de um choque se dê de modo satisfatório.

No modelo temos rigidezes como: de preços, custo de ajustamento do investimento, utilização do capital, hábito de consumo e working capital channel. Vamos então desligar primeiro a utilização do capital e, posteriormente, o canal de crédito para 
financiar a folha de pagamento (working capital channel) e vamos comparar a propagação dos choques de política monetária com a situação onde tudo está ligado.

O desligamento do working capital channel foi feito de modo direto. Isto é, foi eliminada a hipótese de que as firmas tomam emprestado para pagar seus funcionários e pagam, posteriormente, este empréstimo com juro.

Já, o desligamento da utilização do capital foi feito seguindo Christiano, Eichenbaum e Evans(2005). Eles mostram que a elasticidade entre usar capital e taxa de juro depende do parâmetro "sigma a" que faz parte da função utilização do capital. Quanto menor o valor de "sigma a", maior é a elasticidade. E, quanto maior seu valor, menor é a elasticidade. No nosso caso depende de "sigma a" e "sigma b". Mas colocando "sigma a" muito grande temos que esta elasticidade diminui muito de forma que não há decisão por alterar a utilização do capital.

Os gráficos com as funções impulso resposta ao choque de política monetária para o modelo normal e para os modelos com tais alterações seguem na figura 17.

Antes, vale destacar que o conjunto de parâmetros considerado para tais funções foi estimado para cada um dos modelos e foram usados para fazer as funções impulso resposta (os parâmetros estimados seguem na tabela 12 ). ${ }^{13}$.

$\mathrm{Na}$ figura 17, modelo I se refere ao modelo completo, o modelo II é o modelo sem utilização do capital e o modelo III se refere ao modelo sem o working capital channel (firmas tomando recursos emprestados para pagar a folha de salário).

Como se pode notar, quando se tira estas rigidezes, as respostas ao choque de política monetária ficam muito menos inerciais. As respostas são mais rápidas. $\mathrm{O}$ modelo mais completo para o mercado de trabalho parece não conseguir compensar a ausência destas rigidezes.

\footnotetext{
${ }^{13} \mathrm{O}$ único problema ocorreu com o parâmetro de resposta ao produto (ry). Isso porque usamos a moda dos parâmetros estimados para calibrar o modelo e todos funcionaram menos este ry, que quando usado na moda levava a não satisfazer a condição de Blanchard e Khan (para os modelos sem utilização do capital e sem o canal de empréstimo de recursos pela firma). Para contornar este problema optou-se por usar a média ao invés da moda que também não resolveu. Em vista disso, ao invés de usar um número arbitrário, decidiu-se por usar o piso do intervalo de estimação de $90 \%$ do HPD para os três modelos. Com isso conseguimos sair deste problema de indeterminação.
} 
FIGURA 17 - RESPOSTA DAS VARIÁVEIS DO MODELO DE MÉDIO PORTE AO CHOQUE DE POLÍTICA MONETÁRIA.

O MODELO I SE REFERE AO MODELO COMPLETO, O MODELO II É O MODELO SEM UTILIZAÇÃO DO CAPITAL E O MODELO III SE REFERE AO MODELO SEM O WORKING CAPITAL CHANNEL (FIRMAS TOMANDO RECURSOS EMPRESTADO PARA PAGAR A FOLHA DE SALÁRIO).
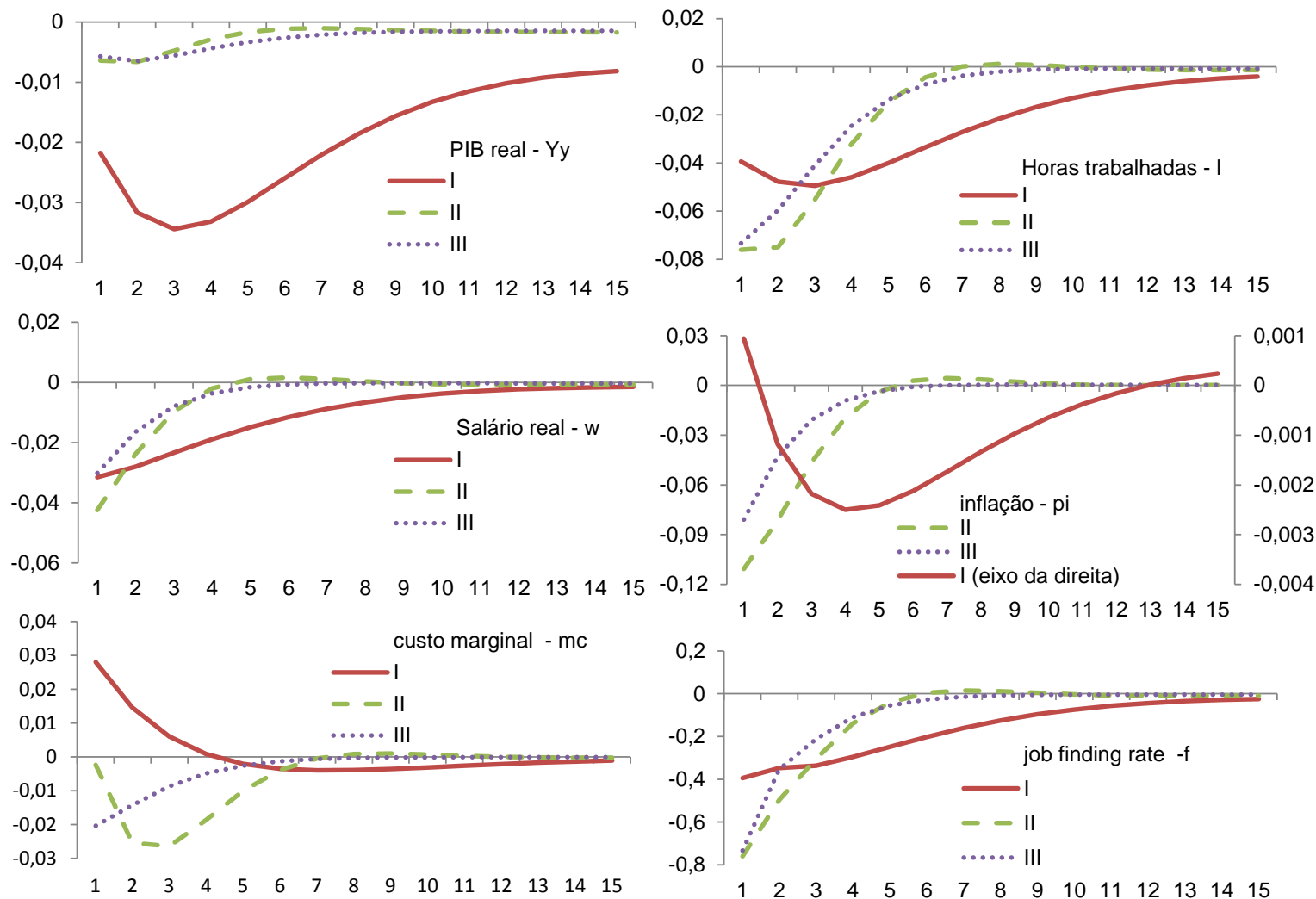

$\begin{array}{lllllllllllllll}1 & 2 & 3 & 4 & 5 & 6 & 7 & 8 & 9 & 10 & 11 & 12 & 13 & 14 & 15\end{array}$
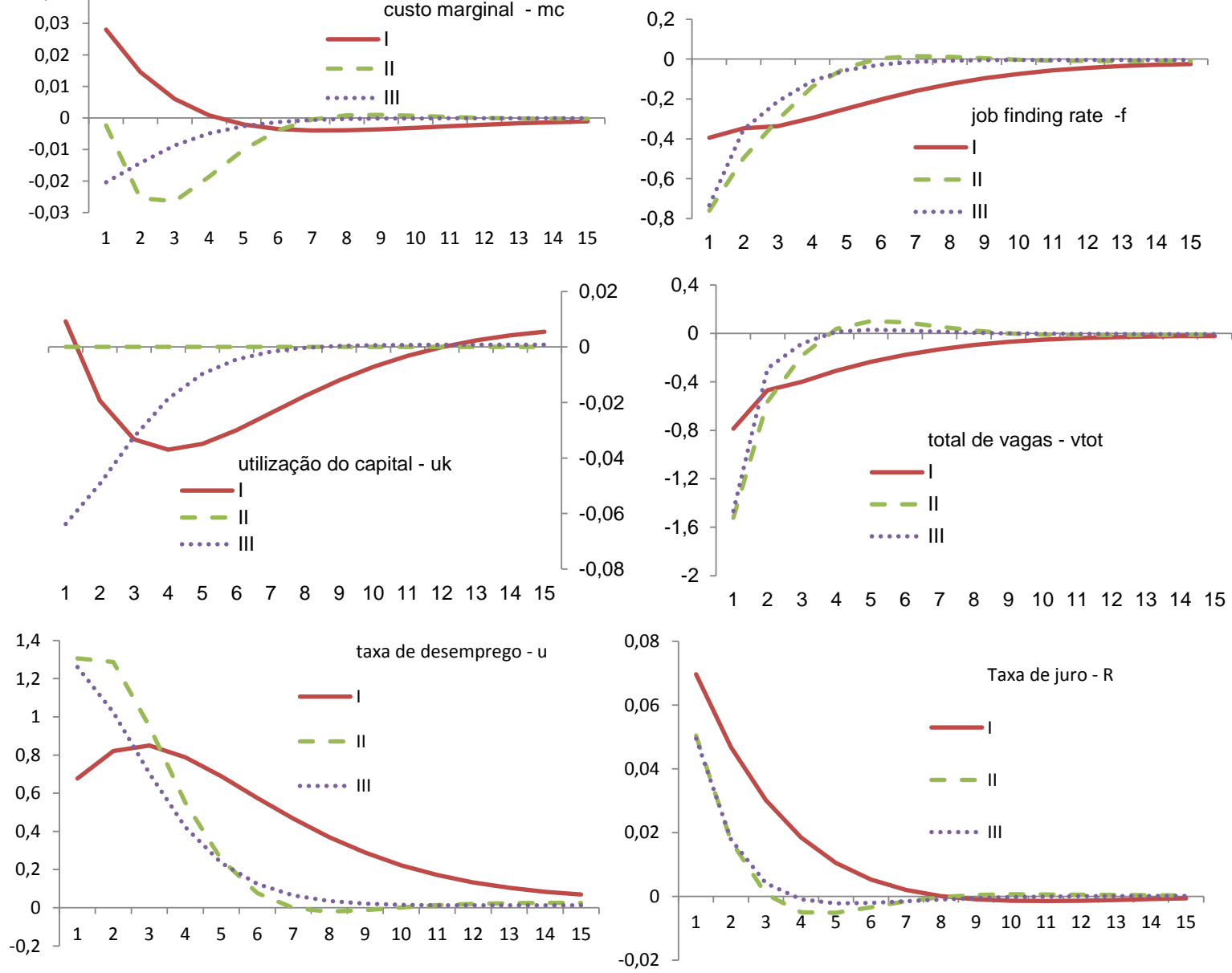
Podemos notar que quando temos o modelo completo (I), perante o choque de política monetária contracionista, o PIB real cai assim como as horas trabalhadas e o salário real. Como as firmas emprestam recursos, o custo sobe, portanto, sobe seu custo marginal. Isso implica numa inflação até positiva no instante inicial e em queda posteriormente dado o impacto que o aumento do juro tem sobre a atividade e inflação.

Como a dinâmica econômica fica mais adversa o incentivo para as empresas contratarem diminui e, com isso, o desemprego aumenta. Mas conforme a atividade piora e a inflação cai, o juro recua e o incentivo a novas contratações vai aumentado de forma que o desemprego recua ao longo do tempo.

Quando tiramos do modelo a utilização do capital, temos então o modelo II, a dinâmica não é tão suave assim. Com aumento do juro, a atividade piora assim como as novas contratações. Embora o juro esteja na função custo da empresa, a piora na atividade é tão grande que o custo marginal cai. A queda do salário real explica também este movimento. Com esta piora na atividade, as horas trabalhadas despencam e o desemprego sobe muito. Neste contexto, a inflação desaba. Tudo isso num curto espaço de tempo. Apesar disso, o impacto no PIB é menor que no modelo I, resultado parecido ao encontrado em Christiano, Eichenbaum e Evans (2005) quando desligam este mesmo canal de seu modelo ${ }^{14}$.

Mas conforme o juro recua, aqui bem mais rapidamente, a atividade vai retornando ao normal. Ou seja, diferentemente do modelo I, aqui não temos o formato hump shaped das variáveis que normalmente é observado.

Por fim, quando tiramos o working capital channel, o modelo III nas figuras, temos uma situação parecida com a do modelo II. A diferença é que como o juro não está no custo da empresa. No primeiro momento, com a queda da atividade em função de um choque de aumento de juro, o emprego piora, os salários caem assim como o custo marginal. A inflação aqui cai rapidamente (tanto neste como no caso do modelo II o movimento da inflação é bem mais acentuado que no modelo I). Mas,

\footnotetext{
${ }^{14}$ Conforme está neste artigo: "notice that que the outuput effect of a monetary shock is roughly cut in halt when variable capital utilization is dropped from the model".
} 
como se pode fazer o ajuste na utilização do capital, os impactos sobre estas variáveis são mais suaves que no caso anterior.

Aqui, novamente, conforme a inflação cai, o juro recua e a atividade vai melhorando, assim como o mercado de trabalho. Os movimentos, assim como no modelo II são mais rápidos, isto é, menos inerciais e persistentes que os observados no modelo I. Portanto, podemos observar que ao desligarmos a rigidez da utilização do capital e a do working capital channel, o modelo mais completo, maior e mais detalhado para mercado de trabalho, parece não ser capaz de dar conta do movimento inercial e persistente observado para as variáveis macroeconômicas como PIB e inflação.

Por fim, ainda, como se pode notar na tabela 12 que traz os parâmetros estimados, quando tiramos a utilização do capital e o working capital channel, o parâmetro que mede a rigidez de preço do modelo (eps) recua muito. O que mostra que o modelo fica muito menos inercial, o que não é razoável dado que a literatura normalmente encontra uma duração de preços bem maior.

TABELA 12 - PARÂMETROS ESTIMADOS PARA OS MODELOS I, II E III.

O MODELO I SE REFERE AO MODELO COMPLETO, O MODELO II É O MODELO SEM UTILIZACÃO DO CAPITAL E O MODELO III SE REFERE AO MODELO SEM O WORKING CAPITAL CHANNEL (FIRMAS TOMANDO RECURSOS EMPRESTADO PARA PAGAR A FOLHA DE SALÁRIO).

\begin{tabular}{|c|c|c|c|c|}
\hline \multirow{2}{*}{$\begin{array}{l}\text { Parâmetros do } \\
\text { modelo }\end{array}$} & \multirow{2}{*}{ Descrição } & \multicolumn{3}{|c|}{ Parâmetros estimados (moda) } \\
\hline & & Modelo I & Modelo II & Modelo III \\
\hline eps & price stickiness & 0,68 & 0,27 & 0,22 \\
\hline lambda & price markup parameter & 1,14 & 1,03 & 1,02 \\
\hline rhor & taylor rule: smoothing & 0,69 & 0,81 & 0,73 \\
\hline rpi & taylor rule: inflation & 2,23 & 1,48 & 1,54 \\
\hline ry *** & taylor rule: gdp & 0,15 & 0,17 & 0,22 \\
\hline b & consumption habit & 0,80 & 0,93 & \\
\hline sigmaa & capacity utilization adj cost & 0,05 & & \\
\hline Spp & Investimento adj cost & 8,06 & 9,15 & \\
\hline alpha & capital share & 0,43 & 0,38 & 0,38 \\
\hline rhog & technology difussion - gov & 0,74 & 0,56 & 0,53 \\
\hline rhod & technology difussion - D & 0,04 & 0,35 & 0,43 \\
\hline deltapercent & Probability of Bargaing breakup & 0,18 & 0,18 & 0,18 \\
\hline D & replacement ratio & 0,39 & 0,39 & 0,39 \\
\hline recSHARE & hiring-search cost $/ Y$ - & 0,91 & 0,91 & 0,91 \\
\hline sigma & matching function parameter - & 0,50 & 0,50 & 0,50 \\
\hline sig_epsR & Standard deviation monetary policy & 0,47 & 0,55 & 0,56 \\
\hline sigmamiz & Standard deviation neutral tech & 0,15 & 0,15 & 0,15 \\
\hline sigmamip & Standard deviation investiment tech & 0,17 & 0,15 & 0,15 \\
\hline rhomipsi & $\mathrm{AR}(1)$ investiment tech & 0,86 & 0,84 & 0,81 \\
\hline
\end{tabular}

*** modelo II e III não satifizeram as condições de Blanchard e Khan para a moda e também para média, por isso optou-se por suar o piso do intervalo $90 \%$ HPD. Os valores são de 0,0661 para o modelo I, de 0,0813 para o modelo II e de 0,0626 para o III 


\subsection{CONCLUSÃO}

Neste trabalho log-linearizamos e estimados o modelo de Christiano, Eichenbaum e Trabandt (2013) para o Brasil. Este modelo difere dos modelos novos keynesianos tradicionais ao colocar uma estrutura de searching (busca) para o mercado de trabalho. Com isso, a rigidez de salário não é assumida como algo exógeno. Ela surge em equilíbrio como resultado de um processo de barganha bilateral entre os trabalhadores desempregados e as firmas.

O modelo foi calibrado considerando o máximo de dados possíveis para o Brasil. As funções resposta ao impulso, por exemplo, a um choque contracionista de política monetária mostraram que o modelo dá conta da persistência e da dinâmica esperada para o crescimento do PIB real, da inflação e desemprego. Inicialmente se observa uma deterioração, com posterior melhora. Esta dinâmica é observada nos modelos novos keynesianos tradicionais. O diferencial aqui é que se consegue analisar a resposta de variáveis importantes do mercado de trabalho, como, por exemplo, a criação de vagas e empregos, algo que não se consegue observar nos modelos novos keynesianos tradicionais.

Quando partimos para a estimação do modelo, os valores estimados mostram que no geral nosso modelo indica que os preços no Brasil são reajustados com uma frequência menor do que a frequência indicada pelos modelos novos keynesianos com rigidez de preços e salários. Ademais, existem algumas diferenças nos valores estimados de alguns parâmetros, como, por exemplo, os da função de reação do Banco Central. Por fim, com nosso modelo base conseguimos estimar parâmetros importantes do mercado de trabalho como a probabilidade das negociações terminarem ou o replacement ratio, algo impossível nos modelos tradicionais.

Quando comparamos estatisticamente nosso modelo base que possui estrutura de busca no mercado de trabalho com o modelo tradicional com rigidez de preços e salários, encontramos que o modelo tradicional apresenta uma melhor aderência aos dados. Portanto, assim como encontrou Rogerson e Shimer (2010), nosso artigo mostrou que ao introduzir estrutura de searching no mercado de trabalho não observamos ganhos claros de primeira ordem para a análise do comportamento cíclico dos agregados macroeconômicos. 
Além disso, quando desligarmos a rigidez da utilização do capital e a do working capital channel, o modelo mais completo, maior e mais detalhado para mercado de trabalho, parece não ser capaz de dar conta do movimento inercial e persistente observado para as variáveis macroeconômicas como PIB e inflação.

Assim, caso o objetivo seja somente analisar impactos do choque de política monetária sobre variáveis como PIB e Inflação, os resultados mostram que não há ganho evidente na utilização do modelo mais complexo e completo que inclui esta maior estrutura para o mercado de trabalho. Apesar disso, existem algumas vantagens em se utilizar estes tipos de modelo que são: (i) tem-se uma estrutura que gere a rigidez de salário em equilíbrio ao invés de adotar isso como hipótese exógena; (ii) consegue-se entender a dinâmica de variáveis importantes do mercado de trabalho ao longo de um choque; e, (iii) pode-se estudar políticas que afetem o mercado de trabalho. 


\section{ESTIMATINA ALTERNATIVA DO MODELO DE CHRISTIANO, EICHENBAUM E TRABANDT (2013) PARA OS EUA}

\subsection{INTRODUÇÃO}

Como exposto na segunda parte, Christiano, Eichenbaum e Trabandt(2013) propuseram um modelo macroeconômico que une a literatura de searching no mercado de trabalho, que prevê um processo complexo e custoso de ajuste, aos modelos novos keynesianos. Nele os autores consideram variáveis do mercado de trabalho (salário, emprego, vagas, desemprego entre outras) e não assumem exogenamente que os salários estão sujeitos à rigidez nominal, ao contrário dos preços. Esta rigidez terá fundamentação teórica e ocorrerá em equilíbrio.

O modelo de mercado de trabalho seguirá o de Hall e Milgrom (2008) descrito anteriormente. Os desempregados e as empresas negociam tendo em mente que há um excedente e a negociação não acaba imediatamente quando ocorre um impasse. A conclusão sofrerá um atraso. Neste caso, a negociação é custosa para os dois lados, mas este custo é insensível ao estado agregado da natureza e esta característica será herdada pelos salários. Portanto, neste arcabouço, diante de um choque positivo, os salários sobem pouco e o incentivo para contratação aumenta e, por conseguinte, o desemprego cai. Como o custo marginal das empresas reage apenas moderadamente, o mesmo ocorre com a inflação, que será bastante inercial mesmo com uma pequena rigidez dos preços.

Nessa seção, vamos estimar bayesianamente o modelo construído por Christiano, Eichenbaum e Trabandt (2013) para os Estados Unidos, mas adotaremos uma estratégia de estimação diferente daquela utilizada por esses autores. Vamos loglinearizar o modelo para posteriormente estima-lo. Até onde temos conhecimento, isto não foi feito. A ideia é comparar os parâmetros estimados por nós com o original, assim como as funções impulso resposta a um choque de política monetária. Além disso, vamos ver como os parâmetros estimados evoluíram ao longo do tempo, ao estender a base de dados do final de 2008 para o final de 2014.

O artigo segue com a descrição do modelo DSGE básico na seção 3.2; na seção 3.3, com as alterações feitas no modelo base; a parte 3.4 traz uma explicação dos dados e das hipóteses utilizadas; já, a parte 3.5 mostra os resultados das 
estimações, enquanto que a seção 3.6 compara as funções impulso resposta. Por fim, a parte 3.7 traz as conclusões.

\subsection{MODELO DSGE DE MÉDIO PORTE}

O modelo utilizado neste trabalho foi o modelo desenvolvido por Christiano, Eichenbaum e Trabandt (2013) que consegue dar conta das respostas dos principais agregados macroeconômicos além de incluir variáveis do mercado de trabalho como salários, emprego, criação de vagas e desemprego. Este modelo desenvolvido por Christiano, Eichenbaum e Trabandt (2013) tem uma estrutura parecida ao Christiano, Eichenbaum e Evans(2005) mas foi modificado para incluir a estrutura de modelos de busca (searching) para o mercado de trabalho. Abaixo segue a explicação do modelo.

\subsubsection{Famílias e Bens de Produção}

Os autores seguem Andolfatto (1995) e Merz (1996) e assumem que cada família é composta por uma unidade de trabalhadores. Como o trabalho não entra na função utilidade, as pessoas não derivam nem utilidade nem desutilidade do trabalho, por isso, ofertam trabalho inelasticamente. $\mathrm{O}$ trabalhador empregado recebe salário real $\mathrm{w}_{\mathrm{t}}$ enquanto $\mathrm{o}$ desempregado recebe $\mathrm{D}$ bens de consumo do governo como compensação pelo desemprego (espécie de seguro desemprego). Os benefícios dos desempregados são financiados por impostos lump-sum pagos pelas famílias. Os trabalhadores maximizam a renda esperada em troca de um seguro perfeito para o consumo concedido pela família. Todos os trabalhadores têm a mesma preferência côncava sobre o consumo. Neste contexto, o acordo que garante o consumo ótimo é alocar o mesmo nível de consumo, $\mathrm{C}_{\mathrm{t}}$, para cada pessoa da família.

Cada família maximiza a seguinte preferência:

$$
E_{0} \sum_{t=0}^{\infty} \beta^{t} \ln \left(C_{t}-b C_{t-1}\right)
$$

Dado que há a suavização do consumo por parte das famílias, o parâmetro $b, 0 \leq b$ $<1$, controla o grau de persistência do consumo. Esta maximização é realizada sujeita a seguinte restrição orçamentária: 


$$
P_{t} C_{t}+P_{i, t} I_{t}+B_{t} \leq\left(R_{k, t} u_{t}^{k}-a\left(u_{t}^{k}\right) P_{i, t}\right) K_{t}+\left(1-l_{t}\right) P_{t} D_{t}+W_{t} l_{t}+R_{t-1} B_{t}-T_{t}
$$

Onde $C_{t}$ é consumo da família; $I_{t}$ é a compra de bens de investimento; $P_{t}$ é o preço do bem de consumo final e $P_{i, t}$ é o preço do bem de investimento; $W_{t}$ é o salário recebido pelos empregados; $T_{t}$ é o tributo lump-sum cobrado líquido de transferências; $D_{t}$ é a compensação recebida pelo trabalhador desempregado, que varia exogenamente no tempo; $\mathrm{B}_{\mathrm{t}+1}$ corresponde aos títulos do governo comprados em $t$ e que pagam taxa de juros $R_{t}$ no início de $t+1 ; e, R_{k, t}$ corresponde a renda nominal recebidas pelos serviços do capital. A variável $a\left(u_{t}^{k}\right)$ representa o custo, em unidades de bens de investimento, para se fazer a utilização $u_{t}^{k}$ do estoque de capital $K_{t}$. Por fim, $l_{t}$ corresponde a fração, $0 \leq l_{t} \leq 1$, das pessoas da família que está empregada.

Neste modelo, fica claro, que a decisão de trabalhar não afeta diretamente a utilidade das famílias, mas afeta sua restrição orçamentária. Com relação à função $a\left(u_{t}^{k}\right)$, ela é definida da seguinte forma:

$$
a\left(u_{t}^{k}\right)=0.5 \sigma_{a} \sigma_{b}\left(u_{t}^{k}\right)^{2}+\sigma_{b}\left(1-\sigma_{a}\right) u_{t}^{k}+\sigma_{b}\left(\frac{\sigma_{a}}{2}-1\right)
$$

Onde $\sigma_{a} e \sigma_{b}$ são escalares positivos. As famílias alugam o estoque de capital que possuem. Ele evolui segundo a seguinte lei:

$$
K_{t+1}=\left(1-\delta_{k}\right) K_{t}+\left[1-S\left(I_{t} / I_{t-1}\right)\right] I_{t}
$$

Com a função S(.), custo de ajustamento do investimento, sendo dada por:

$$
S\left(I_{t} / I_{t-1}\right)=0.5 \exp \left[\sqrt{S^{\prime \prime}}\left(\frac{I_{t}}{I_{t-1}}-\mu \mu_{\Psi}\right)\right]+0.5 \exp \left[-\sqrt{S^{\prime \prime}}\left(\frac{I_{t}}{I_{t-1}}-\mu \mu_{\Psi}\right)\right]-1
$$

Esta função é crescente e convexa. Os autores assumem que no estado estacionário tanto o valor que $\mathrm{S}($.) assume quanto o valor de sua primeira derivada é zero.

Neste modelo, o bem final é homogêneo e é produzido por firmas idênticas que atuam em um mercado perfeitamente competitivo e usam a seguinte tecnologia:

$$
Y_{t}=\left[\int_{0}^{1}\left(Y_{j, t}\right)^{\frac{1}{\lambda}} d_{j}\right]^{\lambda}
$$

Onde $\lambda>1$. A firma representativa escolhe insumo especializado $Y_{j, t}$ a fim de maximizar seu lucro: 


$$
P_{t} Y_{t}-\int_{0}^{1} P_{j, t} Y_{j, y} d_{j}
$$

sujeita a função de produção (3.6). A condição de primeira ordem para o insumo j é:

$$
Y_{j, t}=\left(P_{t} / P_{j, t}\right)^{\frac{\lambda}{\lambda-1}} Y_{t}
$$

Este insumo especializado é produzido por um varejista com a seguinte tecnologia:

$$
Y_{j, t}=k_{j, t}^{\alpha}\left(z_{t} h_{j, t}\right)^{1-\alpha}-\phi_{t}
$$

Este varejista é um monopolista na produção do bem especializado j, mas compra insumos em mercados de fatores competitivos. Na equação $3.9, \mathrm{k}_{\mathrm{j}, \mathrm{t}}$ corresponde à quantidade total de serviços de capital comprados pela empresa j. $\phi_{t}$ é o custo fixo de produção, exógeno, que cresce de forma a garantir uma trajetória balanceada de crescimento. Para tanto, este custo fixo é calibrado para se ter uma condição de lucro zero. $z_{t}$ é um choque tecnológico neutro. Por fim, $h_{j, t}$ é a quantidade de bens intermediários comprados pelo varejista j.

O bem intermediário é comprado em um mercado competitivo de um atacadista com preço, descontado os impostos, $P_{t}^{h}$. O problema enfrentado pelo atacadista será colocado adiante. Assim como em Christiano, Eichenbaum e Evans, Christiano, Eichenbaum e Trabandt (2013) assumem que para produzir no período t, o varejista tem que tomar emprestado $P_{t}^{h} h_{j, t}$ no início do período, pagando uma taxa de juros $R_{t}$. $O$ varejista paga este empréstimo no final do período t quando recebe sua receita das vendas. $O$ varejista j estabelece preço $P_{j, t}$ sujeito (i) a curva de demanda dada por (3.9) e, (ii), a fricção de rigidez de preço à la Calvo dada por :

$$
P_{j, t}=\left\{\begin{array}{l}
P_{j, t-1} \text { com probabilidade } \xi \\
\widetilde{P}_{t} \text { com probabilidade } 1-\xi
\end{array}\right.
$$

Em que $\widetilde{P_{t}}$ é o preço ótimo que é escolhido pela fração $1-\xi$ dos varejistas que têm a oportunidade de atualizar o preço. Não há indexação neste modelo, assim, a parcela $\xi$ dos produtores que não reotimizam o preço, mantem o preço vigente. 


\subsubsection{Atacadistas e mercado de trabalho}

Christiano, Eichenbaum e Trabandt (2013) tem por hipótese que há um grande número de atacadistas idênticos, competitivos que produzem um bem homogêneo usando trabalho. Seja $v_{t}$ a receita marginal de empregar um trabalhador adicional ${ }^{15}$. No início do período $t$, o atacadista paga um custo fixo $\mathrm{K}_{\mathrm{t}}$ que representa o custo para iniciar as negociações com probabilidade 1. Esta variável segue no modelo um processo estocástico exógeno, não correlacionado com os estados da economia. Uma vez que iniciam as negociações começa um processo de barganha bilateral. $E$ se este processo de barganha implicar em acordo, que segundo Christiano, Eichenbaum e Trabandt (2013) sempre ocorrerá em equilíbrio, o empregado começa a produzir imediatamente.

Cada atacadista emprega uma fração dos trabalhadores. $I_{t}$ é força de trabalho do atacadista representativo ao final de t. Esta força de trabalho em t é normalizada para 1. No final do período, aleatoriamente (e exogenamente) uma fração 1- $\rho$ dos empregados são separados das firmas, ou seja, passam a não ter mais emprego e, assim como os demais desempregados, passam a procurar trabalho. Portanto, ao final do período, uma fração $1-\rho l_{t}$ dos trabalhadores está procurando por trabalho. No período $t+1$ uma fração $f_{t+1}$ encontra uma firma para iniciar a barganha enquanto a fração complementar torna-se desempregada. Com probabilidade $\rho$, um trabalhador que está empregado em $t$ continua empregado na mesma firma em $t+1$. Com probabilidade (1- $\rho) \mathrm{f}_{t+1}$ este trabalhador se move para outra empresa em $t+1$. Enquanto que, com probabilidade $(1-\rho)\left(1-f_{t+1}\right)$, este trabalhador passa a ficar desempregado em $t+1$.

A medida de desemprego em $t$ utilizada é $1-\mathrm{I}_{\mathrm{t}}$ O movimento dos empregados que transitam entre uma empresa e outra, entre $t$ e $t+1$, é definida como movimento de emprego para emprego dentre os empregados. Dada esta especificação, os autores

${ }^{15}$ Эt segue um processo estocástico exógeno. 
relatam que este movimento é significativo e pró-cíclico, o que seria consistente com os dados para a economia dos EUA (Shimer(2005)). Assume-se também que a taxa segundo a qual um trabalhador deixa o emprego é acíclica e o período com o qual se trabalha é trimestral.

Seja $\omega_{t}^{p}$ o valor presente descontado dos salários pagos pelos atacadistas aos trabalhadores contratados:

$$
\omega_{t}^{p}=\omega_{t}+\rho E_{t} m_{t+1} \omega_{t+1}^{p}
$$

Onde $\omega_{\mathrm{t}}$ é o salário em $\mathrm{t}$; e, $\mathrm{m}_{\mathrm{t}+1}$ é a taxa de desconto que será determinada adiante. Seja $J_{t} 0$ valor para o atacadista de empregar um trabalhador adicional no período $t:$

$$
J_{t}=v_{t}^{p}-\omega_{t}^{p}
$$

Onde $v_{t}^{p}$ é o valor presente descontado esperado de $v_{t}$,

$$
v_{t}^{p}=v_{t}+\rho E_{t} m_{t+1} v_{t+1}^{p}
$$

Como há livre entrada no mercado de trabalho, que é competitivo, a firmas auferem lucro zero. Sendo assim, segue que:

$$
\kappa_{t}=J_{t}
$$

Ou seja, o custo e o ganho (valor) para atacadistas para conseguir empregar um novo trabalhador são iguais. Denota-se, também, por $V_{t} 0$ valor para um trabalhador ao ser contratado por uma firma que paga $\omega_{t}$ no período $t$ :

$$
V_{t}=\omega_{t}+E_{t} m_{t+1}\left[\rho V_{t+1}+(1-\rho)\left(f_{t+1} \overline{V_{t+1}}+\left(1-f_{t+1}\right) U_{t+1}\right)\right.
$$

Em que $\overline{V_{t+1}}$ denota $o$ valor de trabalhar para outra empresa no período $t+1$. Em equilíbrio, $\overline{V_{t+1}}=V_{t}$. Além disso, $\mathrm{U}_{\mathrm{t}+1}$ representa o valor de estar desempregado em $\mathrm{t}+1$. Rearranjando 3.15, tem-se:

$$
V_{t}=\omega_{t}^{p}+A_{t}
$$

Onde:

$$
A_{t}=(1-\rho) E_{t} m_{t+1}\left(f_{t+1} \overline{V_{t+1}}+\left(1-f_{t+1}\right) U_{t+1}\right)+\rho E_{t} m_{t+1} A_{t+1}
$$

Note que, em 3.16, $V_{t}$ é composto por dois componentes: o primeiro representa o valor presente esperado dos recebimento por parte de um trabalhador que foi contratado por um firma em t; e, o segundo componente, denota o valor presente esperado dos salários em todos os estados da natureza e em todos os períodos para um trabalhador que deixou a empresa.

O valor do desemprego, $\bigcup_{t}$, para os trabalhadores é dado por:

$$
U_{t}=D_{t}+\widetilde{U_{t}}
$$


Onde, $D_{t}$ corresponde aos bens recebidos pelos desempregados que segue um processo estocástico exógeno, que é não correlacionado com estados da economia. Já, $\widetilde{U_{t}}$ é o valor de continuar desempregado, qual seja:

$$
\widetilde{U_{t}} \equiv E_{t} m_{t+1}\left[f_{t+1} V_{t+1}+\left(1-f_{t+1}\right) U_{t+1}\right]
$$

Tanto $U_{t}$ quanto $V_{t}$ são definidas em unidades do bem final. $O$ número de trabalhadores empregados evolui assim:

$$
l_{t}=\left(\rho+x_{t}\right) l_{t-1}
$$

Em que $x_{t}$ é a taxa de contratação de trabalhadores em t. Deste modo, o número de novos empregados no período $t$ é igual a $x_{t} l_{t-1}$. Para contratar $x_{t} t_{-1}$ trabalhadores, o atacadista deve colocar $x_{t} l_{t-1} / Q_{t}$ vagas, onde $Q_{t}$ denota a taxa de preenchimento de vagas agregada e os atacadistas a tomam como dada. Assume-se que não há custo para abrir vagas.

A taxa segundo a qual um trabalhador desempregado encontra trabalho, $f_{t}$, é dada por:

$$
f_{t}=\frac{x_{t} l_{t-1}}{1-\rho l_{t-1}}
$$

$\mathrm{O}$ numerador representa o número de pessoas contratadas em $t$, enquanto $o$ denominador corresponde ao número de pessoas procurando emprego no final de t1. $x_{t}$ e $\left.\right|_{t-1}$ afetam as decisões do atacadista, mas são percebidas pelos indivíduos como dadas e fora de seu controle.

\subsubsection{Determinação do salário}

A especificação básica de Christiano, Eichenbaum e Trabandt (2013) assume barganha período a período. Isto é, trabalhadores e atacadistas barganham no período $\mathrm{t}$ sobre a taxa de salário em $\mathrm{t}$, pegando como dado o resultado das barganhas futuras que irão acontecer enquanto o trabalhador estiver na empresa. Os acordos dos salários futuros importam para negociação presente através do seu valor presente descontado, $\widetilde{\omega_{t}^{p}}$ :

$$
\widetilde{\omega_{t}^{p}} \equiv E_{t} \sum_{l=1}^{\infty} \rho^{l}\left[m_{t+1} \ldots m_{t+l}\right] \omega_{t+l}=\rho E_{t} m_{t+1} \omega_{t+1}^{p}
$$

O problema de barganha é o mesmo para todos os trabalhadores, independentemente do tempo em que eles estão na empresa. Este resultado advém 
das hipóteses de que o custo de contratação é fixo (sunk) no processo de barganha e de que a duração esperada do emprego na empresa que o contratou é o mesmo independente do tempo que o trabalhador já está na empresa.

Consistente com Hall e Milgrom (2008), Christiano, Eichenbaum e Trabandt (2013) relatam que os salários neste modelo são determinados de acordo com protocolo de barganha onde há alternância de ofertas (alternating offer bargaining protocol) proposto por Rubistein (1982) e Binmore, Rubinstein e Wolinsky (1986). Nele, cada período de tempo (um trimestre) é subdividido em M períodos de igual tamanho e $\mathrm{M}$ é par. Os atacadistas fazem a oferta de salário no início do primeiro subperíodo, assim como fazem as contrapropostas no início de cada período ímpar, caso a oferta anterior feita por eles tenha sido recusada. Já, os trabalhadores fazem suas ofertas no início dos períodos pares, caso tenham rejeitado a proposta feita pela empresa no período imediatamente anterior. Como $\mathrm{M}$ é par, a última oferta é feita, no estilo tudo ou nada, pelo trabalhador.

Entre 1 e M-1, o receptor das proposta pode aceitá-la ou rejeitá-la. Se a proposta for rejeitada, o trabalhador pode declarar encerrada a negociação ou ele pode fazer uma contra oferta no início do período seguinte. A probabilidade das negociações serem encerradas ao longo deste período é dada por $\delta$.

Considere um atacadista que faça uma proposta salarial $\omega_{\mathrm{s}, \mathrm{t}}$ no subperíodo $\mathrm{s}<\mathrm{M}$ e $\mathrm{s}$ é ímpar. Este estabelece o menor salário possível sujeito à restrição de que o trabalhador não rejeitará a oferta. A firma quer que o trabalhador aceite a proposta uma vez que a falta de acordo acarreta no atraso do início da produção. Então, é ótimo para o atacadista oferecer o menor salário sujeito ao fato de o trabalhador não o rejeitar. Assim, o salário ofertado satisfaz a seguinte condição de indiferença:

$$
V_{s, t}=\delta U_{s, t}+(1-\delta)\left[\frac{1}{M} D+V_{s+1, t}\right]
$$

Quando o trabalhador está indiferente entre aceitar ou rejeitar, ele aceita a proposta. O lado esquerdo de 3.23 corresponde ao valor para o trabalhador de aceitar a oferta:

$$
V_{s, t}=\omega_{s, t}+\widetilde{\omega_{t}^{p}}+A_{t}
$$

Em que $\widetilde{\omega_{t}^{p}}$ e $A_{t}$ são tomados como dados pelo par trabalhador-atacadista. Por sua vez, o lado direito de 3.23 corresponde ao payoff que o trabalhador terá caso rejeite a proposta e faça uma contra oferta. 
O primeiro termo do lado direito de $3.23\left(\delta U_{s, t}\right)$ representa a possibilidade de a negociação acabar exogenamente o que implicará que 0 trabalhador ficará desempregado. O valor de ficar desempregado, dado que houve o fim das negociações em um subperíodo $\mathrm{s}$, é dado por $\mathrm{U}_{\mathrm{s}, \mathrm{t}}$ :

$$
U_{s, t}=\frac{M-s+1}{M} D_{t}+\widetilde{U_{t}}
$$

Onde a primeira parte representa a hipótese segundo a qual os desempregados recebem seguro-desemprego (benefícios) no período t na proporção do número de subperíodos que eles ficaram desempregados.

Já, o segundo termo do lado direito da equação 3.23, por sua vez, reflete o fato de que com probabilidade $(1-\delta)$ o trabalhador receberá os benefícios como desempregado pelo período $1 / \mathrm{M}$ dado que ele fez uma contraproposta $\omega_{s+1, t}$ e ele espera que a empresa aceite.

A equação 3.23 traz uma importante condição de indiferença assumindo que o payoff dos trabalhadores quando as negociações continuam excede o valor da opção de fora (no caso, de desemprego), que é obtido se houver o fim das negociações.

Pelo lado dos trabalhadores, considere o problema de um trabalhador que faz uma oferta $\omega_{s, t}$ no subperíodo $s$, onde $s<M$ e $s$ é par. Os trabalhadores querem que $o$ atacadista aceite a proposta, pois o atraso no acordo fará com que eles não recebam salário, cujo valor esperado excede o valor esperado dos benefícios recebidos pelos desempregados. Neste caso, é ótimo para os trabalhadores pedirem o maior salário possível restritos a condição de que a empresa não rejeite a oferta. A oferta resultante $\omega_{\mathrm{s}, \mathrm{t}}$ satisfará a seguinte condição de indiferença por parte da firma:

$$
J_{s, t}=\delta * 0+(1-\delta)\left[-\gamma_{t}+J_{s+1, t}\right]
$$

O lado esquerdo da equação 3.26 denota o valor para empresa ao aceitar a oferta $\omega_{\mathrm{s}, \mathrm{t},}$

$$
J_{s, t}=\frac{M-s+1}{M} \vartheta_{t}+\widetilde{\vartheta_{t}^{p}}-\left(\omega_{s, t}+\widetilde{\omega_{t}^{p}}\right)
$$

Onde,

$$
\widetilde{\vartheta_{t}^{p}} \equiv E_{t} \sum_{l=1}^{\infty} \rho^{l}\left[m_{t+1} \ldots m_{t+l}\right] \vartheta_{t+l}=\rho E_{t} m_{t+1} \vartheta_{t+1}^{p}
$$


O termo do lado direito da equação 3.27 representa o valor para a empresa ao aceitar a oferta proposta pelo trabalhador de forma que a produção comece imediatamente. Já, o termo $\frac{M-s+1}{M}$ reflete a hipótese segundo a qual o trabalhador produz 1/M bens em cada subperíodo em que há produção. Por sua vez, o termo $\widetilde{\vartheta_{t}^{p}}$ represente o valor presente esperado da receita marginal associada com 0 trabalhador, enquanto que $\left(\omega_{s, t}+\widetilde{\omega_{t}^{p}}\right)$ corresponde ao valor esperado pela firma dos salários a serem pagos para o trabalhador caso ela aceite a proposta $\omega_{\mathrm{s}, \mathrm{t}}$

A expressão do lado direito da equação 3.26 é o payoff da empresa ao não aceitar a oferta. Se a empresa não aceita a proposta feita pelo trabalhador com a intenção de fazer uma contraproposta, há uma probabilidade $\delta$ de a negociação ser encerrada e, neste caso, a firma vai para a opção de fora, que é produzir zero e cujo valor, portanto, é zero. Com probabilidade 1- $\delta$ a empresa fará uma nova oferta, $\omega_{\mathrm{s}+1, t}$,ao trabalhador no próximo subperíodo. Mas, para fazê-la, a empresa terá que arcar com custo $\mathrm{y}$. Entretanto, neste caso, há um benefício, $J_{s+1, t}$, associado ao sucesso desta contraoferta.

Assim, a equação 3.26 representa uma condição de indiferença relevante que governa a oferta de salários por parte dos trabalhadores assumindo que o payoff para firma com a continuidade da negociação, mesmo que sem acordo, excede o payoff obtido pelo fim da negociação.

Finalmente, considere o último subperíodo, $\mathrm{M}$, no qual o trabalhador faz a proposta do tipo tudo ou nada. Novamente, o trabalhador escolhe o maior salário possível sujeito a condição de que a empresa não o rejeite e vá para sua opção de fora. Como esta opção implica em valor zero, pode-se escrever a condição de indiferença da firma como:

$$
J_{M, t}=0
$$

Onde,

$$
J_{M, t}=\frac{1}{M} \vartheta_{t}+\widetilde{\vartheta_{t}^{p}}-\left(\omega_{M, t}-\widetilde{\omega_{t}^{p}}\right)
$$

A taxa de salário de equilíbrio será determinada da seguinte maneira: note que $\omega_{s, t}$ e $\widetilde{\omega_{t}^{p}}$ sempre aparecem como uma soma nas condições de equilíbrio $3.23,3.24,3.26$, $3.27,3.29$ e 3.30 ,

$$
\omega_{s, t}^{p} \equiv \omega_{s, t}+\widetilde{\omega_{t}^{p}}
$$


Para $s=1, \ldots$, M. Segundo Christiano, Eichenbaum e Trabandt (2013), pode-se resolver para $\omega_{M}^{p}$ dadas as variáveis que são exógenas ao par trabalhador-empresa. Então, 3.23 para $\mathrm{s}=\mathrm{M}-1$ pode ser resolvida para $\omega_{M-1}^{p}$ e 3.26 pode ser resolvida para $\omega_{M-2}^{p}$. Assim, as condições de equilíbrio podem ser usadas para se resolver unicamente para um conjunto de valores:

$$
\omega_{1, t}^{p}, \omega_{2, t}^{p}, \omega_{3, t}^{p}, \ldots, \omega_{M, t}^{p}
$$

condicional nas variáveis que são exógenas ao par trabalhador-empresa. $O$ valor presente descontado para o salário no equilíbrio, $\omega_{t}^{p}$, é $\omega_{1}^{p}$. Como as equações de equilíbrio anteriormente destacadas são equações lineares, elas podem ser resolvidas analiticamente para $\omega_{t}^{p}$ :

$$
\omega_{t}^{p}=\frac{1}{\alpha_{1}+\alpha_{2}}\left[\alpha_{1} \vartheta_{t}^{p}+\alpha_{2}\left(U_{t}-A_{t}\right)+\alpha_{3} \gamma-\alpha_{4}\left(\vartheta_{t}-D_{t}\right)\right]
$$

Com

$$
\begin{gathered}
\alpha_{1}=1-\delta+(1-\delta) M \\
\alpha_{2}=1-(1-\delta)^{M} \\
\alpha_{3}=\alpha_{2}\left(\frac{1-\delta}{\delta}\right)-\alpha_{1} \\
\alpha_{4}=\frac{1-\delta}{2-\delta} \frac{\alpha_{2}}{M}+1-\alpha_{2}
\end{gathered}
$$

$\mathrm{E} \alpha_{i}$, para $\mathrm{i}=1,2,3,4$, são estritamente positivos ${ }^{16}$.

Por fim, utilizando-se as equações 3.11 e 3.22 se computa o salário $\omega_{t}$ para o período $\mathrm{t}$, condicional em $\omega_{t}^{p}$ e dadas as crenças sobre os salários futuros $\widetilde{\omega_{t}^{p}}$. Christiano, Eichenbaum e Trabandt (2013) comentam que suas análises indicaram que $\omega_{t}^{p}$ é unicamente determinado condicional nas variáveis que são exógenas ao par empresa-trabalhador, quais sejam: $\vartheta_{t}, \vartheta_{t}^{p}, U_{t} e A_{t}$. Em princípio, a decomposição aditiva de $\omega_{t}^{p}$ entre salário corrente, $\omega_{\mathrm{t}}$, e pagamentos futuros, sintetizados por $\widetilde{\omega_{t}^{p}}$, não é unicamente determinada. Este potencial problema de falta de unicidade foi

\footnotetext{
${ }^{16}$ Para maiores detalhes vide Anexo A do artigo Christiano, Eichenbaum e Trabandt (2013).
} 
resolvido no artigo assumindo que os salários em cada período de tempo são a mesma função invariante no tempo de um conjunto pequeno de variáveis de estado. Dadas as leis de movimento para $\vartheta_{t}$ e $\mathrm{m}_{\mathrm{t}+1}$, um equilíbrio de barganha período a período é um processo estocástico para dez variáveis,

$$
J_{t}, \omega_{t}^{p}, V_{t}, U_{t}, l_{t}, f_{t}, x_{t}, A_{t}, \widetilde{\omega_{t}^{p}}, \omega_{t}
$$

que satisfazem as seguintes condições de equilíbrio: (i) as primeiras oito variáveis em 3.37 satisfazem as oito equações, 3.12, 3.14, 3.16, 3.17, 3.18, 3.20, 3.21 e 3.32; (ii) o processo estocástico $\widetilde{\omega_{t}^{p}}$ em 3.37 satisfaz 3.22; e, (iii) $\omega_{\mathrm{t}}$ satisfaz 3.11 .

$$
\omega_{t}=\omega_{t}^{p}-\widetilde{\omega_{t}^{p}}
$$

Por fim, é importante destacar que dentro do arcabouço tradicional DMP, $\omega_{t}^{p}$ é determinado pela seguinte Nash sharing rule:

$$
J_{t}=\frac{1-\eta}{\eta}\left(V_{t}-U_{t}\right)
$$

Em que $0 \leq \eta \leq 1$ é a parcela do total do excedente dada aos trabalhadores. Tendo por base a equação 3.32 , os autores mostram que se consegue rearranjá-la de forma a se chegar a seguinte equação, interpretada como Alternatating Offer Bargaining sharing rule:

$$
J_{t}=\beta_{1}\left(V_{t}-U_{t}\right)-\beta_{2} \gamma_{t}+\beta_{3}\left(\vartheta_{t}-D_{t}\right)
$$

Onde $\beta_{i}=\frac{\alpha_{i+1}}{\alpha_{1}}$,para $i=1,2,3$. Então, assim como na Nash sharing rule, $\omega_{t}^{p}$ depende de $J_{t}$ e de $\left(V_{t}-U_{t}\right)$, com pesos determinados por parâmetros que descrevem 0 ambiente econômico do modelo. Entretanto, há dois termos constantes envolvendo Y e D que, por hipótese, não são uma função do estado na economia e são separados em $\vartheta_{t}$.

\subsubsection{Equilíbrio no Mercado de Trabalho}

Segundo Christiano, Eichenbaum e Trabandt (2013), em equilíbrio, o atacadista representativo emprega $I_{t}$ trabalhadores com quais ele negociou (barganha) ao salário $\omega_{t}$. A produção começa imediatamente após a conclusão das negociações sobre o salário e o atacadista vende seu bem intermediário ao preço real $\vartheta_{t} \equiv \frac{P_{t}^{h}}{P_{t}}$. As condições de equilíbrio do mercado de trabalho são as estabelecidas em 3.37. 


\subsubsection{Implicações para o Salário}

No modelo Christiano, Eichenbaum e Trabandt (2013), a barganha ocorre período a período. Os autores mostram que a alocação a que se chega sob este arcabouço é mesma da alocação a que se chega quando se trabalha com o valor presente descontado de barganha. De fato, a proposição 2.1 de Christiano, Eichenbaum e Trabandt (2013) diz que o equilíbrio de barganha período a período é um equilíbrio de barganha considerando o valor presente descontado ${ }^{17}$.

Ademais, Christiano, Eichenbaum e Trabandt (2013) conclui que o equilíbrio a que se chega nestes casos é consistente com os seguintes resultados empíricos: (i) os trabalhadores e firmas incumbentes não negociam salário todos os período; (ii) o salário nominal do trabalhador incumbente é normalmente constante por um prolongado período de tempo; e, (iii) a volatilidade dos salários pagos para os novos contratados é maior do que a volatilidade dos salários pagos aos trabalhadores incumbentes.

\subsubsection{Market Clearing, Política Monetária e Formas Funcionais.}

A quantidade total de bens intermediários comprados pelos varejistas dos atacadistas é:

$$
h_{t} \equiv \int_{0}^{1} h_{j, t} d_{j}
$$

Como a quantidade de bens intermediários produzida pelo atacadista é igual ao número de trabalhadores empregados, tem-se que esta quantidade total produzida é $I_{t}$. Assim, a condição de Market Clearing para o mercado de bens intermediário é : $h_{t}$ $=I_{\mathrm{t}}$. Já, a condição para o mercado de serviços do capital é dada por:

$$
u_{t}^{k} K_{t}=\int_{0}^{1} k_{j, t} d_{j}
$$

Para o mercado de bens finais, por sua vez, tem-se a seguinte condição:

\footnotetext{
${ }^{17}$ Página 12 do artigo.
} 


$$
C_{t}+\frac{I_{t}+a\left(u_{t}^{k}\right) K_{t}}{\psi_{t}}+\kappa_{t} x_{t} l_{t-1}+G_{t}=Y_{t}
$$

Em que, o lado direto, $Y_{t}$, representa $o$ total de bens finais produzidos enquanto 0 lado esquerdo representa suas utilizações. Como se pode observar na identidade 3.43 , os bens finais são usados para o consumo das famílias $\left(C_{t}\right)$; para o consumo do governo $\left(\mathrm{G}_{\mathrm{t}}\right)$; para o custo de utilização do capital $\left(\frac{a\left(u_{t}^{k}\right) K_{t}}{\psi_{t}}\right)$; para custo de se empregar novos trabalhadores $\left(\kappa_{t} x_{t} l_{t-1}\right)$; e, para se produzir bens de investimento segundo a função que transforma 1 bem de consumo final em $\psi_{\mathrm{t}}$ bens de investimentos $\left(\frac{I_{t}}{\psi_{t}}\right)$.

A perfeita competição na produção de bens de investimento implica que:

$$
P_{I, t}=P_{t} / \Psi_{t}
$$

O fator estocástico de desconto, $\mathrm{m}_{\mathrm{t}+1}$, foi construído usando a utilidade marginal do consumo $\left(\mathrm{u}_{\mathrm{c}, \mathrm{t}}\right)$ :

$$
U_{c, t}=\left(C_{t}-b C_{t-1}\right)^{-1}-\beta b E_{t}\left(C_{t+1}-b C_{t}\right)^{-1}
$$

Portanto,

$$
m_{t+1}=\beta \frac{u_{c, t+1}}{u_{c, t}}
$$

Com relação à política monetária, ela é guiada pela seguinte especificação:

$$
\ln \left(\frac{R_{t}}{R}\right)=\rho_{R} \ln \left(\frac{R_{t-1}}{R}\right)+\left(1-\rho_{R}\right)\left[r_{\pi} \ln \left(\frac{\pi_{t}}{\pi}\right)+r_{y} \ln \left(\frac{Y_{t}}{Y}\right)\right]+\sigma_{R} \varepsilon_{R, t}
$$

Onde $\pi$ é a meta de inflação; $R$ e $Y$ são os valores de estado estacionário da taxa de juro e do produto, respectivamente; e; $\varepsilon_{R, t}$ é o choque de política monetária com média zero e variância 1. $Y_{t}$ denota o produto interno bruto da economia que é dado por:

$$
Y_{t}=C_{t}+\frac{I_{t}}{\Psi_{t}}+G_{t}
$$

Por hipótese, $G_{t}$ cresce exogenamente de forma consistente com crescimento balanceado da economia. Christiano, Eichenbaum e Trabandt (2013) também trabalham com a hipótese segundo a qual a taxa de crescimento da produtividade total dos fatores é descrita por um processo i.i.d. Assume-se que $\ln \left(\mu_{z, t}\right) \equiv \ln \left(\frac{z_{t}}{z_{t-1}}\right)$ e que $\ln \left(\mu_{\Psi, t}\right) \equiv \ln \left(\frac{\Psi_{t}}{\Psi_{t-1}}\right)$ segue um processo $\mathrm{AR}(1)$. Os parâmetros que controlam o 
desvio padrão de cada um deles são definidos, respectivamente, por $\sigma_{z} e \sigma_{\Psi}$. Já, $\rho_{\Psi}$ é a coeficiente de autocorrelação de $\ln \left(\mu_{\psi, t}\right)$.

Neste modelo, duas fontes de crescimento são os choques de neutro $\left(z_{t}\right)$ e específico $\left(\psi_{t}\right)$ de investimento, ou de progresso tecnológico. As variáveis $\frac{Y_{t}}{\Phi_{t}}, \frac{C_{t}}{\Phi_{t}}, \frac{\omega_{t}}{\Phi_{t}}$ e $I_{t} /\left(\Psi_{t} \Phi_{t}\right)$ convergem para um estado estacionário não estocástico, no qual

$$
\Phi_{t}=\left(\Psi_{t}\right)^{\alpha /(1-\alpha)} z_{t}
$$

é a média ponderada entre as duas fontes de progresso tecnológico. Se as variáveis como o custo fixo de produção, o custo de contratação, o custo para se fazer uma contra oferta, as compras do governo e os benefícios dos desempregados, definidos respectivamente por $\left(\phi_{t}, \kappa_{t}, \gamma_{t}, G_{t} e D_{t}\right)$, são constantes, eles se tornam irrelevantes ao longo do tempo. Para evitar isso, Christiano, Eichenbaum e Trabandt (2013), seguindo a literatura, colocaram a hipótese que estas variáveis têm a mesma taxa de crescimento do produto, que no presente caso é dada por $\Phi_{t}$. No entanto, uma implicação negativa desta hipótese é que os dois tipos de choque tecnológico afetam imediatamente este conjunto de variáveis. O que é difícil de justificar. Para contornar este problema, os autores procederam como em Christiano, Trabandt e Walentin (2012) e Schmitt-Grohé e Uribe (2012) e assumiram que as compras do governo $\left(G_{t}\right)$ são defasadas e são distribuídas de acordo com um processo de raiz unitária. Deste modo, tem-se que $G_{t}$ é cointegrada com $Y_{t}$ mas tem uma tendência estocástica suavizada.

Em particular, Christiano, Eichenbaum e Trabandt (2013) assumem, então, que:

$$
\left(\phi_{t}, \kappa_{t}, \gamma_{t}, G_{t} e D_{t}\right)^{\prime}=\left(\phi_{t}, \kappa_{t}, \gamma_{t}, G_{t} e D_{t}\right)^{\prime} \Omega_{t}
$$

Onde $\Omega_{t}$ é a diagonal $\left(\Omega_{i, t}\right)$ com $i \epsilon\left(\phi_{t}, \kappa_{t}, \gamma_{t}, G_{t} e D_{t}\right)$ e $\Omega_{i, t}$ corresponde a uma distribuição dos valores passados defasados de $\Phi_{t}$ definida por:

$$
\Omega_{i, t}=\left(\Phi_{t-1}\right)^{\theta_{i}}\left(\Omega_{t-1}^{i}\right)^{\left(1-\theta_{i}\right)}(3.51)
$$

Onde $0<\theta_{i} \leq 1$ são parâmetros a serem estimados. No que $\Omega_{t}^{i}$ cresce, no longo prazo a mesma taxa que $\Phi_{t}$. Quando $\theta_{i}$ é muito próximo de zero, $\Omega_{t}^{i}$ responde muito pouco no curto prazo a qualquer tipo de inovação tecnológica. Na prática, os autores colocaram a restrição de que os quatro primeiros valores de $\theta_{i}$ deveriam ser iguais, podendo ser diferente apenas $\theta_{D}$. 
Com relação à equação que define o custo de ajustamento (3.5), temos que $\mu$ e $\mu_{\Psi}$ representam as taxas de crescimento incondicional de $\Phi_{t} e \Psi_{t} . O$ valor de $\mathrm{I}_{t} / \mathrm{I}_{\mathrm{t}-1}$ no estado estacionário não estocástico é dado por $\mu \mu_{\Psi}$. Adicionalmente, $S$ " é um parâmetro que coincide com a segunda derivada de $S($.$) avaliado no estado$ estacionário.

No que tange a equação que define a utilização do capital (3.3), temos que no estado estacionário $u_{t}^{k}$ é normalizado para 1.

Por fim, cabe a discussão sobre como as contratações são determinadas. Os autores utilizam uma função de matching padrão, qual seja:

$$
x_{t} l_{t-1}=\sigma_{m}\left(1-\rho l_{t-1}\right)^{\sigma}\left(l_{t-1} v_{t}\right)^{(1-\sigma)}(3.52)
$$

Onde $l_{t-1} v_{t}$ corresponde ao total de vagas abertas e $v_{t}$ representa a taxa de vagas abertas. Dados $\mathrm{x}_{\mathrm{t}}$ e $\mathrm{I}_{\mathrm{t}-1,1}$ usa-se 3.51 para resolver para $v_{t}$. É importante lembrar que o número total de vagas foi definido por $\left.x_{t}\right|_{t-1} / Q_{t}$. Portanto, temos que:

$$
Q_{t}=\frac{x_{t}}{v_{t}}
$$

Christiano, Eichenbaum e Trabandt (2013) destacam que o equilíbrio a que se chega tem uma estrutura recursiva particular. Pode-se primeiro resolver para todas as variáveis do modelo, exceto $Q_{t}$ e $v_{t}$, que são resolvidas usando 3.52 e 3.53 .

\subsection{ALTERAÇÕES DO MODELO ORIGINAL E LOG-LINEARIZAÇÃO}

Christiano, Eichenbaum e Trabandt (2013) trabalham com três choques no modelo, quais sejam: choque de política monetária, choque de investimento tecnológico $(\psi t)$ e choque neutro de investimento (zt). Além disso, eles utilizam o modelo no nível. No presente trabalho, as equações apresentadas no apêndice técnico B.1 de Christiano, Eichenbaum e Trabandt (2013) para o modelo de médio porte foram loglinearizadas para que pudessem ser estimadas bayesianamente. $O$ processo de estimação será explicado em uma próxima seção 
3.3.1 Conjunto de Equações do Modelo e o Resultado da Log-linearização

As equações presentes no apêndice técnico e a sua forma log-linearizada serão apresentadas respeitando a ordem do apêndice técnico B.1 de Christiano, Eichenbaum e Trabandt (2013).

\subsubsection{Equações Originais do Modelo}

Condição de Primeira Ordem para o consumo:

$$
\left.\psi_{\mathrm{t}}=\left(\mathrm{c}_{\mathrm{t}}-\frac{\mathrm{bc} \mathrm{t}}{\mu_{\mathrm{t}}}\right)^{-1}-\beta \mathrm{c} \mathrm{E}_{\mathrm{t}}\left(\mathrm{c}_{\mathrm{t}+1} \mu_{\mathrm{t}+1}-\mathrm{bc}\right)_{\mathrm{t}}\right)^{-1}
$$

Condição de Primeira Ordem para os títulos:

$$
\psi_{\mathrm{t}}=\frac{\beta E_{\mathrm{t}} \psi_{\mathrm{t}+1} R_{\mathrm{t}}}{\pi_{\mathrm{t}+1} \mu_{\mathrm{t}+1}}
$$

Condição de Primeira Ordem para o investimento:

$$
1=p_{k^{\prime}, t}\left[1-S_{t}-\frac{S_{t}^{\prime} \mu_{t} \mu_{\Psi, t} i_{t}}{i_{t-1}}\right]+\frac{\beta E_{t} \psi_{t+1}}{\psi_{t}} p_{k^{\prime}, t+1} S_{t+1}^{\prime}\left(\frac{i_{t+1}}{i_{t}}\right)^{2} \mu_{\Psi, t+1} \mu_{t+1}
$$

Condição de Primeira Ordem (CPO) para o capital:

$$
\psi_{\mathrm{t}}=\frac{\beta \mathrm{E}_{\mathrm{t}} \psi_{\mathrm{t}+1} \mathrm{R}_{\mathrm{t}+1}^{\mathrm{k}}}{\pi_{\mathrm{t}+1} \mu_{\mathrm{t}+1}}
$$

Lei de movimento do capital:

$$
\mathrm{k}_{\mathrm{t}}=\frac{\left(1-\delta^{\mathrm{k}}\right)}{\mu_{\mathrm{t}} \mu_{\Psi, \mathrm{t}}} \mathrm{k}_{\mathrm{t}-1}+\left(1-\mathrm{S}_{\mathrm{t}}\right) \mathrm{i}_{\mathrm{t}}
$$

Minimização do custo:

$$
0=\frac{a^{\prime}\left(u_{t}^{k}\right) u_{t}^{k} k_{t-1}}{\mu_{\Psi, t} \mu_{t}}-\frac{\alpha}{1-\alpha} \vartheta_{t}\left[v^{f} R_{t}+1-v^{f}\right] l_{t}, \operatorname{com} v^{\mathrm{f}}=1
$$

Produção:

$$
y_{t}=\dot{p}^{\frac{\lambda}{1-\lambda}}\left[\left(\frac{u_{t}^{k} k_{t-1}}{\mu_{t} \mu_{\Psi, t}}\right)^{\alpha} 1_{t}^{1-\alpha}-\eta_{\phi, t} \phi\right.
$$

Recursos da Economia:

$$
y_{t}=\eta_{g, t} g_{t}+c_{t}+i_{t}+\frac{a\left(u_{t}^{k}\right) k_{t-1}}{\mu_{t} \mu_{\Psi, t}}+\eta_{k, t} k_{t-1}
$$

Regra de Taylor: 


$$
\ln \left(\frac{R_{t}}{R}\right)=\rho_{R} \ln \left(\frac{R_{t-1}}{R}\right)+\left(1-\rho_{R}\right)\left[r_{\pi} \ln \left(\frac{\pi_{t}}{\pi}\right)+r_{y} \ln \left(\frac{Y_{t}}{Y}\right)\right]+\sigma_{R} \varepsilon_{R, t} / 400
$$

Equação do preço 1:

$$
F_{t}=\psi_{t} y_{t}+\beta \xi E_{t}\left(\frac{\pi}{\pi_{t+1}}\right)^{\frac{1}{1-\lambda}} F_{t+1}
$$

Equação do preço 2:

$$
K_{t}=\lambda \psi_{t} y_{t} m c_{t}+\beta \xi E_{t}\left(\frac{\pi}{\pi_{t+1}}\right)^{\frac{\lambda}{1-\lambda}} K_{t+1}
$$

Equação do preço 3:

$$
(1-\xi)\left(\frac{K_{t}}{F_{t}}\right)^{\frac{1}{1-\lambda}}=1-\xi\left(\frac{\pi}{\pi_{t}}\right)^{\frac{1}{1-\lambda}}
$$

Dispersão de preços:

$$
\dot{p}_{t} \frac{\lambda}{1-\lambda}=(1-\xi)^{1-\lambda}\left[1-\xi\left(\frac{\pi}{\pi_{t}}\right)^{\frac{\lambda}{1-\lambda}}\right]^{\lambda}+\xi\left[\frac{\pi}{\pi_{t}} \dot{p_{t}}\right]^{\frac{\lambda}{1-\lambda}}
$$

Valor presente dos salários:

$$
\omega_{t}^{p}=\omega_{t}+\rho \beta E_{t} \frac{\psi_{t+1}}{\psi_{t}} \omega_{t+1}^{p}
$$

Valor presente da receita:

$$
\vartheta_{t}^{p}=\vartheta_{t}+\rho \beta E_{t} \frac{\psi_{t+1}}{\psi_{t}} \vartheta_{t+1}^{p}
$$

Condição de livre entrada:

$$
\eta_{\kappa, t} \kappa=J_{t}
$$

Valor para a firma:

$$
J_{t}=\vartheta_{t}^{p}-\omega_{t}^{p}
$$

Valor para o trabalhador:

$$
\begin{gathered}
V_{t}=\omega_{t}^{p}+A_{t} \\
A_{t}=(1-\rho) \beta E_{t}\left\{\left(\frac{\psi_{t+1}}{\psi t}\right)\left[f_{t+1} V_{t+1}-\left(1-f_{t+1}\right) U_{t+1}\right]\right\}+\rho \beta E_{t}\left(\frac{\psi_{t+1}}{\psi_{t}}\right) A_{t+1}
\end{gathered}
$$

Valor do desemprego:

$$
U_{t}=\eta_{D, t} D+\beta E_{t}\left\{\left(\frac{\psi_{t+1}}{\psi t}\right)\left[f_{t+1} V_{t+1}+\left(1-f_{t+1}\right) U_{t+1}\right]\right\}
$$

Regra de divisão do excedente:

$$
\alpha_{1} J_{t}=\alpha_{2}\left(V_{t}-U_{t}\right)-\alpha_{3} \eta_{\gamma, t} \gamma+\alpha_{4}\left(\vartheta_{t}-\eta_{D, t} D\right)
$$

PIB real: 


$$
Y_{t}=\eta_{g, t} g_{t}+c_{t}+i_{t} \quad, \text { com } g_{t}=g \text { para todo } t
$$

Taxa de desemprego:

$$
u_{t}=1-l_{t}
$$

Taxa com que o desempregado encontra emprego (finding rate):

$$
f_{t}=\left(\frac{x_{t} l_{t-1}}{1-\rho l_{t-1}}\right)
$$

Função de matching:

$$
x_{t} l_{t-1}=\sigma_{m}\left(1-\rho l_{t-1}\right)^{\sigma} v_{t}^{\text {tot }}(1-\sigma)
$$

Vagas:

$$
v_{t}^{\text {tot }}=v_{t} l_{t-1}
$$

Taxa de preenchimento de vagas:

$$
Q_{t}=\frac{x_{t}}{v_{t}}
$$

Lei de movimento do emprego:

$$
l_{t}=\left(\rho+x_{t}\right) l_{t-1}
$$

Tecnologia composta:

$$
\ln \mu_{t}=\frac{\alpha}{1-\alpha} \ln \left(\mu_{\psi, t}\right)+\ln \mu_{z, t}
$$

Tecnologia neutra:

$$
\ln \mu_{z, t}=\left(1-\rho_{\mu_{z}}\right) \ln \mu_{z}+\rho_{\mu_{z}} \ln \mu_{z, t-1}+\frac{\sigma_{\mu_{z}} \varepsilon_{\mu_{z}, t}}{100}
$$

Tecnologia do Investimento:

$$
\ln \mu_{\Psi, t}=\left(1-\rho_{\mu_{\Psi}}\right) \ln \mu_{\Psi}+\rho_{\mu_{\Psi}} \ln \mu_{\Psi, t-1}+\frac{\sigma_{\mu_{\Psi}} \varepsilon_{\mu_{\Psi}, t}}{100}
$$

Difusão da tecnologia:

$$
\eta_{i, t}=\eta_{i, t-1}^{1-\theta_{i}} \mu_{t}^{-1} \text { para } i \epsilon\{\phi, \kappa, \gamma, g, D\}
$$

Retorno do capital:

$$
R_{t}^{k}=\frac{\pi_{t}}{\mu_{\Psi, t} p_{k^{\prime}, t-1}}\left[u_{t}^{k} a^{\prime}\left(u_{t}^{k}\right)-a\left(u_{t}^{k}\right)+\left(1-\delta^{k}\right) p_{k^{\prime}, t}\right]
$$

Custo Marginal:

$$
m c_{t}=\frac{\left(\mu_{\Psi, t} \mu_{t}\right)^{\alpha} \vartheta_{t}\left[v^{f} R_{t}+1-v^{f}\right]\left(\frac{u_{t}^{k} k_{t-1}}{l_{t}}\right)^{-\alpha}}{1-\alpha}, \operatorname{com} v^{f}=1
$$




\subsubsection{Log-linearização}

As variáveis com barra $\left({ }^{-}\right)$indicam que elas estão no estado estacionário enquanto as variáveis indicam a diferença do logaritmo da variável em relação ao valor do logaritmo quando ela esta no estado estacionário.

Condição de Primeira Ordem para o consumo:

$$
\begin{gathered}
\widetilde{\psi_{t}}=\left(\frac{\bar{\mu} \overline{\Gamma_{c}}}{(\bar{\mu}-\beta b)}\right)\left[\frac{b}{\bar{\mu}-b} \widetilde{\mu_{t}}-\frac{\bar{\mu}}{\bar{\mu}-b} \widetilde{c_{t}}+\frac{b}{\bar{\mu}-b} \widetilde{c_{t-1}}\right] \\
-\left(\frac{\beta b \overline{\Gamma_{c}}}{\bar{\mu}-\beta b}\right) E_{t}\left[\left(\frac{\bar{\mu}}{\bar{\mu}-b}\right)\left(\widetilde{c_{t+1}}+\widetilde{\mu_{t+1}}\right)+\left(\frac{b}{\bar{\mu}-b}\right) \widetilde{c_{t}}\right]
\end{gathered}
$$

Condição de Primeira Ordem para os títulos:

$$
\widetilde{\psi_{t}}=E_{t}\left[\overline{\psi_{t+1}}+\widetilde{R_{t+1}}-\widetilde{\pi_{t+1}}-\widetilde{\mu_{t+1}}\right]
$$

Condição de Primeira Ordem para o investimento:

$$
0=\widetilde{p_{k^{\prime}, t}}-\left(\widetilde{\mu \mu_{\Psi}}\right)^{2} S^{\prime \prime}\left[\widetilde{\mu_{t}}+\widetilde{\mu_{\Psi, t}}+\widetilde{l_{t}}-\widetilde{l_{t-1}}-\beta E_{t}\left(\widetilde{\mu_{t+1}}+\widetilde{\mu_{\Psi, t+1}}+\widetilde{l_{t+1}}-\widetilde{\imath_{t}}\right)\right](3.8
$$

Condição de Primeira Ordem (CPO) para o capital:

$$
\widetilde{\psi_{t}}=E_{t}\left[\widetilde{\psi_{t+1}}+\widetilde{R_{t+1}^{k}}-\widetilde{\pi_{t+1}}-\widetilde{\mu_{t+1}}\right]
$$

Lei de movimento do capital:

$$
\widetilde{k_{t}}=\frac{1-\delta^{k}}{\overline{\mu \mu_{\Psi}}}\left[\widetilde{k_{t-1}}-\widetilde{\mu_{t}}-\widetilde{\mu_{\Psi}, t}\right]+\frac{\bar{l}}{\bar{k}} \widetilde{l_{t}}
$$

Minimização do custo:

$$
\begin{aligned}
& 0=\left(\frac{\bar{k}}{\bar{\mu} \overline{\mu_{\Psi}}}\right)\left[\sigma_{b}\left(\widetilde{k_{t-1}}-\widetilde{\mu_{t}}-\widetilde{\mu_{\Psi}, t}\right)+\left(\sigma_{b}-\sigma_{a} \sigma_{b}\right) \widetilde{u_{t}^{k}}\right] \\
& -\left(\frac{\alpha}{1-\alpha}\right) \bar{\vartheta} \bar{l}\left[(\bar{R})\left(\widetilde{\vartheta_{t}}+\widetilde{l_{t}}\right)+\bar{R} \widetilde{R_{t}}\right]
\end{aligned}
$$

Produção:

$$
\begin{aligned}
\bar{y} \widetilde{y_{t}}=\overline{\dot{p}}^{\left(\frac{\lambda}{\lambda-1}\right)}\{ & \left\{\left(\frac{\bar{k}}{\overline{\mu \mu_{\Psi}}}\right)^{\alpha}\left[\left(\frac{\lambda}{\lambda-1}\right) \widetilde{\dot{p}_{t}}+\alpha *\left(\widetilde{u_{t}^{k}}+\widetilde{k_{t-1}}-\widetilde{\mu_{t}}-\widetilde{\mu_{\Psi}, t}\right)+(1-\alpha) \widetilde{l_{t}}\right]\right. \\
& \left.-\left[\overline{\eta_{\phi}}\left(\left(\frac{\lambda}{\lambda-1}\right) \widetilde{p_{t}}+\widetilde{\eta_{\phi}, t}\right)\right]\right\}
\end{aligned}
$$

Recursos da Economia:

$$
\bar{y} \widetilde{y_{t}}=\left(\overline{\eta_{g}} \bar{g}\right)\left(\widetilde{\eta_{g, t}}+\widetilde{g_{t}}\right)+\bar{c} \widetilde{c_{t}}+\widetilde{\imath \iota_{t}}+\left(\frac{\sigma_{b} \bar{k}}{\overline{\mu \mu_{\Psi}}}\right) \widetilde{u_{t}^{k}}+\kappa\left(\overline{\eta_{\kappa, t}} \bar{x} \vec{l}\right)\left(\widetilde{\eta_{\kappa, t}}+\widetilde{x_{t}}+\widetilde{l_{t-1}}\right)
$$


Regra de Taylor:

$$
\widetilde{R_{t}}=\rho_{R} \widetilde{R_{t-1}}+\left(1-\rho_{R}\right)\left[r_{\pi} \widetilde{\pi_{t}}+r_{y} \widetilde{Y}_{t}\right]+\sigma_{R} \varepsilon_{R, t} / 400
$$

Equação do preço 1:

$$
\widetilde{F_{t}}=\left(1-\beta \xi\left(\frac{1}{\overline{\bar{\pi}}}\right)^{\frac{1}{1-\lambda}}\right)\left[\widetilde{\psi_{t}}+\widetilde{y_{t}}\right]+\beta \xi\left(\frac{1}{\overline{\bar{\pi}}}\right)^{\frac{1}{1-\lambda}} \widetilde{E_{t}} \widetilde{F_{t+1}}-\left(\frac{\beta \xi}{1-\lambda}\right)\left(\frac{1}{\overline{\bar{\pi}}}\right)^{\frac{1}{1-\lambda}} E_{t} \widetilde{\pi_{t+1}}
$$

Equação do preço 2:

$$
\begin{aligned}
\widetilde{K_{t}}=\left(1-\beta \xi\left(\frac{1}{\overline{\bar{\pi}}}\right)^{\left(\frac{\lambda}{1-\lambda}\right)}\right)\left(\widetilde{\psi_{t}}+\widetilde{y_{t}}+\widetilde{m c_{t}}\right) \\
+\beta \xi\left(\frac{1}{\overline{\bar{\pi}}}\right)^{\left(\frac{\lambda}{1-\lambda}\right)} E_{t}\left[\left(-\frac{\lambda}{1-\lambda}\right) \widetilde{\pi_{t+1}}+\widetilde{K_{t+1}}\right]
\end{aligned}
$$

Equação do preço 3:

$$
\widetilde{K_{t}}-\widetilde{F_{t}}=\frac{\xi\left(\frac{1}{\overline{\bar{\pi}}}\right)^{\frac{1}{1-\lambda}} \widetilde{\pi_{t}}}{1-\xi\left(\frac{1}{\bar{\pi}}\right)^{\frac{1}{1-\lambda}}}
$$

Dispersão de preços:

$\overline{\dot{p}}^{\lambda /(1-\lambda)} \widetilde{\dot{p}}_{t}=\xi(1-\xi)^{1-\lambda}\left[1-\xi\left(\frac{1}{\bar{\pi}}\right)^{\left(\frac{1}{1-\lambda}\right)}\right]^{\lambda-1}\left(\frac{1}{\overline{\bar{\pi}}}\right)^{\left(\frac{1}{1-\lambda}\right)} \widetilde{\pi_{t}}+\xi\left(\frac{\overline{\dot{p}}}{\bar{\pi}}\right)^{\lambda /(1-\lambda)}\left[\widetilde{p_{t-1}}-\widetilde{\pi_{t}}\right](3.99)$

Valor presente dos salários:

$$
\widetilde{\omega_{t}^{p}}=(1-\rho \beta) \widetilde{\omega_{t}}+\rho \beta E_{t}\left[\widetilde{\psi_{t+1}}-\widetilde{\psi_{t}}+\widetilde{\omega_{t+1}^{p}}\right]
$$

Valor presente da receita:

$$
\widetilde{\vartheta_{t}^{p}}=(1-\rho \beta) \widetilde{\vartheta_{t}}+\rho \beta E_{t}\left[\widetilde{\psi_{t+1}}-\widetilde{\psi_{t}}+\widetilde{\vartheta_{t+1}^{p}}\right]
$$

Condição de livre entrada:

$$
\widetilde{\eta_{\kappa, t}}=\widetilde{J_{t}}
$$

Valor para a firma:

$$
\widetilde{J_{t}}=\left(\overline{\frac{\vartheta^{p}}{\bar{J}}}\right) \widetilde{\vartheta_{t}^{p}}-\left(\overline{\frac{\omega^{p}}{\bar{J}}}\right) \widetilde{\omega_{t}^{p}}
$$

Valor para o trabalhador:

$$
\widetilde{V}_{t}=\left(\frac{\overline{\omega^{p}}}{\bar{V}}\right) \widetilde{\omega_{t}^{p}}+\left(\frac{\bar{A}}{\bar{V}}\right) \widetilde{A_{t}}
$$




$$
\begin{aligned}
\bar{A} \widetilde{A_{t}}=(1 & -\rho) \beta \bar{f} \bar{V} E_{t}\left[\overline{\psi_{t+1}}-\widetilde{\psi_{t}}+\widetilde{V_{t+1}}+\widetilde{f_{t+1}}\right]+(1-\rho) \beta \bar{U} E_{t}\left[\widetilde{\psi_{t+1}}-\widetilde{\psi_{t}}+\widetilde{U_{t+1}}\right] \\
& -(1-\rho) \beta \bar{f} \bar{U} E_{t}\left[\widetilde{\psi_{t+1}}-\widetilde{\psi_{t}}+\widetilde{f_{t+1}}+\widetilde{U_{t+1}}\right] \\
& +\bar{A} \bar{f} \beta E_{t}\left[\widetilde{\psi_{t+1}}-\widetilde{\psi_{t}}+\widetilde{A_{t+1}}\right]
\end{aligned}
$$

Valor do desemprego:

$$
\begin{aligned}
\widetilde{U_{t}}=\left(\frac{\overline{\eta_{D}} D}{\bar{U}}\right) \widetilde{\eta_{D, t}} & +\left(\frac{\beta \bar{f} \bar{V}}{\bar{U}}\right) E_{t}\left[\widetilde{\psi_{t+1}}-\widetilde{\psi_{t}}+\widetilde{f_{t+1}}+\widetilde{V_{t+1}}\right]+\beta E_{t}\left[\widetilde{\psi_{t+1}}-\widetilde{\psi_{t}}+\widetilde{U_{t+1}}\right] \\
& -\beta \bar{f} E_{t}\left[\widetilde{\psi_{t+1}}-\widetilde{\psi_{t}}+\widetilde{f_{t+1}}+\widetilde{U_{t+1}}\right]
\end{aligned}
$$

Regra de divisão do excedente:

$$
\widetilde{J_{t}}=\left(\frac{\alpha_{2} \bar{V}}{\alpha_{1} \bar{J}}\right)\left(\widetilde{V_{t}}-\widetilde{U_{t}}\right)-\frac{\alpha_{3} \overline{\eta_{\gamma} \gamma}}{\alpha_{1} \bar{J}}\left(\widetilde{\eta_{\gamma, t}}\right)+\frac{\alpha_{4} \bar{\vartheta}}{\alpha_{1} \bar{J}}\left(\widetilde{\vartheta_{t}}\right)-\frac{\alpha_{4} \overline{\eta_{D}} D}{\alpha_{1} \overline{\eta_{D, t}}}
$$

PIB real:

$$
\widetilde{Y_{t}}=\frac{\overline{\eta_{g}} \bar{g}}{\bar{Y}} \widetilde{\eta_{g, t}}+\frac{\bar{c}}{\overline{\bar{Y}}} \widetilde{c_{t}}+\frac{\bar{\imath}}{\overline{\bar{Y}}} \widetilde{l_{t}}
$$

Taxa de desemprego:

$$
\widetilde{u_{t}}=\left(\frac{\bar{l}}{\bar{l}-1}\right) \widetilde{l_{t}}
$$

Taxa com que o desempregado encontra emprego (finding rate):

$$
\widetilde{f}_{t}=\widetilde{x}_{t}+\left(\frac{1}{1-\rho \bar{l}}\right) \widetilde{l_{t-1}}
$$

Função de matching:

$$
\widetilde{x_{t}}=(1-\sigma) \widetilde{v_{t}^{t o t}}-\left(1+\frac{\sigma \rho \bar{l}}{1-\rho \bar{l}}\right) \widetilde{l_{t-1}}
$$

Vagas:

$$
\widetilde{v_{t}^{t o t}}=\widetilde{v_{t}}+\widetilde{l_{t-1}}
$$

Taxa de preenchimento de vagas:

$$
\widetilde{Q_{t}}=\widetilde{x_{t}}-\widetilde{v_{t}}
$$

Lei de movimento do emprego:

$$
\widetilde{l_{t}}=\widetilde{l_{t-1}}+\bar{x} \widetilde{x_{t}}
$$

Tecnologia composta: 


$$
\widetilde{\mu_{t}}=\left(\frac{\alpha}{1-\alpha}\right) \widetilde{\mu_{\Psi, t}}+\widetilde{\mu_{z, t}}
$$

Tecnologia neutra:

$$
\widetilde{\mu_{z, t}}=\rho_{\mu_{z}} \widetilde{\mu_{z, t-1}}+\frac{\sigma_{\mu_{z}} \varepsilon_{\mu_{z}, t}}{100}
$$

Tecnologia do Investimento:

$$
\widetilde{\mu_{\Psi}, t}=\rho_{\mu_{\Psi}} \widetilde{\mu_{\Psi, t-1}}+\frac{\sigma_{\mu_{\Psi}} \varepsilon_{\mu_{\Psi}, t}}{100}
$$

Difusão da tecnologia:

$$
\widetilde{\eta_{l, t}}=\left(1-\theta_{i}\right) \widetilde{\eta_{l, t-1}}-\widetilde{\mu_{t}}, \text { para } i \epsilon\{\phi, \kappa, \gamma, g, D\}
$$

Retorno do capital:

$$
\begin{gathered}
\overline{R^{k}} \widetilde{R_{t}^{k}}=\frac{\bar{\pi} \sigma_{b}}{\overline{\mu_{\Psi} p_{k^{\prime}}}}\left[\widetilde{\pi_{t}}-\widetilde{\mu_{\Psi, t}}-\widetilde{p_{k^{\prime}, t-1}}\right]+\frac{\bar{\pi}}{\overline{\mu_{\Psi} p_{k^{\prime}}}}\left[\sigma_{b}+\sigma_{b} \sigma_{a}\right] \widetilde{u_{t}^{k}}-\frac{\bar{\pi} \sigma_{b}}{\overline{\mu_{\Psi} p_{k^{\prime}}}} \widetilde{u_{t}^{k}} \\
+\frac{\left(1-\delta^{k}\right) \bar{\pi}}{\overline{\mu_{\Psi}}}\left[\widetilde{\pi_{t}}+\widetilde{p_{k^{\prime}, t}}-\widetilde{p_{k^{\prime}, t-1}}-\widetilde{\mu_{\Psi, t}}\right]
\end{gathered}
$$

Custo Marginal:

$$
\begin{gathered}
\overline{m c} \widetilde{m c_{t}}=\overline{\Gamma_{m c}}\left(\overline{\mu \mu \mu_{\Psi}}\right)^{\alpha} \bar{\vartheta} \bar{R}\left(\frac{\bar{k}}{\bar{l}}\right)^{-\alpha}\left(\frac{1}{1-\alpha}\right)\left[\widetilde{R_{t}}+\alpha \widetilde{\mu_{\Psi}, t}+\alpha \widetilde{\mu_{t}}+\widetilde{\vartheta_{t}}-\alpha \widetilde{u_{t}^{k}}-\alpha \widetilde{k_{t-1}}\right. \\
\left.+\alpha \widetilde{l_{t}}\right]
\end{gathered}
$$

\subsection{METODOLOGIA, DADOS E PARÂMETROS}

\subsubsection{Metodologia Econométrica}

O presente modelo foi estimado utilizando métodos bayesianos. De posse dos modelos log-linearizado, este procedimento permite que as informações disponíveis a priori (distribuições priors) sejam atualizadas pelos dados e forneçam a distribuição posterior dos parâmetros de interesse. Isso ocorre através do Filtro de Kalman que leva à função de máxima verossimilhança que é então estimada pelo método de mesmo nome (qual seja, máxima verossimilhança).

Uma vantagem de assim proceder ocorre porque se tem muitos parâmetros nestes tipos de modelos de forma que a identificação fica comprometida. Esta situação se 
agrava no caso do Brasil dado que a séries históricas são muito curtas. Uma saída seria usarmos a calibragem pura dos parâmetros, mas neste caso nosso conjunto de dados não estaria dizendo nada sobre eles. Através destas técnicas econométrica, conseguimos então atualizar estes parâmetros calibrados, que seguem uma distribuição a priori, com os dados que temos disponíveis.

Maiores detalhes sobre esta metodologia constam tanto no livro de Canova (2007) quanto no livro de Dejong e Dave (2011). O programa utilizado para estimação foi o Dynare.

\subsubsection{Dados, parâmetros e distribuições a priori utilizadas}

O modelo por nós utilizado tem três choques e, desta forma, conseguimos estimar o modelo utilizando apenas três variáveis observáveis, quais sejam: produto interno bruto (PIB), taxa de juro Fed Fund e uma medida de preços (CPI, PCE ou salários). Sempre utilizaremos o hiato das variáveis extraído via filtro HP.

É importante destacar que vamos estimar os parâmetros considerando dois períodos. O primeiro é coincidente com o utilizado no artigo de Christiano, Eichenbaum e Trabandt (2013) que vai de 1951 até 2008, enquanto o segundo tem o mesmo início mas termina ao final de 2014. A ideia é comparar os resultados estimados por nós com os obtidos em Christiano, Eichenbaum e Trabandt (2013), assim como, ver como os parâmetros estimados evoluíram ao longo do tempo.

A fim de facilitar a comparação, com relação aos valores calibrados e no estado estacionário e às distribuições priors das variáveis, seguimos os valores utilizados por Christiano, Eichenbaum e Trabandt (2013).

\subsection{RESULTADOS}

\subsubsection{Estimação Bayesiana dos Parâmetros até 2008}

Os valores da moda dos valores estimados para o período até o final de 2008 estão na tabela 13. Como se pode ver, enquanto a estimativa de Christiano, Eichenbaum e Trabandt (2013) indica grau moderado de rigidez de preço, com as alterações ocorrendo, em média, a cada 2,4 trimestres, nossas estimativas indicam um grau de 
rigidez um pouco maior, com atualização de preços em média a cada 3,2 trimestres quando usamos CPI e PCE e a cada 2,8 trimestres quando utilizamos o salário como variável observável. Embora indique rigidez maior, os valores por nós encontrados estão em linha com a literatura. O próprio artigo de Christiano, Eichenbaum e Trabandt (2013) diz que a literatura recente para os Estados Unidos, utilizando microdados diz que o reajuste da mediana dos preços se dá, em média, a cada 1,5 trimestres quando "sales (promoção)" são incluídos e a cada 3 trimestres, em média, quando se exclui "sales".

\section{TABELA 13 - PARÂMETROS ESTIMADOS PARA OS EUA COM DADOS ATÉ 2008}

ABAIXO TEMOS A MODA DOS PARÂMETROS ESTIMADOS COM DADOS ENTRE 1951 (QUANDO DISPONÍVEL) ATÉ O FINAL DE 2008, PERÍODO COINCIDENTE AO UTILIZADO POR CHRISTIANO, EICHENBAUM E TRABANDT (2013 - CET). A PRIMEIRA COLUNA TRAZ OS NOMES DOS PARÂMETROS ENQUANTO A SEGUNDA OS DESCREVE. A TERCEIRA COLUNA TRAZ OS VALORES ESTIMADOS NO ARTIGO CET (2013) ENQUANTO A QUARTA E A QUINTA COLUNAS TRAZEM NOSSAS ESTIMATIVAS USANDO COMO VARIÁVEIS OBSERVÁVEIS O PIB, A TAXA DE JURO FED FUND E A INFLAÇÃO DO CPI E DO CPE, RESPECTIVAMENTE. POR FIM, A SEXTA COLUNA MOSTRA A ESTIMATIVA QUANDO USAMOS PIB, TAXA DE JURO FED FUND, MAS SALÁRIO AO INVÉS DA INFLAÇÃO PARA FAZER AS ESTIMATIVAS.

\begin{tabular}{|c|c|c|c|c|c|}
\hline \multicolumn{6}{|c|}{ Parâmetros estimados (moda) } \\
\hline & & $\begin{array}{l}\text { Artigo CET } \\
\text { (até 2008) }\end{array}$ & $\begin{array}{l}\text { PIB, CPI e Fed } \\
\text { Fund (até 2008) }\end{array}$ & $\begin{array}{l}\text { PIB, PCE e Fed } \\
\text { Fund (até 2008) }\end{array}$ & $\begin{array}{l}\text { PIB, salário e Fed } \\
\text { Fund (até 2008) }\end{array}$ \\
\hline eps & price stickiness & 0,58 & 0,82 & 0,80 & 0,74 \\
\hline lambda & price markup parameter & 1,43 & 1,38 & 1,23 & 1,18 \\
\hline rhor & taylor rule: smoothing & 0,86 & 0,37 & 0,56 & 0,64 \\
\hline rpi & taylor rule: inflation & 1,36 & 1,40 & 1,34 & 2,12 \\
\hline ry & taylor rule: gdp & 0,04 & 0,05 & 0,01 & 0,21 \\
\hline b & consumption habit & 0,83 & 0,94 & 0,92 & 0,91 \\
\hline sigmaa & capacity utilization adj cost & 0,08 & 0,16 & 0,03 & 0,37 \\
\hline Spp & Investimento adj cost & 13,67 & 21,43 & 8,96 & 21,10 \\
\hline alpha & capital share & 0,24 & 0,16 & 0,24 & 0,21 \\
\hline rhog & technology difussion - gov & 0,01 & 0,12 & 0,83 & 0,01 \\
\hline rhod & technology difussion - D & 0,74 & 0,74 & 0,44 & 0,82 \\
\hline deltapercent & Probability of Bargaing breakup & 0,30 & 2,21 & 0,18 & 0,59 \\
\hline D & replacement ratio & 0,67 & 0,63 & 0,55 & 0,45 \\
\hline recSHARE & hiring-search cost/Y - & 0,50 & 1,23 & 0,87 & 0,43 \\
\hline sigma & matching function parameter - & 0,56 & 0,74 & 0,48 & 0,46 \\
\hline sig_epsR & Standard deviation monetary policy & 0,60 & 0,38 & 0,38 & 0,38 \\
\hline sigmamiz & Standard deviation neutral tech & 0,14 & 0,06 & 0,20 & 0,11 \\
\hline sigmamip & Standard deviation investiment tech & 0,13 & 0,17 & 0,07 & 0,10 \\
\hline rhomipsi & $\mathrm{AR}(1)$ investiment tech & 0,73 & 0,93 & 0,92 & 0,67 \\
\hline \multirow{2}{*}{\multicolumn{3}{|c|}{ Aceitação das cadeias de Markov }} & $26,2 \%$ & $26,8 \%$ & $31,0 \%$ \\
\hline & & & $23,5 \%$ & $33,2 \%$ & $32,3 \%$ \\
\hline
\end{tabular}

Com relação à probabilidade de se ter um término exógeno na negociação entre empresa e trabalhadores quando a oferta é rejeitada, o artigo original estimou $0,3 \%$. Quando usamos o CPI como medida de inflação, a estimativa a que chegamos é 
bem maior, 2,2\%, comparado com 0,18\% obtido pela estimação que considera além do PIB e da taxa de juro Fed Fund, o PCE. Quando se utilizou o salário, como medida de preços, o percentual estimado foi de 0,59\%.

O custo de contratação (hiring cost) sobre o PIB estimado no artigo original foi de 0,5\%. Encontramos 1,23\% para o primeiro conjunto de variáveis onde usamos o $\mathrm{CPI}$ e 0,87\% para o segundo caso onde usamos o PCE. Quando foi considerado o salário, este percentual recuou para 0,43\%. Christiano, Eichenbaum e Trabandt (2013) mostram que esta estimativa indica que o custo de contratação sobre o total de salários dos novos empregados é de $6,7 \%$, que está dentro do intervalo entre $4 \%$ e 14\% encontrado por Silva e Toledo (2009), a depender dos custos incluídos. Nossas estimativas indicam, respectivamente, 16,5\%,11,7\% e 5,7\%, percentuais que ou estão dentro ou muito próximos ao intervalo indicado por Silva e Toledo (2009).

A moda da distribuição posterior da renda necessária para um desempregado manter o mesmo padrão de vida (replacemente ratio) encontrado por nós variou entre 0,63 e 0,45, pouco abaixo do 0,67 estimado em Christiano, Eichenbaum e Trabandt (2013). Mas, novamente, os valores a que chagamos estão dentro do intervalo entre 0,40 e 0,70 indicado por Gertler, Sala e Trigari (2008) como plausível. Com relação à regra de política monetária, podemos observar na tabela 13 que nossas estimativas indicam menor inércia, pois as estimativas do coeficiente da defasagem do juro variam entre 0,37 (CPI) e 0,64 (salário) contra 0,86 encontrado por Christiano, Eichenbaum e Trabandt (2013); a reação com relação à inflação encontrada por nós está próxima à do artigo original para os casos em que usamos CPI e PCE, mas é mais forte $(2,12$ contra 1,36) quando usamos salário como variável observável; e, por fim, a reação com relação ao desvio do produto é bem mais baixa que à inflação em todas as estimativas encontradas, em linha com Christiano, Eichenbaum e Trabandt (2013), sendo a reação do caso da utilização dos salários um pouco mais acentuada.

Por fim, podemos destacar também que nossas estimativas para hábito de consumo indicam uma persistência maior, entre 0,91 e 0,94, acima do 0,83 encontrado no artigo original. Além disso, a participação do capital estimada em nosso modelo em todos os casos variou entre 0,16 e 0,24, próximo ao 0,24 encontrado por Christiano, Eichenbaum e Trabandt (2013). 
Portanto, podemos concluir que ao procedermos da maneira que propusemos para fazer a estimação, chegamos a valores, normalmente, em linha com os encontrados na literatura e, em geral, não muito distantes dos estimados por outro processo no artigo original. Os parâmetros por nós estimados indicam um modelo com um pouco mais de rigidez de preços e de hábito de consumo e uma regra de política monetária com pouco menos de inércia em relação ao artigo original, mas que reage aqui, assim como lá, muito mais à inflação do que ao produto.

\subsubsection{Estimação Bayesiana dos parâmetros até 2014}

Quando utilizamos a amostra até o final de 2014 para fazer a estimação encontramos que os preços continuam mais rígidos, segundo os parâmetros estimados por nós (tabela 14), com pouca alteração em relação aos valores encontrados na estimação com a amostra reduzida. Da mesma forma, na regra de política monetária, continuamos a ter uma menor inércia, com a autoridade monetária reagindo bem mais aos desvios da inflação do que do produto. E a participação do capital continua ao redor de $20 \%$. 
TABELA 14 - PARÂMETROS ESTIMADOS PARA OS EUA COM DADOS ATÉ 2014

ABAIXO TEMOS A MODA DOS PARÂMETROS ESTIMADOS COM DADOS ENTRE 1951 (QUANDO DISPONÍVEL) ATÉ O FINAL DE 2014. A PRIMEIRA COLUNA TRAZ OS NOMES DOS PARÂMETROS ENQUANTO A SEGUNDA OS DESCREVE. A TERCEIRA COLUNA TRAZ OS VALORES ESTIMADOS NO ARTIGO CET (2013) ENQUANTO A QUARTA E A QUINTA COLUNAS TRAZEM NOSSAS ESTIMATIVAS USANDO COMO VARIÁVEIS OBSERVÁVEIS O PIB, A TAXA DE JURO FED FUND E A INFLAÇÃO DO CPI E DO CPE, RESPECTIVAMENTE. POR FIM, A SEXTA COLUNA MOSTRA A ESTIMATIVA QUANDO USAMOS PIB, TAXA DE JURO FED FUND, MAS SALÁRIO AO INVÉS DA INFLAÇÃO PARA FAZER AS ESTIMATIVAS.

\begin{tabular}{|c|c|c|c|c|c|}
\hline \multicolumn{6}{|c|}{ Parâmetros estimados (moda) } \\
\hline & & $\begin{array}{l}\text { Artigo CET } \\
\text { (até 2008) }\end{array}$ & $\begin{array}{l}\text { PIB, CPI e Fed } \\
\text { Fund (até 2014) }\end{array}$ & $\begin{array}{l}\text { PIB, PCE e Fed } \\
\text { Fund (até 2014) }\end{array}$ & $\begin{array}{l}\text { PIB, salário e Fed } \\
\text { Fund (até 2014) }\end{array}$ \\
\hline eps & price stickiness & 0,58 & 0,82 & 0,81 & 0,81 \\
\hline lambda & price markup parameter & 1,43 & 1,35 & 1,28 & 1,47 \\
\hline rhor & taylor rule: smoothing & 0,86 & 0,28 & 0,62 & 0,41 \\
\hline rpi & taylor rule: inflation & 1,36 & 1,26 & 1,43 & 1,74 \\
\hline ry & taylor rule: gdp & 0,04 & 0,03 & 0,008 & 0,149 \\
\hline b & consumption habit & 0,83 & 0,95 & 0,92 & 0,18 \\
\hline sigmaa & capacity utilization adj cost & 0,08 & 0,07 & 0,03 & 1,98 \\
\hline Spp & Investimento adj cost & 13,67 & 18,75 & 13,23 & 23,61 \\
\hline alpha & capital share & 0,24 & 0,16 & 0,24 & 0,21 \\
\hline rhog & technology difussion - gov & 0,01 & 0,10 & 0,86 & 0,04 \\
\hline rhod & technology difussion - D & 0,74 & 0,69 & 0,45 & 0,11 \\
\hline deltapercent & Probability of Bargaing breakup & 0,30 & 0,03 & 0,12 & 2,12 \\
\hline D & replacement ratio & 0,67 & 0,91 & 0,38 & 0,27 \\
\hline recSHARE & hiring-search cost/Y - & 0,50 & 0,28 & 0,89 & 0,20 \\
\hline sigma & matching function parameter - & 0,56 & 0,45 & 0,53 & 0,19 \\
\hline sig_epsR & Standard deviation monetary policy & 0,60 & 0,44 & 0,38 & 0,38 \\
\hline sigmamiz & Standard deviation neutral tech & 0,14 & 0,09 & 0,24 & 0,04 \\
\hline sigmamip & Standard deviation investiment tech & 0,13 & 0,13 & 0,10 & 0,24 \\
\hline rhomipsi & $\mathrm{AR}(1)$ investiment tech & 0,73 & 0,90 & 0,92 & 0,96 \\
\hline \multirow{2}{*}{\multicolumn{3}{|c|}{ Aceitação das cadeias de Markov }} & $21,5 \%$ & $30,8 \%$ & $29,3 \%$ \\
\hline & & & $16,6 \%$ & $28,8 \%$ & $30,9 \%$ \\
\hline
\end{tabular}

Com relação ao hábito de consumo, as estimativas indicam elevada persistência tanto quando estimamos com PIB, taxa de juro Fed Fund e CPI quanto quando trocamos o CPI pelo PCE. Entretanto, quando consideramos salários como variável observável para preços, observamos expressiva redução do hábito de consumo estimado com a amostra até $2008(0,91)$ em relação ao valor obtido com a amostra até $2014(0,18)$. Provavelmente, os dados pós-crise aguda parecem trazer ruídos para o modelo afetando a estimação.

Já, a probabilidade estimada no modelo com a amostra até 2014 de fim exógeno das negociações, por exemplo, recuou de $2,21 \%$ para $0,03 \%$ no modelo considerando $\mathrm{CPI}$, de $0,18 \%$ para $0,12 \%$ com PCE e subiu de $0,59 \%$ para $2,12 \%$ quando consideramos o salário. Com relação ao custo de contratação em relação ao PIB, notamos que o custo estimado diminuiu nos modelos estimados com $\mathrm{CPI}$ e salário, mas ficou praticamente inalterado quando consideramos o PCE. Por fim a 
renda necessária para manter o padrão de vida quando desempregado (replacemente ratio), passou a ficar fora do intervalo desejado entre 0,4 e 0,7 , foi para 0,91 no caso da estimativa via CPI e para 0,38 e 0,27 na estimação usando PCE e salário, respectivamente.

Em suma, considerando a amostra até o final de 2014, observamos que o modelo estimado continuou a ter uma maior rigidez de preço em relação ao modelo estimado em Christiano, Eichenbaum e Trabandt (2013), com uma regra de política monetária menos inercial. Além disso, notamos que os dados mais recentes afetam de modo mais expressivo os valores estimados para variáveis do mercado de trabalho.

\subsection{FUNÇÕES IMPULSO RESPOSTA}

Fizemos dois conjuntos de funções impulso resposta ao choque de politica monetária de um desvio padrão. Em todos os casos as funções impulso resposta foram feitas considerando no modelo os valores estimados para os parâmetros ${ }^{18}$. Nas figuras 18 e 19, "CPI" se refere à estimação realizada via CPI, GDP (produto interno bruto) e taxa de juro Fed Fund; "PCE" se refere ao conjunto inflação PCE, produto interno bruto e taxa de juro Fed Fund; e, "wage" está relacionada ao conjunto GDP, salário e taxa de juro Fed Fund.

Além disso, o resultado da figura 18 advém dos choques das três estimações realizadas anteriormente para o período até 2008. Nos três modelos estimados, os choques têm magnitudes muito semelhantes e menores que a do CET (2013). Ademais, na figura 18, calculamos as funções impulso resposta (FIR) usando o desvio padrão dos nossos modelos estimados e comparamos o resultado com o modelo original (CET). Enquanto que, na figura 19, calculamos as funções de reação a um choque normalizado de política monetária.

${ }^{18} \mathrm{Em}$ todos os casos foram usadas a média da posterior. 
Analisando as funções de impulso resposta, observamos na figura 18 que, diante de um choque expansionista de política monetária, a taxa de juros cai inicialmente, mas volta ao equilíbrio apenas após algum tempo. Portanto, há inércia, conforme esperado. Mas, respeitando os resultados das estimações, nos três modelos que estimamos, a volta é mais rápida, pois a inércia é menor que no modelo original. Isso fica mais fácil perceber na figura 19, quando normalizamos o choque.

Com a menor taxa de juro, no modelo original de Christiano, Eichenbaum e Trabandt (2013), o PIB, a inflação, o salário real, o investimento, o consumo e a finding rate demoram um pouco para responder enquanto que, nos nossos modelos, as respostas são mais rápidas mas, no geral, mais suaves. Entretanto, a direção da resposta é a mesma. Diante de um choque expansionista de política monetária, o juro cai e, com isso, a atividade é estimulada ao longo do tempo, a inflação sobe, o consumo e o investimento aumentam e o PIB cresce. Nesta dinâmica, o mercado de trabalho aquece, o salário real aumenta e a probabilidade de encontrar emprego também sobe.

Este estímulo, no entanto, não é eterno. Conforme a taxa de juro vai voltando para o nível de estado estacionário, o estímulo diminuiu, a atividade desacelera e a inflação vai voltando ao normal.

No geral, é interessante destacar também que as funções impulso resposta dos modelos PCE e wage têm trajetórias mais próximas entre si e em relação a do modelo original do que a trajetória do modelo estimado usando o $\mathrm{CPI}$. 
FIGURA 18 - FUNÇÕES IMPULSO RESPOSTA A UM CHOQUE DE UM DESVIO PADRÃO DE POLITICA MONETÁRIA.

"CPI" SE REFERE À ESTIMAÇÃO REALIZADA VIA O CONJUNTO CPI, PIB E FED FUND; "PCE" PARA O CONJUNTO PCE, PIB E FED FUND; E, "WAGE" PARA O CONJUNTO PIB, WAGE E FED FUND. ALÉM DISSO, "CET" SE REFERE A DINÂMICA DO MODELO CHRISTIANO,EICHENBAUM E TRABANDT (2013).
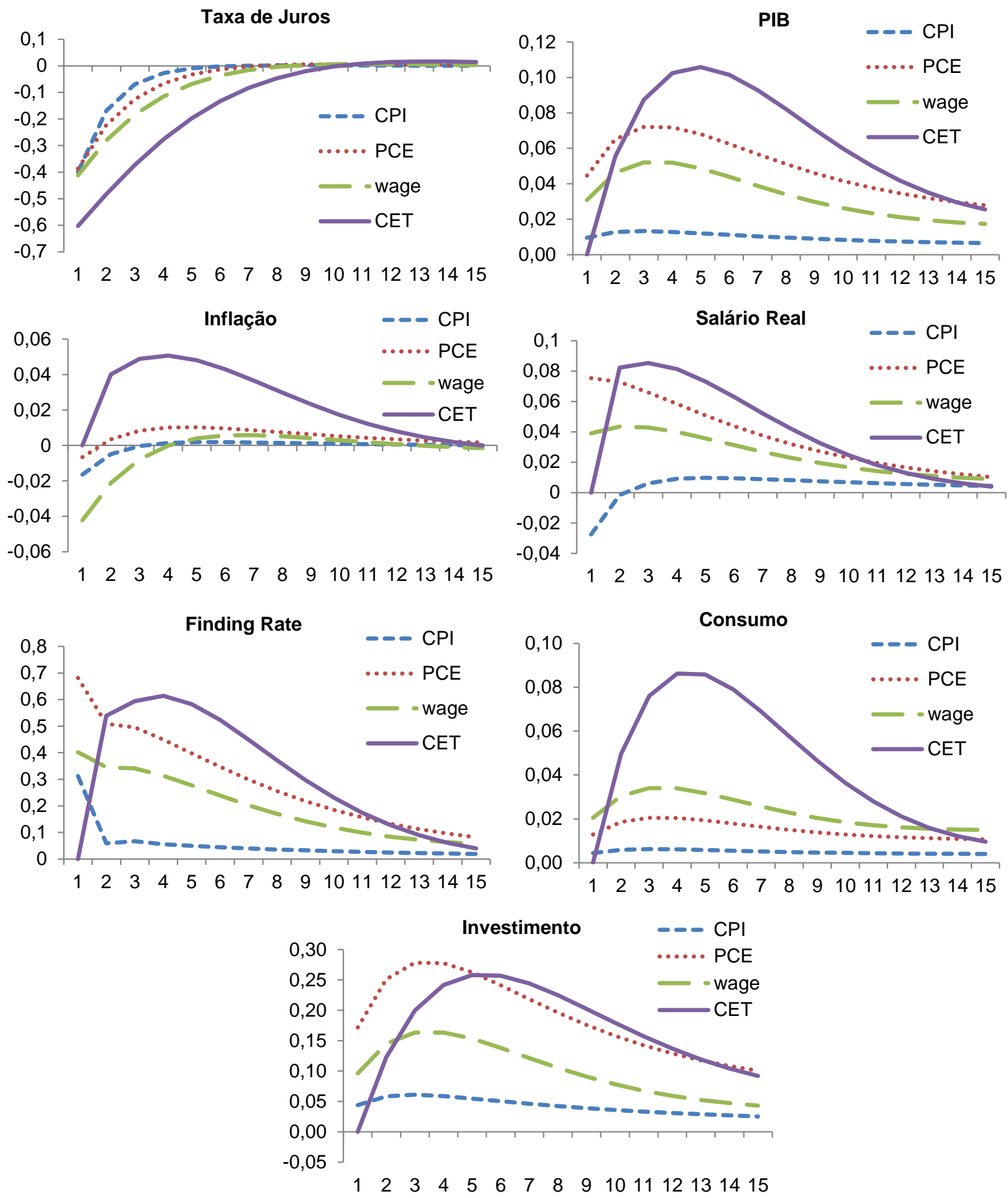
FIGURA 19 - FUNÇÕES IMPULSO RESPOSTA A UM CHOQUE PADRONIZADO DE POLÍTICA MONETÁRIA.

"CPI" SE REFERE A ESTIMAÇÃO REALIZADA VIA O CONJUNTO CPI, PIB E FED FUND; "PCE" PARA O CONJUNTO PCE, PIB E FED FUND; E, "WAGE" PARA O CONJUNTO PIB, WAGE E FED FUND. ALÉM DISSO, "CET" SE REFERE A DINÂMICA DO MODELO CHRISTIANO,EICHENBAUM E TRABANDT (2013).
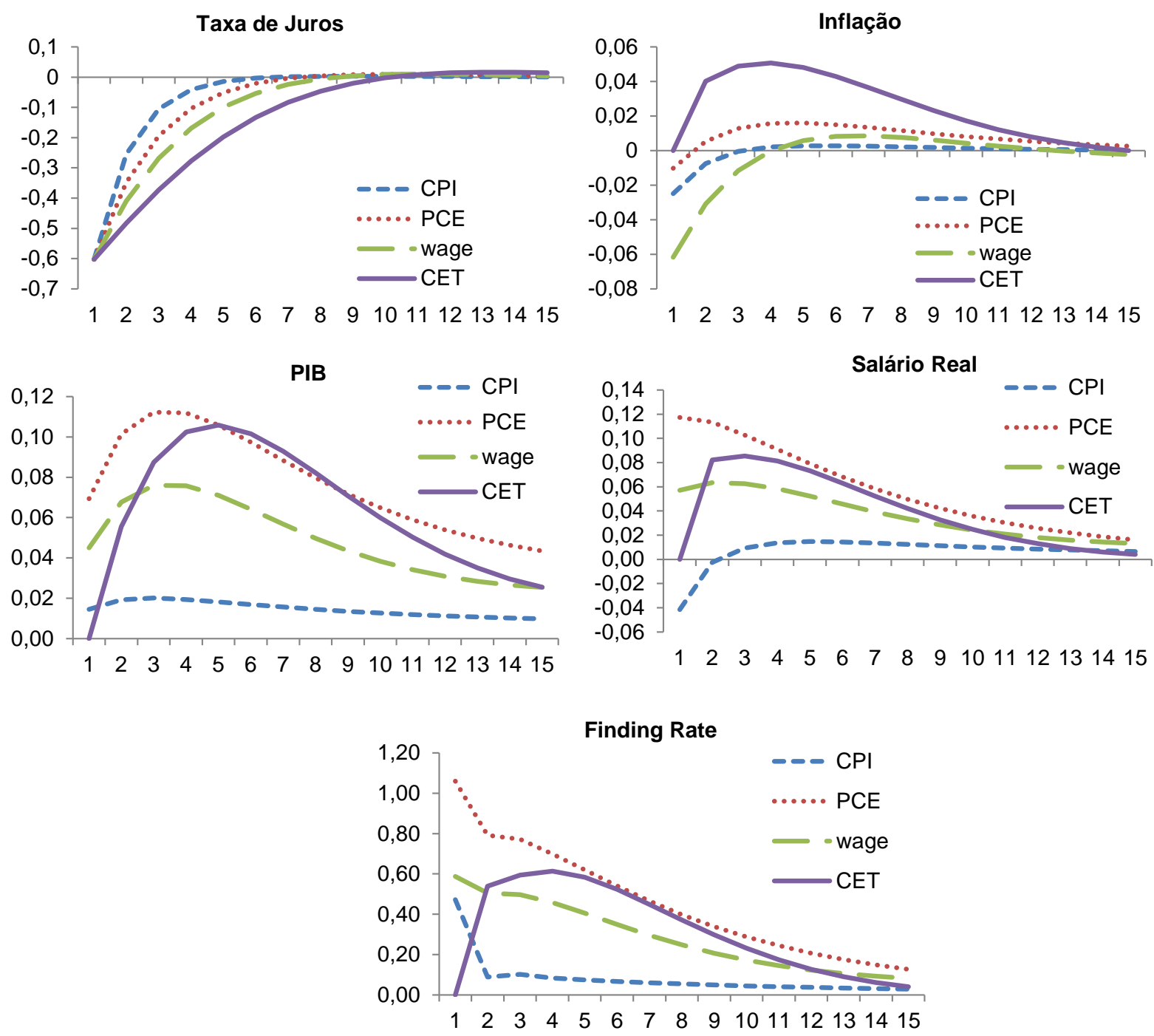


\subsection{CONCLUSÃO}

Neste trabalho, estimamos o modelo Christiano, Eichenbaum e Trabandt (2013) para os Estados Unidos, mas adotamos uma estratégia de estimação diferente. Optamos por primeiro log-linearizar o modelo para depois fazer a estimação com objetivo de comparar os resultados da nossa estimativa com as de Christiano, Eichenbaum e Trabandt (2013) assim como as funções impulso resposta a um choque de política monetária. Além disso, analisamos como os parâmetros estimados evoluíram ao longo do tempo, estendendo a base de dados do final de 2008 para o final de 2014 . Para o conjunto de dados até 2008 , os resultados indicam que os valores estimados estão em linha com os encontrados na literatura e, no geral, não estão muito distantes das estimações do artigo original. Os parâmetros por nós estimados indicam um modelo com um pouco mais de rigidez de preços, mais persistência no consumo e com uma regra de política monetária com um pouco menos de inércia em relação ao artigo de Christiano, Eichenbaum e Trabandt (2013), mas que reage, assim como lá, muito mais à inflação do que ao produto.

Considerando a amostra até o final de 2014, observamos que o modelo estimado continuou a ter uma maior rigidez de preço em relação ao modelo de Christiano, Eichenbaum e Trabandt (2013), com uma regra de política monetária menos inercial. Além disso, notamos que os dados mais recentes afetam de modo mais expressivo os valores estimados para as variáveis do mercado de trabalho.

Por sua vez, as funções impulso resposta refletiram esta menor inércia da política monetária e, no geral, apresentaram trajetórias esperadas. Em apenas um conjunto de dados utilizado para estimação as respostas ficaram mais distantes das indicadas no modelo original. 


\section{REFERÊNCIAS BIBLIOGRÁFICAS}

ALTIG, DAVID; CHRISTIANO, LAWRANCE; EICHENBAUM, MARTIN; e LINDE, JESPER. Firm-Specific Capital, Nominal Rigidities and the Business Cycle. Review of Economic Dynamics, Elsevier for the Society for Economic Dynamics, vol. 14(2), pages 225-247, April 2011.

ANDOLFATTO, D.Business Cycles and Labor Market Search. Americam Economic Review, 86(1), Março, pp. 112-132. 1996.

ATTUY, GUILHERME. Ensaios sobre Macroeconomia e Mercado de Trabalho.São Paulo, 2012. Tese (Doutorado em Economia) - Programa de PósGraduação em Economia, Faculdade de Economia e Administração, Universidade de São Paulo.

BINMORE, KEN; RUBINSTEIN, ARIAL; WOLINSKY, ASHER. The Nash Bargaining Solution in Economic Modelling. Journal of Economics, 17(2), pp. 176-88, 1986.

BLANCHARD, OLIVIER; DIAMOND, PETER. The Cyclical Behavior of the Gross Flows of US Workers. Brookings Papers on Economic Activity 2, 85-143, 1990.

BLEAKLEY, HOYT; FERRIS, ANN E.; FUHRER, JEFFREY C. New Data on Workers Flows during Business Cycle. New England Economic Review, 0(00, pp 49-76, 1999.

CAMPOLIETI, MICHELI. The Ins and Outs of Unemployment in Canada, 1976-2008. Canadian Journal of Economics. vol. 44 (4), 1331-1349, novembro de 2011.

CANOVA, FABIO. Methods for Applied Macroeconomics Research. ICREA, Princeton University Press, 2007.

CASTRO, MARCOS R.; GOUVEA, SOLANGE N.; MINELLA, ANDRÉ; SANTOS, RAFAEL C.; e, SOUZA-SOBRINHO, NELSON F. SAMBA: Stochastic Analytical Model with a Bayesian Approach. Banco Central do Brasil, working paper 239. Abril, 2011.

CHRISTIANO, LAWRANCE. Comment on "Unemployment in an Estimated New Keynesian Model" by Gali, Smets and Wouters. NBER Macroeconomics Annual 2011, Volume 26, pp 361-380, University of Chigado Press, outubro de 2011.

CHRISTIANO, LAWRANCE; EICHENBAUM, MARTIN; EVANS, CHARLES L.. Monetary Policy Shocks: What Have We Learned and to What End? Handbook of Macroeconomics, editado por John B. Taylor e Michael Woodford, pp. 65-148, Amsterdam, New York e Oxford: Elsevier Science, North-Holland. 1999.

Nominal Rigidities and the Dynamic Effects of a Shock to Monetary Policy . Journal of Political Economy, 113(1), pp. 1-45, 2005. 
CHRISTIANO, LAWRANCE; TRABANDT, MATHIAS; WALENTIN, KARL. Involuntary Unemployment and the Business Cycle. Manuscript, Northwestern University, 2012.

CHRISTIANO, LAWRANCE; EICHENBAUM, MARTIN; TRABANDT, MATHIAS.. Unemployment and Business Cycles. NBER, working paper 19265, Julho, 2013.

DAVIS, STEVEN; HALTIWANGER, JOHN; SCHUH, SCOTT. Job Creation and Destruction. MIT press, Cambridge, MA, 1996

DEJONG, DAVID N.; DAVE, CHETAN. Structural Macroeconomics. Princeton University Press. Segunda edição, 2011.

DEN HAAN, WOUTER; RAMEY, GAREY; WATSON, JOEL. Job Destruction and Propagation of Shocks. American Economic Review, 90(3), pp. 482-98, 2000.

DIAMOND, PETER. Aggregate Demand Management in Search Equilibrium. Jounal of Political Economy, 90(5), pp 881-894. 1982

ELSBY, MICHAEL W; MICHAELS, RYAN; SOLON, GARY. The Ins and Outs of Cyclical Unemployment. National Bureau of Economic Research. Working paper no 12853, janeiro de 2007.

FUJITA, SHIGERU; RAMEY, GAREY. The Cyclicality of Separation and Job Finding Rates. Federal Reserve Bank of Philadelphia. Working Paper no 07-19/R. Janeiro de 2008.

FUJITA, SHIGERU; RAMEY, GAREY. The cyclicality of separation and job finding rates. Internacinal Economic Review, vol 50 (2) pp 415-430, 2009.

GALI, JORDI. Monetary Policy, Inflation and the Business Cycle: An Introduction to the New Keynesian Framework. Princeton University Press, 2008.

. The Return of the Wage Inflation Phillips Curve. Journal of the European Economic Association,3 , 436,461, 2011a

Keynesian Perspective. The MIT Press, $2011 \mathrm{~b}$

GELMAN, ANDREW; CARLIN, JOHN B.; STERN, HAL S.; DUNSON, DAVID B.; AKI; VEHTARI; RUBIN, DONALD. Bayesian Data Analysis, Chapman \& Hall, 2004

GELMAN, ANDREW ; Hill, JENNIFER. Data Analysis Using Regression and Multilevel/Hierarchical Models. Cambridge University Press, 2007

GERTLER, MARK; SALA, LUCA ; TRIGARI, ANTONELLA. An Estimated Monetary DSGE Model with Unemployment and Staggered Nominal Wage Bargaining. Journal of Money, Credit and Banking, 40(8), pp. 1713-1764, 2008. 
GERTLER, MARK; TRIGARI, ANTONELLA. Unemployment Fluctuations with Staggerred Nash Wage Bargaining. Journal of Political Economy, vol.117(1), pp. 36-38, 2009.

GONZAGA, GUSTAVO. Rotatividade e Qualidade do Emprego no Brasil. Revista de Economia Política, 18(1), pp 120-140, 1998.

GONZAGA, GUSTAVO. Labor Tournover and Labor Legislation in Brazil. Journal of the Latin American and Caribbean Economic Association, 4(1), pp 165-207, 2003.

GONZAGA, GUSTAVO; REIS, MAURICIO. Oferta de Trabalho e Ciclo Econômico: os Efeitos Trabalhador Adicional e Desalento no Brasil. Revista Brasileira de Economia, v. 65 (2), pp 177-205, 2011

HANSEN, GARY. Indivisible Labor and the Business Cycle. Journal of Monetary Economics, 16(3), pp. 309-327, 1985.

HALL, ROBERT E. Employmetn Fluctuations with Equilibrium Wage Stickiness. American Economic Review, 95(1), pp 50-65, $2005 .$.

HALL, ROBERT E.; MILGROM, PAUL R..The Limited Influence of Unemployment on the Wage Bargain. The American Economic Review, 98(4), pp. 1653-1674, 2008.

KYDLAND, FINN E. ; PRESCOTT, EDWARD. Time to Build and Aggregate Fluctuations. Econometrica, pp. 1345-1370, 1982.

KOOP, G. Bayesian Econometrics. New York, Wiley, 2003.

MERZ, M. Search in the Labor Market and in the Real Business Cycle. Journal of Monetary Economics, 36(2), pp. 269-300, novembro, 1995

MORTENSEN, DALE. Property Rights and Efficiency in Mating, Racing and Related Games. American Economic Review, 72(5), pp.968-979, 1982

MORTENSEN, DALE; PISSARIDES, CHRISTOPHER. Job Creation and Job Destruction in the Theory of Unemployment. Review of Economic Studies, v.61, n.3, pp. 397-415, 1994.

Job Reallocation, Employment Fluctuations and Unemployment, em John B. Taylor e Michael Woodford, eds., Handbook of Macroeconomics. vol 1, Elsevier, dezembro de 1999, capitulo 18, pp. 1171-1228.

New Developments in Models of Search in the Labor Markets, em Orley Ashenfelter e David E. Card, eds, Handbook of Labor Economics, v. 3, Elsevier, 1999, capítulo 39, pp. 2567-2627. 
PACIELLO, LUIGI. Does Inflation Adjust Faster than Aggregate Technology Shocks than to Monetary Policy Shocks. Journal of Money, Credit and Banking, 43(8), 2011.

PETRONGOLO, BARBARA; PISSARIDES, CHRISTOPHER.The Ins and Outs of European Unemployment. CEP Discussion Paper, no 853. Fevereiro de 2008.

PISSARIDES, CHRISTOPHER. Short-Run Equilibrium Dynamics of Unemployment, Vacancies and Real Wages. American Economic Review, 75(4), pp.676-690, 1985

PISSARIDES, CHRISTOPHER. Equilibrium Unemployment Theory. Segunda Edição. MIT Press, 2000.

RAVENNA, FEDERICO; WALSH, CARL.Vacancies, Unemployment, and the Phillips Curve .European Economic Review, 52, pp. 1494-1521, 2008.

RIBAS, RAFAEL; SOARES, SERGIE. Sobre o Painel da Pesquisa Mensal do Emprego do IBGE.Texto para discussão IPEA 1348. Rio de Janeiro, 2008.

ROGERSON, RICHARD; SHIMER, ROBERT. Search Macroeconomics Models of the Labor Market . NBER, working paper No.15901. Abril, 2010.

RUBINSTEIN, ARIEL. Perfect Equilibrium in a Bargaining Model.Econometrica, 50(1), pp. 97-109, 1982.

SCHMITT-GROHE, STEPHANIE; URIBE, MARTIN. What's News in Business Cycles?. Econometrica, 80, pp. 2733-2764, 2012.

SANTOS, FERNANDO G. Ensaios sobre Macroeconomia Bayesiana Aplicada. São Paulo 2012. Tese (Doutorado em Economia) - Programa de Pós-Graduação em Economia, Faculdade de Economia e Adiminsitração, Universidade de São Paulo.

SILVA, FÁBIO JOSÉ FERREIRA; PIRES, LEONARDO SIANI. Evolução do Desemprego no Brasil no Período 2003-2013: Análise através das Probabilidades de Transição . Banco Central do Brasil. Trabalhos para discussão no 349. Fevereiro de 2014.

SHIMER, ROBERT. The Cyclical Behavior of Equilibrium Unemployment and Vacancies. American Economic Review 95 (1) 25-49, 2005.

Labor Market and Business Cycles. Princeton University Press, 2010.

. Reassessing the Ins and Outs of Unemployment. Review of Economic Dynamic 15: 127-148, 2012.

SILVA, J. VAZQUEZ GRENNO, J. The Ins and Outs of Unemployment and the Assimilation of Recent Immigrants in Spain. Journal of Population Economics 24, pp: 1309-1330, 2011. 
SMETS, FRANK; WOUNTERS, RAFAEL. An Estimated Dynamic Stochastic General Equilibrium Model of the Euro Area. Journal of the European Economic Association, MIT Press, 1(5), pp. 1123-1175, 2003.

. Shocks and Frictions in US Business Cycles: A Bayesian DSGE Approach. American Economic Review, 97(3), pp. 586-606, 2007.

SMITH, JENNIFER C. The Ins and Outs of UK Unemployment. The Economic Journal, vol 121 (552), pp 402-444, 2011.

WALSH, CARL. Labour Market Search and Monetary Shocks. Capítulo 9 em Dynamic Macroeconmic Analyis, Theory and Policy in General Equilibrium. Editado por Sumru Altug, Jagjit S. Chadha and Charles Nolan, Cambridge University Press, 2003.

. Monetary Theory and Policy. MIT Press, 2003.

WOODFORD, MICHAEL. Interest and Prices: Foundations of a Theory of Monetary Policy. Princeton University Press, 2003.

ZELLNER, ARNOLD. An Introduction to Bayesian Inference in Econometrics. John Wiley \& Sons, 1971. 